\title{
Das Vorsorgeverhältnis - die richtige Frage für einen Rechtsvergleich?
}

\author{
Peter A. Köhler
}

I. Bedeutung und Bedeutungswandel des Wortes „Vorsorge“

1. Das Wort „Vorsorge" versteht sich nicht von selbst

2. Deutsche Etymologie und aktuelle Bedeutung

3. Das Wort "Vorsorge“ in anderen Sprachen

II. „Vorsorge“ als rechtlicher Terminus

1. "Vorsorge" im deutschen Sozialgesetzbuch

2. "Vorsorge“ und „Vorsorgeprinzip“ in internationalen und supranationalen Rechtsdokumenten

a) Internationale Rechtsdokumente

b) Supranationales Recht

3. Unsicherheit - ein neues altes Rechtsproblem

III. Die Unsicherheit des Daseins und die Sicherung des Daseins durch

Daseinsvorsorge

1. Soziale Unsicherheit: Daseinsangst

2. Daseinsvorsorge und deutsche Verwaltungswirklichkeit der Zwischenkriegszeit

3. Funktioniert der funktionale Rechtsvergleich und wenn ja, warum?

a) Funktionaler, nicht funktionalistischer Rechtsvergleich

b) Form ever follows function

c) Die Frage nach dem tertium comparationis richtig stellen

IV. Att lägga livet till rätta - Sich das Leben zurecht legen in Schweden

1. Funktionalismus in Schweden: „Funkis”

2. „Folkhem” und „Volksgemeinschaft”
a) In Schweden: „Folkhem“
b) In Deutschland: „Volksgemeinschaft“

178

3. Vorbeugende Daseinsvorsorge: Volksgesundheit und Homogenität des Volkes

a) Der Ansatz der „Sozialingenieure“

(1) Die Myrdals

(2) Die Stockholm-Ausstellung 1930

(3) Die Sterilisierungsgesetze von 1934 und $1941 \quad 188$

b) Der Ansatz im Maßnahmestaat

c) „Wie konnte das nur geschehen?“

(1) Alle machten mit

(2) Daseinsvorsorge statt Grundrechtsschutz 
V. Vorsorge und das Problem, die Zukunft rechtlich zu regeln 204

1. Individuelle Rechtssicherheit vor (Daseins-)Vorsorge 204

2. Vorsorge gegen die Unsicherheit der Zukunft durch Recht? 205

3. Neue Unsicherheit für individualrechtliche Vorsorge? 208

\section{Bedeutung und Bedeutungswandel des Wortes „, Vorsorge“}

\section{Das Wort „Vorsorge“ versteht sich nicht von selbst}

Bei seinem Versuch, das weite Feld des Sozialrechts durch typisieren übersichtlich zu machen, verdichtet Zacher das Wesen der von ihm so genannten „Vorsorgesysteme“ auf den Satz:

„Es wird geleistet, weil und wie vorgesorgt ist.“'

Damit wird ein sowohl final wie kausal von „Vorsorge“ bestimmtes Rechtsverhältnis beschrieben. Das Verb des Kausalsatzes steht in der Perfektform (Passiv) und lässt damit offen, was tatsächlich und rechtlich unter „Vorsorge“ begriffen wird. Wer sorgt vor für welche Situation und für wen? Freiwillig oder aus Verpflichtung? Der Einzelne im Eigeninteresse oder für seine Familie? Eine Solidargemeinschaft für ihre Mitglieder? Der Staat für alle Bürger oder für die Alten oder für spätere Generationen? „Vorsorge“ wird notwendig in jedem dieser Fälle rechtlich unterschiedlich ausgestaltet sein müssen. Meist wird die beitragsfinanzierte Sozialversicherung als die im Sozialrecht bedeutendste Ausformung eines „Vorsorgesystems“ verstanden. Das Beispiel „Versicherung“ liegt dabei nahe, denn zweifellos stellt eine gesetzlich geregelte Versicherung einen Weg dar, „Vorsorge" zu treffen. Jenseits des nationalen Grenzen ist es die Aufgabe des internationalen Sozialrechts, Regelungen dafür zu schaffen, ob und wie das in einem Staat ,angesparte Vorsorgekonto" realisiert werden kann, wenn die Situation, für die vorgesorgt wurde, in einem anderen Staat eintritt. ${ }^{2}$ Das bedeutet aber noch keine den Begriff „Vorsorge“ erhellende „Internationalisierung“. Eine Reduzierung des Begriffs „Vorsorge“ auf Beitragszahlungen zu einem (national-)staatlichen System mit der Funktion, die daraus abgeleiteten (Versicherungs-)Leistungen rechtlich zu bestimmen, würde dessen

1 Zacher, Grundtypen des Sozialrechts, in: v. Maydell/Eichenhofer (Hrsg.), Abhandlungen zum Sozialrecht, Heidelberg 1993, S. 257-278 (268).

2 Zacher, Horizontaler und vertikaler Sozialrechtsvergleich, in: ders. (Hrsg.), Sozialrechtsvergleich im Bezugsrahmen internationalen und supranationalen Rechts, Berlin 1978, S. 434, spricht von „Zugang des Fremden zur Vorsorge“ einerseits und von der „Wirksamkeit (Verfügbarkeit) der Vorsorge über Grenzen hin“" andererseits. 
Sinngehalt nicht ausschöpfen. ${ }^{3}$ Eine am Ergebnis anknüpfende Definition, etwa die Feststellung:

„Die primäre soziale Leistung der Vorsorge ist Sicherheit“4

ersetzt, wenn man die Begriffsinhalte des Substantivs „Vorsorge“ und des Verbs „Sichern" als verwandt anerkennt, im Grunde idem per idem:

„Nicht die Abwehr unmittelbar drohender Gefahr, sondern die Vorsorge gegenüber möglichen, jedoch hinsichtlich ihres Eintretens ungewissen und vielfach auch unbestimmten Gefahren für bestimmte Güter macht den Vorgang des Sicherns aus." 5

Es hilft auch wenig, wenn mit der ,primären Leistung“ allein das sozialpolitische Ziel von Vorsorge skizziert werden soll. Denn „Sicherheit"6 konstituiert nach modernem Staatsverständnis das Staatsziel allgemein (mit), ${ }^{7}$ weshalb dieser Definitionsversuch jedenfalls für einen Rechtsvergleich zu weit führen würde.

Weil „Sicherheit“ zudem im Kontext wohlfahrtsstaatlicher Semantiken ${ }^{8}$ begrifflich den „Wertideen“, 9 also eher der Sphäre des Gefühlten (weniger der des gewiss Gewuss-

3 Das sieht natürlich auch Zacher, in: Grundtypen des Sozialrechts (Fußn. 1), der darin zahlreiche Abweichungen vom „Grundtypus“ aufführt und später (S. 271) noch „Vorsorge-analoge Systeme“ und „Möglichkeiten der Mischung“ (S. 273) nennt.

4 Ders., ebda., S. 269.

5 Kaufmann, Sicherheit: Das Leitbild beherrschbarer Kompetenz, in: Lessenich (Hrsg.), Wohlfahrtsstaatliche Grundbegriffe, Historische und aktuelle Diskurse, Frankfurt/New York 2003, S. 73-104 (91).

6 Zur Begriffsgeschichte von „Sicherheit“ s. Kaufmann, ebda., ,Sicherheit’ im Kontext der Staatsund Rechtstheorie, S. 75 ff. und ders., Ambivalenzen der sozialen Sicherheit, in: Allmendinger (Hrsg.), Entstaatlichung und soziale Sicherheit, Verhandlungen des 31. Kongresses der Deutschen Gesellschaft für Soziologie in Leipzig 2002, Opladen 2003, S. 114-133.

7 Statt vieler aktuell Murswiek, Das Recht auf Sicherheit, in: Wahl (Hrsg.), Verfassungsänderung, Verfassungswandel, Verfassungsinterpretation, Berlin 2008, S. 357: „Die Gewährleistung von Sicherheit ist die Kernaufgabe des Staates, der fundamentale Staatszweck.“

8 Ein Ansatz, den Kaufmann, Sicherheit (Fußn. 5), S. 98, so kritisiert: „Die Rede von ,wohlfahrtsstaatlichen Semantiken' stammt von sozialwissenschaftlichen Beobachtern, welche den ,Ernstfall' der Politik aus der sicheren (hier: gefahrlosen) Distanz des Wissenschaftssystems beobachten. Die Formulierung ,Semantik' suggeriert fehlende Ernsthaftigkeit oder zum mindesten einen Mangel an ,politischer Bodenhaftung'“. Für den Juristen scheint die Untersuchung von „Signalworten“ näher liegend, s. Rückert, „Sozialstaatsprinzip“, Neuer Mut in alten Fragen, in: Acham u. a. (Hrsg.), Der Gestaltungsanspruch der Wissenschaft. Aufbruch und Ernüchterung in den Rechts-, Sozial- und Wirtschaftswissenschaften auf dem Weg von den 1960er zu den 1980er Jahren, Stuttgart 2006, S. 643-717 (652 ff.): „Der Wandel der Signalworte in der Literatur nach 1945“, wonach „,eine Erhöhung des normativen Rangs und des Gestaltungsanspruchs für [den Begriff] Sozialstaat“" (S. 654) feststellbar ist.

9 Lessenich, in: ders. (Hrsg.), Wohlfahrtsstaatliche Grundbegriffe (Fußn. 5), S. 16-17, differenziert die Semantiken des Wohlfahrtsstaates nach Wertideen (wie Sicherheit) - Sozialfiguren (wie den Bürger) - Strukturkategorien (wie das Risiko); sie treten nach Lessenich,,allesamt in einer Doppelrolle als wissenschaftliche und politische Konzepte auf", was wegen der teilweisen Überschneidung der Begriffsinhalte von „Sicherheit“, „Vorsorge“ und „Risiko“ einen Rechtsvergleich noch zusätzlich erschwert. 
ten) zuzuordnen ist, bietet sie nicht die Trennschärfe und Detailgenauigkeit, ${ }^{10}$ um für einen Rechtsvergleich praktikabel zu sein.

Wie schwierig der Ansatz an der „Wertidee“ Sicherheit sein kann, zeigt das nur geografisch weit hergeholte Beispiel des Doppelsinns dieses Wortes im Japanischen:

„Das Wort ,Sicherheit (anzen)' verwendet man heutzutage in Japan oft im gleichen Atemzug mit dem Wort ,Sorgenfreiheit (anshin)' vor allem dann, wenn es um anfallende Risiken und Gefahren geht. Die Sorgenfreiheit ist ein subjektiver Begriff, der Seelenzustand ohne Bedenken und Sorge, Sanssouci. Die Sicherheit weist auf einen objektiven $\mathrm{Zu}-$ stand ohne Risiken und Gefahren hin. (...) Vom Staat wird erwartet, die objektive Sicherheit zu schützen."11

Das Phänomen, subjektiven „Seelenzustand“ und objektiven Zustand sprachlich annähernd in eins zu setzen, bestätigt indirekt einen allgemeingültigen Befund: „Sicherheit" beschreibt anthropologisch offenbar mehr ein Gefühl, keinen definitiv hergestellten Zustand. ${ }^{12}$ Für moderne Wohlfahrts- oder Sozialstaaten wird dafür aktuell eine neue Spielart konstatiert, eine „Wiederkehr der Unsicherheit" 13 die entsteht durch die

„Kluft zwischen einer gesellschaftlich konstruierten Sicherheitserwartung und dem tatsächlichen Vermögen einer Gesellschaft, die Sicherheitsleistungen in die Praxis umzusetzen." 14

Man sieht: Es handelt sich nicht um Sprachspiele als l'art pour l'art, sondern um den Versuch, aus der sprachlichen Bedeutung Erkenntnis zu gewinnen. Das sprachliche Verständnis ist die erste Voraussetzung des Rechtsverständnisses ebenso wie die jedes Rechtsvergleichs: Geht man darin einig, dass Rechtsvergleich dem „besseren Erfassen, Verstehen und Bewerten von Recht" 15 dienen soll und darin, dass die „Sprache Mittel zum Erfassen und Bewerten der Welt, (...) Form und Zeichen für Recht, Instrument rechtsstaatlicher Gewalt [ist]“16 und gesteht man zu, dass diese Erkenntnis nicht bei der

10 Gemeint sind etwa politisch camouflierte Zieländerungen, die von außen nur sehr schwer zu erkennen sind, etwa Eingriffe in die Rentenformel, wie sie Ruland, Die Zukunft der Alterssicherung aus heutiger Perspektive, SGb 10/2008, S. 570 ff., für die deutsche Rentenversicherung feststellt (S. 573): „War für die Anpassung früher das Ziel der Sicherung eines angemessenen Lebensstandards maßgeblich, dominiert nun das Ziel, dass der Beitragssatz bis 2030 die gesetzliche Vorgabe von $22 \%$ nicht übersteigt.“

11 Kawamata, Das Recht auf Sicherheit, in: Wahl (Hrsg.), Verfassungsänderung (Fußn. 7), S. 369-382 (369).

12 Sofsky, Das Prinzip Sicherheit, Frankfurt/Main 2005.

13 van Dyk/Lessenich, Unsichere Zeiten, Die paradoxale „Wiederkehr“ der Unsicherheit, Mittelweg 36, 17. Jg. Heft 5, S. 13-45.

14 Castel, Die Stärkung des Sozialen, Leben im neuen Wohlfahrtsstaat, Hamburg 2005, S. 10. S. auch die Beiträge in Social Policy Administration, vol. 42 / 2008 Nr. 6, Special Issue: Living in Dangerous Times - Fear, Insecurity, Risk and Social Policy, und in Ulbert/Werthes (Hrsg.), Menschliche Sicherheit, Globale Herausforderungen und regionale Perspektiven, Baden-Baden 2008.

15 Zacher, Vorfragen zu den Methoden der Sozialrechtsvergleichung, in: v. Maydell/Eichenhofer (Hrsg.), Abhandlungen zum Sozialrecht (Fußn. 1), S. 329.

16 Kirchhof, Deutsche Sprache, in: HStR II, 3. Aufl. München 2004, Rdnr. 6. In Rdnr. 23 macht Kirchhof den etymologischen Zusammenhang deutlich: „Die Begriffe Recht und Rede, Nomos und Namen, Lex und Wort haben einen gemeinsamen Stamm. Recht lebt in der Sprache und durch die 
„Banalität stehen [bleibt], dass sich das Recht der Sprache bedient“" ${ }^{17}$ so liegt es nahe, nach der lexikalischen Semantik des Wortes „Vorsorge“ und seiner Anwendung im Sozialrecht zu fragen. Damit kann zugleich der Vorwurf entkräftet werden, der dem deutschen Rechtsdenken bisweilen von außen gemacht wird:

"German lawyers seek to reveal a hidden reality by using relevant words, rather than finding words to express a reality already revealed. In German legal culture, the word creates the meaning, not the other way round." 18

Der Vergleichsansatz am Verstehen der (Rechts-) Sprache bedeutet kein „sich verstecken hinter der Hermeneutik, um auf theoretisch avancierte Weise zu erklären, warum man etwas Wesentliches nicht erklären kann", ${ }^{19}$ denn

„In contrast to humanists and aestheticists, lawyers and theologians have a common subject and therefore a related method, namely normative texts, and a dogmatic exegesis. “20

Für den Rechtsvergleich ist objektiv der enge Zusammenhang ,Zwischen Rechtsverständnis und Sprachverständnis unübersehbar". ${ }^{21}$ Es gilt:

„Comparative law's most visible connection to language is due to different legal system's legal texts being in different languages." 22

Sprache.“ S. auch die Beiträge in Lötscher/Nussbaumer (Hrsg.), Denken wie ein Philosoph und schreiben wie ein Bauer, Sprache, mit der ein Staat zu machen ist, Zürich 2007 (insbes. Schweizer, Die Sprache als Grundlage des Rechts, S. 13-33).

17 Forsthoff, Recht und Sprache, Prolegomena zu einer richterlichen Hermeneutik, Königsberg 1940, S. 17; „Le droit -on le sait- utilise la langue pour ses besoins.” s. Sacco, Les chances du droit comparé, in: Castonguay/Kasirer (Hrsg.), Étudier et enseigner le droit: hier, aujourd'hui et demain, Études offertes à Jaques Vanderlinden, Québec 2006, S. 157-176 (172); Mattila, Comparative Legal Linguistic, Ashgate 2006, S. 31: „Given that the law is a metaphysical phenomenon that is only ,alive' in language, it is only by language means that is possible to change legal relations." Auf die praktischen Problem verweist Cao, Translating Law, Toronto 2007.

18 Mattila, Comparative Legal Linguistic (Fußn. 17). Kap. 6: Legal German, S. 174 unter Verweis auf Bergmans, L'enseignement d'une terminologie juridique étrangère comme mode d'approche du droit comparé: l'exemple de l'allemand. In: Revue international de droit comparé 1987 Nr. 1, S. 90110 .

19 Andersson, Skyddsändamål och adekvanz, Uppsala 1933, S. 221: „Man får dock inte gömma sig bakom hermeneutikk, for att på ett teoretisk avancerat sätt förklara varför man inte kan förklara något väsentligt”, als Motto zitiert von Graver, Vanlig juridisk metode? Om rettsdogmatikken som juridisk sjanger, Tidsskrift for Rettsvitenskap 2/2008, S. 149.

20 So Jørgensen, Lawyers and Hermeneutics, Scandinavian Studies in Law, (SSiL) Vol. 40/2000, S. 181.

21 Forsthoff, Recht und Sprache (Fußn. 17), S. 15, der dabei an die historische Schule Savignys anknüpft. Heute ist selbstverständlich, dass ,the study of language is a cognitive model for comparative law." Grosswald Curran, Comparative Law and Language, in: Reimann/Zimmermann (Hrsg.), The Oxford Handbook of Comparative Law, Oxford 2006, S. 676.

22 Grosswald Curran, Comparative Law (Fußn. 21), S. 677. Zur zentralen Bedeutung der Sprache im Rechtsvergleich s. Reichelt, Sprache und Recht, Ein Beitrag zur Integralen Multilinguistik im Europarecht, in: Frantzen u. a. (Hrsg.), Rett og tolerans, Festskrift til Helge Johan Thue, Oslo 2007, S. 557 ff.; Großfeld, Kernfragen der Rechtsvergleichung, Tübingen 1996; ders., Macht und Ohnmacht der Rechtsvergleichung, Tübingen 1984, insbes. S. 149 ff.; ganz ähnlich die Problemskizze der 
Die Feststellung dieser Verbindung ist nur vordergründig der Ausspruch einer einfachen Wahrheit 23 - sie kann (neben vielen anderen Komplikationsvarianten) wegen der im Deutschen unbegrenzten Möglichkeit, Wörter mit anderen Wörtern zusammenzusetzen und so ihren Sinn abzuwandeln, ${ }^{24}$ spezifisch erschwert werden. So finden sich bei der erwähnten Darstellung des sozialrechtlichen Grundtypus „Vorsorgesystem“ bei $\mathrm{Za}$ cher neben dieser Fügung selbst auf wenigen Seiten Text noch weitere acht Kombinationen („Doppelwörter"), die von „Vorsorgeverhältnis“ über „Vorsorgefähigkeit“ bis zum Adjektiv „vorsorgeschwach“ reichen. ${ }^{25}$ Damit sind aber längst nicht alle Variationen ausgeschöpft, allein in den Beiträgen in vorliegendem Band finden sich zahlreiche andere Beispiele wie „Vorsorgegerechtigkeit“, „Vorsorgegedanke“, „Altersvorsorge“ oder „Vorsorgestaat" etc. Weil beispielsweise den skandinavischen Sprachen diese Modifikationsmöglichkeit ebenfalls geläufig ist, ist eine Beschränkung der sprachlichen Untersuchung auf das „Stammwort“ (Jean Paul) „Vorsorge“ umso mehr selbst ein Gebot der Vorsorge, will man nicht „bei der Übersetzung verloren gehen“.26

\section{Deutsche Etymologie und aktuelle Bedeutung}

Das Wort ist im Deutschen seit dem 17. Jahrhundert belegt. Lange Zeit wurden Vorsorge und Fürsorge synonym ${ }^{27}$ gebraucht, die Bedeutungstrennung erfolgte erst im

„terminologischen Hürde” von $I g l$, Soziale Hilfe und soziale Förderung in Frankreich im Rahmen der ,action sociale“, in diesem Band, S. 265 f.

23 Grosswald Curran, Comparative Law (Fußn. 21), S. 677, spricht von ,simple observation“.

24 Mit Jean Paul lässt sich sagen: „Dem Anschein nach ist nichts regelloser als die Art, auf welche unsere Sprache in den Doppelwörtern das Bestimmwort mit dem Grundworte (z. B. im Doppelwort Baumschule ist Baum das Bestimm- und Schule das Grundwort) verknüpft; und die menschlichen Ehen werden bei den verschiedenen Völkern kaum mannigfaltiger geschlossen als bei uns die grammatischen der Doppelwörter.“ Paul, Über das Zusammenfügen der deutschen Doppelwörter; in 12 Briefen an eine vornehme Dame; nebst einer geharnischten Nachschrift an die Gelehrten, Berlin 1828, Sämtliche Werke Bd. LV, Einl., S. 1.

25 Das sind: „,vorsorgefähig“, ,,vorsorgebedürftig“, „Vorsorgeleistungen“, ,,vorsorgeanalog“ und „,vorsorgebezogen“, s. Zacher, Grundtypen des Sozialrechts (Fußn. 1), S. 268-273.

26 „Words Cannot be Translated - [...] Übersetzung von Rechtstexten ohne Rechtsvergleichung ist ein ,bunter Luftballon', dessen Bodenberührung zweifelhaft ist.“ So Großfeld, Neue Rechtsvergleichung, in: Gottwald u. a. (Hrsg.), Festschrift für Dieter Henrich zum 70. Geburtstag 1. Dezember 2000, Bielefeld 2000, S. 215. Großfeld zitiert Hoffman, Lost in Translation, New York 1991, S. 272: „In order to transport a single word without distortion, one would have to transport the entire language around it."

27 Synonymie, deren griechische Wurzel $\sigma v v \omega v v \mu 1 \alpha$ wörtlich „gleichnamig“ heißt, meint heute „gleichbedeutend“ und weist damit, da selbst eben dem Stammwort nur ,ähnlich“, auf die Problematik des Verhältnisses zwischen Wort und Begriff hin; s. Linsky (Hrsg. und Übersetzer), Semantics and the Philosophy of Language, Urbana 1952; Sinnreich (Hrsg.), Zur Philosophie der idealen Sprache, München 1972, darin insbes. Quine, Zwei Dogmen des Empirismus, S. 167-194 (im Original Quine, Two Dogmas of Empiricism, The Philosophical Review 60 (1951), S. 20-43, Nachdruck in Quine, From a Logical Point of View., 2. Aufl. Harvard 1961). 
18. Jahrhundert. Das Wörterbuch von Jacob und Wilhelm Grimm differenziert nach dem damals „heutigen“ Sprachgebrauch die beiden Begriffe wie folgt:

„Vorsorge, die aus klugheit zum voraus geschieht, und fürsorge für oder zum besten eines dinges." 28

Vorsorge, so liest man weiter, trifft man nicht nur aus Klugheit, sondern aus „einem voraus gefühlten inneren Druck, voraus empfundener Besorgnis, Furcht“. Belegt wird dies mit Beispielen aus der Literatur, etwa einem Zitat aus Johann Georg Zimmermanns damals vielbeachteten Werk von 1784 „Über die Einsamkeit“

„wo sind die Spiele der zarten Jugend, jene geschäftigen Tage ohne Vorsorge und ohne Gram?“,

mit Lichtenbergs Aphorismus

„Wo vorsorge unnütz war, da hatte ich sie; wo sie aber hätte nützlich seyn können, trat der leichtsinn ein."

oder mit dem Goethewort von der ,vorsorglichen Hausfrau“, der Voss'schen HorazÜbersetzung von der Ameise, ${ }^{29}$ die ,wohl kundig und wohl vorsorgend der zukunft“ (non incauta futuri) mit dem Munde schleppt, „wie viel sie nur kann“ oder mit dem sprichwörtlichen „Vorsorge verhütet Nachsorge“.

Als neu wird die Wortverbindung „Vorsorgeversicherung“ erwähnt, für deren Definition aus dem Versicherungslexikon von Manes ${ }^{30}$ zitiert wird:

„,vorsorgeversicherung erstreckt sich auf alle haftpflichtgefahren aus personen- und sachschäden.“

Aus der über Jahrzehnte führenden Oeconomischen Encyclopädie von Krünitz zitieren die Grimms:

„(1) Vorsorge, die vorhergehende Sorge zur klugen Einrichtung einer künftigen Sache und (2) die Sorgfalt für das Beste und die Erhaltung einer Sache."31

Thomas Mann, der mit dem 1943 in Kalifornien geschriebenen vierten Band seiner Joseph-Tetralogie bestrebt war, „Roosevelt zum großen Gegenspieler Hitlers zu stilisieren und ihm in dieser Rolle in ,Joseph der Ernährer' ein Denkmal zu setzen,"32 macht „Vorsorge“ zur Charaktereigenschaft eines Mannes mit Überblick:

28 Grimm/Grimm, Deutsches Wörterbuch, 16 Bände, [in 32 Teilbänden], Leipzig 1854-1960, Bd. 26, Sp. 1591-1592, Lemma „Vorsorge“.

29 Bei Kaufmann, Sicherheit, (Fußn. 5), findet sich der Hinweis auf einen Bewertungswandel von Verhaltensmustern im Kontext reformatorischer Weltanschauung (S. 79): „Als die ,Sicheren' galten häufig die Sorglosen, die Gott nicht fürchten; bei Calvin erschien ,sécurité' als ,verdammenswerte Selbstberuhigung und Unbekümmertheit der Seele'." Die sorglose Grille aus der Fabel wird damit zweifach negativ gezeichnet! Die Fabel stammt ursprünglich von Aesop, Fabulae Aesopicae collectae, ex recognitione Caroli Halmii, Lipsiae, Sumptibus et typis B, G. Teubneri, MDCCCLXIII Versio digitalis: Herbert Wenger, Bibliotheka Augustana.

30 Manes, Versicherungslexikon, 1. Aufl. Leipzig 1909.

31 Krünitz, Oekonomische Encyklopädie oder allgemeines System der Staats- Stadt- Haus- und Landwirthschaft, 1773 bis 1858 in 242 Bänden, Band 231, 1855, Lemma: Vorsorge.

32 Schöll, Joseph im Exil, Zur Identitätskonstruktion in Thomas Manns Exil-Tagebüchern sowie im Roman Joseph und seine Brüder, Bamberg 2003, S. 316; Mann war durch die Lektüre von Bing- 
„Denn hier denke ich nur an den verständigen und weisen Mann, [...] an ihn, der erfüllt ist vom Geist der Vorsorge, den Herrn des Überblicks, der alles sieht bis an des Landes Grenzen und noch darüber hinaus..."33

Gegenwärtig führt der aktuelle Band „Herkunftswörterbuch“ des Duden ${ }^{34}$ „Vorsorge“ dennoch gar nicht mehr als eigenes Lemma, sondern verweist auf „Sorge“, wo dann der Bedeutungswandel zwischen Fürsorge und Vorsorge im 17. Jahrhundert erwähnt und Vorsorge als „Besorgnis vor Zukünftigem“ beschrieben wird.

Das neue Große Wörterbuch der deutschen Sprache des Duden enthält nicht nur das eigenständige Lemma „Vorsorge“, sondern immerhin zehn Kombinationen mit anderen Begriffen und erklärt das Wort:

„Maßnahmen, mit denen einer möglichen späteren Entwicklung od. Lage vorgebeugt, durch die eine spätere materielle Notlage od. Krankheit nach Möglichkeit vermieden werden soll; ““35

Scheint bereits bei der Erklärung der Vorsorge an sich das Vermeiden von Krankheit auf, so überwiegt bei den mit Vorsorge zusammengesetzten Begriffen mit „Vorsorgemedizin“, „Vorsorgeuntersuchung“ und den primär medizinisch erklärten „Vorsorgemaßnahmen" das medizinische Anwendungsfeld des Begriffs. Im Wahrig ${ }^{36}$, wo Vorsorge als „vorausschauende Fürsorge“ erklärt wird, werden als Beispiel „,vorsorgliche (medizinische) Maßnahmen“ genannt. Der sprachliche Befund scheint ein Reflex sozialer Verhaltensweisen zu sein - angesichts der im Alltag allgegenwärtigen medizinischen Angebote wird aktuell mit dem Appell: „Vorsicht Vorsorge!“ inzwischen schon (mit guten Gründen) vor den Gefahren übergroßer (präventivmedizinischer) Vorsorge gewarnt. 37

\section{Das Wort „Vorsorge“ in anderen Sprachen}

Alles in allem ist „Vorsorge“ also damals wie heute nicht Sache der Jugend; es überwiegt die emotionale Note des sich um die Zukunft grämen. Die Grimms wählen deshalb als lateinische Übersetzung die schwermütige ,praemolestia“, das ist die „Ahnung künftigen Verdrusses“, und eben nicht die nüchterne „providentia“, die Voraus-

ham, Wesen und Aussichten des New Deal, in: Mass und Wert, 3. Jg. 1939, Heft 1, S. 50-61, über Roosevelts Politik gut informiert, auch die Parallele Josephs des Ernährers zu Franklin D. Roosevelt und dessen New Deal wurde zur Entstehungszeit des Romans in den USA gesehen und gewürdigt.

33 Mann, Joseph und seine Brüder, Teil IV, Joseph der Ernährer, Gesamtausgabe in einem Band, Frankfurt/Main 1975, S. 1095.

34 Duden, Herkunftswörterbuch, Etymologie der deutschen Sprache, Dudenredaktion (Hrsg.), 3. Aufl. Mannheim u. a. 2001, Lemma: Sorge.

35 Duden, Das große Wörterbuch der deutschen Sprache, Dudenredaktion (Hrsg.), Bd. 10, 3. Aufl. Mannheim u. a. 1999, Lemma: Vorsorge.

36 Wahrig-Burfeind (Hrsg.), Deutsches Wörterbuch, Gütersloh u. a. 2008, Lemma: Vorsorge.

37 Bartens, Vorsicht Vorsorge! Wenn Prävention nutzlos oder gefährlich wird, Frankfurt/Main 2008. 
sicht und Vorsicht. ${ }^{38}$ Im Altgriechischen findet sich noch die Konnotation von Vorsorge und Fürsorge: $\pi \rho o v o 1 \alpha$ bedeutet Voraussicht, Vorsicht und, wenn sie einer Sache oder Person gilt, Fürsorge. ${ }^{39}$

Im Englischen hat „provision“ ein derart weites (vielfach ökonomisches und finanztechnisches) Bedeutungsfeld, dass die daneben auch mögliche Bedeutung „Vorsorge“ den deutschen Begriff wohl nicht trifft. Am nächsten kommt diesem ,precaution“40, doch dabei überwiegt der Aspekt der Vorsicht, der Vorbeugung und auch der Versicherung. Als Synonyme werden „safeguard, preventive measure, safety measure“ genannt. 41

Die Romanischen Sprachen haben aus dem Lateinischen nur die „providentia“ nicht die „praemolestia“ - übernommen; italienisch: providentia, spanisch: prevision und französisch: prévoyance. Weil mit „,providence“ im Französischen eigentlich die (göttliche) Vorsehung gemeint ist und in der Kombination mit dem Wort Staat der englische (!) welfare state bezeichnet wird, ${ }^{42}$ ist das berühmte Werk von Ewald, L'Etat Providence ${ }^{43}$ mit „Vorsorgestaat" ${ }^{“ 44}$ nicht nur wörtlich unrichtig übersetzt, sondern auch vom Inhalt her. Denn analysiert wird darin primär die Transformation des Haftungsrechts bei Arbeitsunfällen durch (Sozial-)Versicherung. Nach Ewald ein umfassender neuer Gesellschaftsvertrag:

„Gesellschaft ist nichts anderes als eine umfassende Versicherung gegen die Risiken, die sie durch ihre eigene Entwicklung verursacht." 45

Mit dem vermeintlichen Vorsorgestaat ist somit eigentlich ein „Versicherungsstaat“46 gemeint. Das bestätigt ein Blick in die mehrsprachige ${ }^{47}$ Schweiz: „Vorsorge“

38 Grimm/Grimm, Deutsches Wörterbuch (Fußn. 28).

39 Gemoll, Griechisch-Deutsches Schul- und Handwörterbuch, 9. Aufl. Wien u. a. 1965. Das Verb $\pi \rho \circ{ }^{\prime} \varepsilon \omega$ meint primär noch ganz wörtlich: vorher bemerken, vorherahnen und dann erst abgeleitet für etwas/jemand Sorge tragen.

40 Natürlich verwandt mit dem oben bei der Ameisenfabel genannten „cautus/incautus“, vorsichtig/unvorsichtig; , ,praecautus“ kennt das Lateinische nicht. Schon hier aber der Hinweis: Trotz dieser linguistischen Bedenken wird in internationalen Rechtsdokumenten ,precaution“ mit „Vorsorge“ übersetzt und umgekehrt, s. u. II 2.

41 Lindberg, The Oxford American Writer's Thesaurus, Oxford 2004, Lemma: precaution. Als erklärender Beispielssatz wird genannt: ,the guard rails are just a precaution“.

42 Robert, Le nouveau Petit Robert, Dictionnaire alphabétique et analogique de la langue francaise, Nouvelle edition, Paris 2004, Lemma: providence. Als Synonyme werden genannt: secours, protecteur, protection, support.

43 Ewald, L'Etat providence, Paris 1986.

44 Ewald, Der Vorsorgestaat, Frankfurt/Main 1993.

45 Ders., ebda. ,S. 443: Zur Sozialpolitik: „Keine Sicherheitspolitik, die nicht als Versicherungspolitik formuliert wurde." Im französischen Text selbst ist dementsprechend auch durchweg von Caisse national de prévoyance die Rede.

46 Leibfried/Wagschal, Der deutsche Sozialstaat: Bilanzen - Reformen - Perspektiven, Frankfurt/Main 2000, S. 29, übersetzen L'Etat providence mit drei Begriffen: „Vorsorge-, Vorsehungs- oder Schutzengelstaat“. Ähnlich die Argumentation von Rüb, Risiko: Versicherung als riskantes Geschäft, in: Lessenich (Hrsg.), Wohlfahrtsstaatliche Grundbegriffe (Fußn. 5), S. 303-330 (313-314). 
steht im Sozialrecht weitgehend für Versicherung, als „berufliche Vorsorge“/,prévoyance professionnelle“48 ist sie terminus technicus der „Zweiten Säule“ der Alterssicherung. Das „Vorsorgeverhältnis“ wird folglich als rechtliche Dreiecksbeziehung zwischen Vorsorgeeinrichtung, Versicherer und Vorsorgebegünstigtem erklärt. ${ }^{49}$ Der umweltschutzrechtliche Gebrauch, etwa in Art. 1 Abs. 2 des schweizerischen Umweltschutzgesetzes, nähert sich dem Alltagssprachgebrauch. Er lautet:

„Im Sinne der Vorsorge sind Einwirkungen, die schädlich oder lästig sein können, frühzeitig zu begrenzen." 50

Der Konjunktiv macht deutlich, dass Vorsorge auch und gerade dann zu treffen ist, wenn der Eintritt des Schadens nicht absehbar ist.

Im österreichischen Sozialrecht führt eine Suche über das Stichwort „Vorsorge“ wieder zu „vorbeugenden Maßnahmen“ im Rahmen der Krankenversicherung, also zu „Vorsorgeuntersuchungen“" etc. 51

Die nordischen Sprachen haben die Trennung Fürsorge/Vorsorge nicht mit vollzogen. Alle Worte im Umfeld „zukunftsgerichteter Sorge“ haben den alten Doppelsinn behalten. Im Dänischen ist das Wort „forsorg“ aus dem Deutschen „Für-, Vorsorge übernommen“, es wird erklärt als

„eine aus Zuneigung oder Pflicht erfolgende Handlung, die vorausschauend jemanden, "der unerfahren, hilflos etc. ist, Anleitung und Hilfe bringt. " 52

Das Wort hat also eine starke Beimischung von Fürsorge. Auch im Schwedischen ist „försorg“ ein deutsches Lehnwort aus „Für- oder Vorsorge“, 53 als Synonyme werden „omsorg“, Fürsorge und Sorgfalt, und „omtanke“, Fürsorge, angegeben. ${ }^{54}$ Ein deutschschwedisches Lexikon gibt umgekehrt für Vorsorge nur „omsorg“ und „försorg“, für Fürsorge an. ${ }^{55}$ Der Bedeutungswandel der deutschen Vor- und Fürsorge zu zwei unter-

47 Wie sehr Recht und Rechtsprechung auch und gerade in zweisprachige Ländern mit Übersetzungsproblemen zu kämpfen haben, zeigen für Canada die Beiträge von Pallard, Kasirer, Snow und Foucher im 7. Kapitel, Droit et langue, in: Castonguay/Kasirer (Hrsg.), Étudier et enseigner le droit; s. a. Cao, Translating Law (Fußn. 17).

48 Beispielhaft der Titel der renommierten zweisprachigen Schweizerischen Zeitschrift für Sozialversicherung und berufliche Vorsorge/Revue suisse des assurances sociales et de la prévoyance professionnelle, die Zacher zu ihren ständigen Mitarbeitern zählen kann.

49 Brühwiler, Obligatorische berufliche Vorsorge, in: Meyer (Hrsg.), Soziale Sicherheit. 2. Aufl. Basel u. a. 2007 (Schweizerisches Bundesverwaltungsrecht Bd. XIV), § 20.

50 S. Zitat und Fundstelle bei Rippe, Vorsorge als umweltethisches Leitprinzip, Zürich (Ethik im Diskurs) 2002, S. 3.

51 S. z.B. Grillberger, Österreichisches Sozialrecht, 7. Aufl. Wien/New York 2008, S. 45.

52 Det Danske Sprog- og Litteraturselskap (Hrsg.), Ordbog over det Danske Sprog, Kopenhagen 2008. Hier zitiert nach ODS på nettet 2008, forsorg: ,efter ty. für-, vorsorge; jf. Eftersorg, forsørge en af kærlighed ell. pligt fremkaldt (omsorgsfuld) virksomhed (...), der tjener til (paa forudseende maade) at værne, lede, hjælpe en (der er mere ell. mindre uerfaren, hjælpeløs osv.)".

53 Svenska Akademien (Hrsg.), Svenska Akademiens ordbok, Webbversion 2008, Lemma: försorg.

54 Friedländer, Ord för ord, Stockholm 1977, Lemma: försorg.

55 Svensk-tysk-tysk-svensk ordbok, Stockholm: Esselte Studium, 1983, Lemma: Vorsorge. 
schiedlichen Begriffen scheint im Norden noch gar nicht realisiert und in den Sprachen jedenfalls nicht übernommen worden zu sein.

Da der Rechtsvergleich sich also nicht über ein sinnverwandtes oder gar sinnidentisches Wort des allgemeinen Sprachgebrauchs führen lässt, soll nun geprüft werden, ob dies durch den „Blick in das Gesetz“ gelingen kann.

\section{II. , Vorsorge“ als rechtlicher Terminus}

Zunächst soll das deutsche Sozialgesetzbuch auf die Verwendung des Terminus untersucht werden, sodann verschiedene Texte internationaler Rechtsdokumente. Obwohl das Sozialrecht als Rechtsgebiet viel mehr umfaßt, 56 ist die Konzentration auf die Bücher des SGB nicht eigentlich eine Reduktion des Untersuchungsgegenstandes: Da hier die Sozialversicherung geregelt ist, sollten im SGB auch am ehesten die rechtliche Gestaltung oder doch wenigstens normative Reflexe von „Vorsorgeverhältnissen“ nachweisbar sein.

\section{1. „,Vorsorge“ im deutschen Sozialgesetzbuch}

Es mag deshalb erstaunen, dass die Bücher I (Allgemeiner Teil), III (Arbeitsförderung), IV (Gemeinsame Vorschriften für die Sozialversicherung) und IX (Behindertenrecht und Rehabilitation) des Sozialgesetzbuches das Wort "Vorsorge“ überhaupt nicht enthalten und auch keine Kombinationen daraus! Im SGB II (Grundsicherung für Arbeitssuchende), VII (Unfallversicherung), XI (Soziale Pflegeversicherung) und XII (Sozialhilfe) findet sich „Vorsorge“ je ein Mal:

- In $\S 11$ Abs. 2 Ziff. 3 a und b SGB II, wonach Beiträge zur „Vorsorge für den Fall der Krankheit“" und zur „Altersvorsorge“ bei der Einkommensberechnung nicht berücksichtigt werden,

- in § 199 Abs. 1 Ziff. 5 SGB VII, wonach „Vorsorge für eine wirksame Erste Hilfe“ zum Aufgabenkatalog der Unfallversicherungsträger gezählt wird,

- § 71 Abs. 4 SGB XI nimmt stationäre Einrichtungen, in denen „Leistungen zur medizinischen Vorsorge (...) im Vordergrund des Zwecks der Einrichtung stehen“ vom Katalog der Pflegeeinrichtungen aus,

56 So definiert etwa das Gesetz über Schutzmaßnahmen bei psychischen Krankheiten (PsychKG) in $\S 7$ das Ziel der vorsorgenden Hilfe: „Die vorsorgende Hilfe soll insbesondere dazu beitragen, dass Betroffene rechtzeitig medizinisch und ihrer Krankheit angemessen behandelt werden, und sicherstellen, dass zusammen mit der ärztlichen und psychotherapeutischen Behandlung psychosoziale Maßnahmen und Dienste in Anspruch genommen werden." Viele untergesetzliche Vorschriften regeln die arbeitsmedizinische Vorsorge (s. etwa Röntgenverordnung (RöV), Abschnitt 4, oder die Gefahrstoffverordnung (GefStoffV), § 15). 
- $§ 33$ SGB XII sieht unter dem Titel „Beiträge für die Vorsorge“ die Übernahme der erforderlichen Kosten für den Anspruch auf eine angemessene Alterssicherung oder auf ein angemessenes Sterbegeld vor.

Im SGB VIII (Kinder- und Jugendhilfe) wird die Erlaubnis zum Betrieb von Einrichtungen dann ausgeschlossen, wenn ,die gesundheitliche Vorsorge und medizinische Betreuung" nicht gewährleistet ist ( $\$ 45$ Abs. 2 Ziff. 2 lit. b) und bei der Bedarfsplanung wird festgesetzt, dass dabei ,Vorsorge zu treffen [ist], dass auch ein unvorhergesehener Bedarf befriedigt werden kann“ (§ 80 Abs. 1 Ziff. 3).

Das SGB X (Verwaltungsverfahren) sieht in $\S 92$ im Fall der Auftragsvergabe von einem Leistungsträger zu einem anderen vor, dass ein Auftrag nur gekündigt werden kann, wenn sicher gestellt ist, dass ,,auf andere Weise rechtzeitig Vorsorge“ getroffen ist. $\S 100$ SGB X dehnt die Auskunftspflicht des Arztes in Abs. 2 entsprechend auf „Vorsorge- und Rehabilitationseinrichtungen“ aus.

Im SGB V (Krankenversicherung) kommt „Vorsorge“ 32 Mal vor - in den meisten Fällen jedoch in der Kombination ,,Vorsorge- und Rehabilitationseinrichtungen“, die in $\S 107$ Abs. 2 Ziff. 1 als Einrichtungen beschrieben werden,

„die der stationären Behandlung der Patienten dienen, um a) eine Schwächung der Gesundheit, die in absehbarer Zeit voraussichtlich zu einer Krankheit führen würde, zu beseitigen oder einer Gefährdung der gesundheitlichen Entwicklung eines Kindes entgegenzuwirken (Vorsorge)“.

Die Legaldefinition von „Vorsorge“ versteht sich im SGB V also primär als medizinische Vorsorge, wie etwa in $\S 24$ (Medizinische Vorsorge für Mütter und Väter) oder in $\S 71$ Abs. 1 im Zusammenhang mit Früherkennungsmaßnahmen. (,Ausgabensteigerungen auf Grund von gesetzlich vorgeschriebenen Vorsorge- und Früherkennungsmaßnahmen“).

Die Rentenversicherung, SGB VI, gilt zwar geradezu als Fallbeispiel eines Vorsorgesystems - dennoch wird im Gesetzestext „Vorsorge“ nur als private/geförderte Altersvorsorge erwähnt ( $§ 154)$, was dann sogar einen Befreiungstatbestand von der Versicherungspflicht in der gesetzlichen Rentenversicherung bildet ( $\$ 231$ Abs. 5, 6: eine vergleichbare Form der Vorsorge). ${ }^{57}$ Innerhalb des Systems des SGB VI wird „Altersvorsorge“ nur als „Altersvorsorgeanteil“" bei der komplizierten Formel zur Bestimmung des aktuellen Rentenwerts nach $\S 255$ e relevant, also wiederum als Reflex der Aufwendungen, die neben den Beiträgen zur gesetzlichen Rentenversicherung zusätzlich für den Aufbau einer privaten Alterssicherung aufgewendet werden.

Die weitgehende Besetzung des Begriffs Vorsorge durch den spezifischen Fall der medizinischen Vorsorge entspricht also einerseits durchaus der allgemeinen Sprachentwicklung. Da andererseits der Begriff „Vorsorge“ in vier der zwölf Bücher des SGB überhaupt fehlt und der Gesetzestext des SGB VI selbst für die Alterssicherung aus sich heraus kein „Vorsorgesystem“ erschließen lässt, wäre ein Ansatz am Gesetz bei der

57 Am Rande sei noch die Zuordnung von „Vorsorgekuren“ für Versicherte, die ständig unter Tage arbeiten, als (knappschaftliche) Anrechnungs- bzw. Zurechnungszeit in den $\S \S 60,61$ SGB VI erwähnt. 
Suche nach einem rechtlichen „Vorsorgesystem“ der falsche Weg - er würde einen darauf angelegten Rechtsvergleich auf die medizinische Prävention reduzieren.

\section{2. „Vorsorge“ und „,Vorsorgeprinzip“ in internationalen und supranationalen Rechtsdokumenten}

Das internationale und das supranationale Recht stehen rein quantitativ inzwischen wohl keinem nationalen Sozialrecht mehr nach. Sie sind in ihren vielfältig diversifizierten Geltungsbereichen längst das Arbeitsfeld von Spezialisten. Von der Staatengemeinschaft universal akzeptierte Rechtsdokumente können aber gerade deshalb auch als Argumente im „Zweisprachigen“ Rechtsvergleich dienen, weil sie wegen der für ihr $\mathrm{Zu}$ standekommen notwendigen internationalen Sprachregelungen dabei helfen, das Sprachproblem zu überwinden. Aus diesem Grund sollen zunächst Ergebnisse des Bemühens der Vereinten Nationen, die Menschenrechte universal zu formulieren, 58 untersucht werden.

\section{a) Internationale Rechtsdokumente}

Im Rahmen der Vereinten Nationen wurden neben der ,Allgemeinen Erklärung der Menschenrechte" vom 10.12.194859 bisher sieben Abkommen60 in Kraft gesetzt. Wegen seines sozialrechtlichen Inhalts soll der Internationale Pakt über Wirtschaftliche, Soziale und Kulturelle Rechte 61 ausgewählt werden.

Gewöhnlich werden die in den Art. 9, 10, 11 und 12 des „Sozialrechtspaktes“ aufgeführten Rechte als ,soziale Menschenrechte“ bezeichnet. Neben dem Recht auf soziale Sicherheit (Art. 9), den Schutzrechten für die Familie, Mütter und Kinder (Art. 10) und

58 VN-Charta Kap. 1, Ziele und Grundsätze, Art. 1 Ziff. 3: „... eine internationale Zusammenarbeit herbeizuführen, um [...] die Achtung vor den Menschenrechten und Grundfreiheiten für alle [...] zu fördern und zu festigen;““

59 Angenommen mit Resolution der Generalversammlung 217 A (III), kein verbindliches Rechtsdokument, aber ein „Dokument des Rechts“, so Zacher, Internationales und Europäisches Sozialrecht, Percha 1976, Einleitung, S. XXXVII.

60 Die weiteren Abkommen sind: Internationale Pakt über Bürgerliche und Politische Rechte vom 16. Dezember 1966 (in Kraft getreten 23. März 1976), Internationale Übereinkommen zur Beseitigung jeder Form von Rassendiskriminierung vom 7. März 1966, Übereinkommen zur Beseitigung jeder Form von Diskriminierung der Frau vom 18. Dezember 1979, UN-Anti-Folter-Konvention vom 10. Dezember 1984, UN-Kinderrechtskonvention vom 20. November 1989, Internationale Konvention zum Schutz der Rechte aller Wanderarbeitnehmer und ihrer Familien vom 18. Dezember 1990.

61 Angenommen und zur Ratifizierung aufgelegt mit Resolution der Generalversammlung 2200 A (XXI) vom 16. Dezember 1966, in Kraft getreten am 3. Januar 1976. Zum Sozialrechtspakt s. eingehend Köhler, Sozialpolitische und sozialrechtliche Aktivitäten in den Vereinten Nationen, BadenBaden 1987, S. 905-1007. 
dem Recht auf einen angemessenen Lebensstandard (Art.11) enthält Art. 12 das Recht auf Gesundheit. In dessen Abs. 2 werden die von den Vertragsstaaten zu unternehmenden Schritte zur vollen Verwirklichung dieses Rechtes genannt.

Sie umfassen die erforderlichen Maßnahmen

a) zur Senkung der Zahl der Totgeburten und der Kindersterblichkeit sowie zur gesunden Entwicklung des Kindes;

b) zur Verbesserung aller Aspekte der Umwelt- und der Arbeitshygiene;

c) zur Vorbeugung, Behandlung und Bekämpfung epidemischer, endemischer, Berufs- und sonstiger Krankheiten;

d) zur Schaffung der Voraussetzungen, die für jedermann im Krankheitsfall den Genuss medizinischer Einrichtungen und ärztlicher Betreuung sicherstellen. a) The provision for the reduction of the stillbirth-rate and of infant mortality and for the healthy development of the child;

b) The improvement of all aspects of environmental and industrial hygiene;

c) The prevention, treatment and control of epidemic, endemic, occupational and other diseases;

d) The creation of conditions which would assure to all medical service and medical attention in the event of sickness. a) La diminution de la mortinatalité et de la mortalité infantile, ainsi que le développement sain de l'enfant;

b) L'amélioration de tous les aspects de l'hygiène du milieu et de l'hygiène industrielle;

c) La prophylaxie et le traitement des maladies épidémiques, endémiques, professionnelles et autres, ainsi que la lutte contre ces maladies;

d) La création de conditions propres à assurer à tous des services médicaux et une aide médicale en cas de maladie.

Man sieht, dass die deutsche, englische und französische Fassung unterschiedliche Formulierungen für die gleiche Aussage enthalten. In allen drei Texten scheinen aber weder „Vorsorge“ noch „,precaution“ oder „prévoyance“ auf. Gemeinsam ist den Textversionen weiter, dass sie inhaltlich insgesamt (im Französischen sogar ausdrücklich: „prophylaxie“!) „medizinische Vorbeugemaßnahmen“ beschreiben und damit als internationalrechtliche Parallele zu der schon für das SGB festgestellten Einengung des Begriffs angeführt werden können.

Im Jahr 1972 brachten die Vereinten Nationen mit der „Konferenz über die menschliche Umwelt" in Stockholm ${ }^{62}$ das Thema Umweltschutz dauerhaft in die internationale Diskussion. Das ,laissez faire“ des internationalen Rechts sollte durch einen internationalen Konsens

„to treat the eco-sphere no longer in an egoistic and short-sighted manner as an object of unthoughtful exploitation but as something exhaustible"63

ersetzt werden. Der Sache nach wurde, da man die Begrenztheit der Ressourcen erkannt hatte, ${ }^{64}$ also „Vorsorge“" angemahnt.

62 Köhler, ebda., S. 751-757. Die Konferenz ist dokumentiert bei Rüster/Simma, International Protection of the Environment, Treaties and Related Documents, Vol. I., New York 1975. Zur Vorgeschichte Dicke, Mensch, Umwelt, Natur. In: Vereinte Nationen 2/1985, S. 59 ff.

63 Rüster/Simma, International Protection of the Environment (Fußn. 62), Einleitung, S. VII. 
Die weitere Entwicklung des (internationalen) Umweltschutzes ${ }^{65}$ bildet den Hintergrund für die Entstehung eines neuen Rechtsbegriffs: Zehn Jahre nach Stockholm lud das UNEP zu einer Folgekonferenz nach Nairobi, die neben der Errichtung einer UN World Commission on Environment and Development (WCED) ${ }^{66}$ den Anstoß gab zu einer von der Generalversammlung der Vereinten Nationen feierlich verkündeten „Welt-Charta für die Natur". ${ }^{67}$ In diesem Dokument findet sich neben der Mahnung, beim Verbrauch natürlicher Ressourcen ,the benefit of present and future generations" ${ }^{\text {"68 }} \mathrm{zu}$ beachten, erstmals in einem internationalen Rechtsdokument das Wort ,precautions":

„Special precautions shall be taken to prevent discharge of radioactive or toxic wastes.“69

Ein weiterer Begriff, der eng damit zusammenhängt, gelangte fast zeitgleich ${ }^{70}$ in den internationalen Sprachgebrauch, i. e. das Adjektiv „sustainable“, meist im Zusammenhang mit „sustainable development“ stehend, was gewöhnlich (wenig geglückt ${ }^{71}$ ) mit „nachhaltig“ übersetzt wird. Die Generalversammlung der VN beauftragte in der Gründungsresolution die WCDE unter Ziff. 8, (a):

„To propose long-term environmental strategies for achieving sustainable development to the year 2000 and beyond.“

64 Dabei spielte der erste Bericht des „Club of Rome“ (Meadows et al., Grenzen des Wachstums Berichte des Club of Rome zur Lage der Menschheit, München 1972) international eine wichtige Rolle.

65 Hier muss genügen, auf das organisatorische Aufgreifen des Themas durch die VN durch die Gründung der UN Environment Programme (UNEP) noch im selben Jahr 1972 (GA/Res. 2997 [XXVII] vom 15. Dezember 1972) und des Zentrums für menschliches Siedlungswesen (HABITAT) im Jahr 1977 hinzuweisen. Ausführlich Köhler (Fußn. 61), S. 475-482; Kilian, Stichwort Umweltschutz und Stichwort UNEP, in: Wolfrum/Philipp (Hrsg.), Handbuch Vereinte Nationen, 2. Aufl. München 1991.

66 Mit GA/Res. 38/161, Process of preparation of the Environmental Perspective to the Year 2000 and Beyond.

67 GA/Res. $37 / 7$ vom 28. Okt. 1982, World Charter for Nature.

68 GA/Res. ebda., Präambel, Abs. 4, Reaffirming; unter II Ziff. 7 heißt es: Bei der Planung und Umsetzung von wirtschaftlichen und sozialen Entwicklungsmaßnahmen ist die Tatsache zu berücksichtigen, dass ,the conservation of nature is an integral part of those activities.“

69 GA/Res. ebda., II Ziff. 12 (b).

70 Das erstmalige Aufgreifen des Wortes in internationalen Foren ist nicht eindeutig nachzuweisen, die weltweite Aufnahme ist aber eng mit diesen Aktionen der VN verbunden, s. Reinisch, Nachhaltige Entwicklung seit der Rio-Konferenz 1992, in: Raza (Hrsg.), Recht auf Umwelt oder Umwelt ohne Recht? Lateinamerika-Jahrbuch, Vol. 4, 2000, S. 137-148. Konsequent am Umweltschutzrecht setzen an Hohmann, Präventive Rechtspflichten und -prinzipien des modernen Umweltschutzrechts, Zum Stand des Umweltvölkerrechts zwischen Umweltnutzung und Umweltschutz, Berlin 1992, Rehbinder, Das Vorsorgeprinzip im internationalen Rechtsvergleich, Düsseldorf 1991, und Reich, Gefahr - Risiko - Restrisiko, Das Vorsorgeprinzip am Beispiel des Immissionsschutzrechts, Düsseldorf 1989.

71 Vorzuziehen sind m. E. die semantisch ebenfalls möglichen Übersetzungen „zukunftsfähig“ oder „dauerhaft“, das auch mehr der französischen Fassung „développement durable“ entspricht. 
„Nachhaltigkeit“ ist inzwischen zu einem jener Worte geworden, die in der „deutschen Rechtskultur einen Inhalt kreieren“, zweifellos auch deshalb, weil der Begriff selbst wiederum nur mit einer Wortneuschöpfung zu fassen ist: Unter dem Titel „Nachhaltigkeit als Verbundbegriff“72 wurde zuletzt „Nachhaltigkeit“ unter nicht weniger als neunzehn Zuordnungen diskutiert und man kann nicht sagen, dass damit schon alle Möglichkeiten ausgeschöpft wären.

Ein demgegenüber durchaus greifbares Ergebnis des Auftrags der Generalversammlung war der sog. „Brundtlant-Bericht“73. Die darin entworfene Definition von „,sustainable development" ist seither weltweit akzeptiert:

„Sustainable development is development that meets the needs of the present without compromising the ability of future generations to meet their own needs. "74

Der Bericht sprach von „inter-generational equity” und der deshalb erforderlichen Rücksichtnahme bei der Nutzung von Ressourcen (,sustainable use of natural resources”). ${ }^{75}$ Er gab damit den Anstoß für die VN-Konferenz „Umwelt und Entwicklung“ 1992 in Rio de Janeiro. Deren (angesichts der ehrgeizigen Zielsetzung für viele enttäuschendes ${ }^{76}$ ) unmittelbares Ergebnis war die (völkerrechtlich eben nicht verbindliche)

72 Kahl (Hrsg.), Nachhaltigkeit als Verbundbegriff, Tübingen 2009. Neben der sprachlichen Herkunft „aus der deutschen Forstwirtschaft des 18. Jahrhunderts“ (Klippel/Otto, Nachhaltigkeit und Begriffsgeschichte, ebda., S. 39-59) wird darin Nachhaltigkeit „im weiten Sinne“, „im engen Sinne“, als „,interdisziplinärer/temporaler/räumlicher und personaler Verbundbegriff“" (Kahl, Einleitung) diskutiert, in der Zuordnung zu Ethik, Christentum und Gemeinwohl, zum Völkerrecht und zum Gemeineuropäischen Verfassungsrecht, es werden „drei Säulen der Nachhaltigkeit““ (Kap. 6) ausgemacht, darunter neben der ökologischen und wirtschaftlichen Säule die Säule der sozialen Nachhaltigkeit, s. Glaser, Nachhaltigkeit und Sozialstaat, S. 620-650, und Gitter, Nachhaltigkeit und Sozialversicherung, S. 651-668. Da es sich bei dem Werk um Bd. 2 einer Schriftenreihe handelt, ist wohl nachhaltig mit weiteren Nachhaltigkeitsvarianten zu rechnen. Man wird sehen, ob diese den Leser ähnlich berühren werden, wie den Grünen Heinrich nach der Lektüre der Werke Goethes: „...ich empfand ein reines und nachhaltiges Vergnügen, das ich früher nicht gekannt...“ (Keller, Der Grüne Heinrich, Ausgabe 1879/80, Kap. 1.03).

73 GA. Doc. A/42/427, Report of the WCED: Our Common Future. In vielen Sprachen als "Brundtlant-Bericht" (benannt nach der ehemaligen norwegischen Ministerpräsidentin Gro Harlem Brundtlant, die als Vorsitzende der WCED den Bericht an die Generalversammlung erstattete), s. etwa The Report of the Brundtlant Commission, Our Common Future, Oxford 1987, oder Hauff (Hrsg.), Unsere gemeinsame Zukunft, Greven 1987. Aktuell hat Jerkø, Det Norske Formålet "Bærekraftig utvikling". In: Tidsskrift for Rettsvitenskaft 3/2009, S. 323-387 untersucht, ob sich die Zielvorgabe „Nachhaltige Entwicklung” (=bærekraftig utvikling) inzwischen im norwegischen Recht nachweisen lässt. Sein Ergebnis (S. 387) ist ernüchternd: „Dechiffriert man des Gesetzgebers ,newspeak’ findet man wenig anderes als ,business as usual'.“

74 Our Common Future, Prinzip 1.

75 S. Reinisch, in: Raza (Hrsg.), Lateinamerika-Jahrbuch (Fußn. 70), S. 137. Das ist auch der Berührungspunkt zum ,precautionary Principle“, s. z. B. Dovers, Precautionary policy assessment for Sustainability, in: Fisher u. a. (Hrsg.), Implementing the Precautionary Principle: Perspectives and Prospects, Cheltenham 2006, S. 88-112.

76 Reinisch, ebda. (Fußn. 70), S. 139 ff.; Ahrens (Hrsg.), Umweltschutz und Entwicklungspolitik, Berlin 1993. 
Erklärung von Rio zu Umwelt und Entwicklung, die „Rio-Deklaration“, 77 deren 27 teilweise eher vage Prinzipien den Kompromisscharakter des Dokuments reflektieren. Die Formulierung „sustainable development“/,développement durable“ findet sich als feststehender Ausdruck zwölf mal dort, wo es in VN-Dokumenten bis dato allgemein „development“ hieß, und einmal in der Negativversion „unsustainable“78 - im Deutschen durchweg mit ,nachhaltig“ bzw. ,nicht nachhaltig“ übersetzt. Hervorzuheben ist, dass Prinzip 27 die Staaten und Völker zur (Weiter-)Entwicklung eines ,internationalen Rechtsgebiets der nachhaltigen Entwicklung" aufruft:

„States and people shall cooperate in good faith and in a spirit of partnership in the fulfilment of the principles embodied in this declaration and in the further development of international law in the field of sustainable development."

Der in „Vorsorge“ mit enthaltene Aspekt der Nachhaltigkeit/Zukunftsfähigkeit/Dauerhaftigkeit ist damit zum definitiven Kennzeichen der internationalen entwicklungspolitischen Zielsetzung geworden und inzwischen von der Rechtsprechung des IGH als Norm anerkannt. ${ }^{79}$

Vorliegend interessiert aber Grundsatz (principle/principe) 15 noch mehr; weil dessen Satz 1 nämlich ausdrücklich den „Vorsorgegrundsatz“/,precautionary approach"/,,mesures de prècaution“" enthält:

\begin{abstract}
,Zum Schutz der Umwelt wenden die Staaten im Rahmen ihrer Möglichkeiten weitgehend den Vorsorgegrundsatz an."
\end{abstract}

\begin{abstract}
„In order to protect the environment, the precautionary approach shall be widely applied by States according to their capabilities."
\end{abstract}

\begin{abstract}
„Pour protéger l'environnement, des mesures de précaution doivent être largement appliquées par les Etats selon leurs capacités."
\end{abstract}

Satz 2 beschreibt die Konsequenzen des Prinzips für die politisch zu treffenden Entscheidungen und damit auch die für ein dem Prinzip entsprechendes Recht:

77 I. e. The United Nations Conference on Environment and Development, A/CONF.151/26 (Vol. I), Rio Declaration on Environment and Development.

78 The United Nations Conference on Environment and Development, ebda., Principle 8: „To achieve sustainable development and a higher quality of life for all people, States should reduce and eliminate unsustainable patterns of production and consumption and promote appropriate demographic policies."

79 Nach dem IGH gelten diese „neuen Normen” auch für „Altfälle”, ICJ Rep. 1997, 140 (Hungary v. Slovakia) heißt es: „Solche neue Normen und solche neuen Standards müssen nicht nur bei der Planung neuer Aktivitäten, sondern auch bei der Fortsetzung bereits begonnener Aktivitäten berücksichtigt werden. Diese Notwendigkeit, wirtschaftliche Entwicklung mit dem Schutz der Umwelt in Einklang zu bringen, wird durch das Konzept der nachhaltigen Entwicklung adäquat zum Ausdruck gebracht." 
„Drohen schwerwiegende oder bleibende Schäden, so darf ein Mangel an vollständiger wissenschaftlicher Gewissheit kein Grund dafür sein, kostenwirksame Maßnahmen zur Vermeidung von Umweltverschlechterungen aufzuschieben."
„Where there are threats of serious or irreversible damage, lack of full scientific certainty shall not be used as a reason for postponing costeffective measures to prevent environmental degradation."
„En cas de risque de dommages graves ou irréversibles, l'absence de certitude scientifique absolue ne doit pas servir de prétexte pour remettre à plus tard l'adoption de mesures effectives visant à prévenir la dégradation de l'environnement."

Das „Vorsorgeprinzip" 80 ist seither in zahlreichen internationalen Rechtsdokumenten zum Umweltschutz ebenso enthalten, wie in der entsprechenden nationalen Gesetzgebung vieler Staaten. 81

Nun ist Umweltschutzrecht nicht Sozialrecht - auf der Suche nach dem (im SGB weithin) verlorenen Begriff kann aber der Blick auf ein anderes Rechtsgebiet, für das ein „Vorsorgeprinzip“ tatsächlich bestimmend geworden ist, vielleicht weiterhelfen.

80 In ihrem Einleitungskapitel, S. 2-3, orten Fisher $u$. a. (Hrsg.), Implementing the Precautionary Principle (Fußn. 75), ,the precautionary principle's birth as an explicit principle (Vorsorgeprinzip) in West Germany's environmental policy of the late 1970s although 'precautionary-type'-policies clearly have a long history in many jurisdictions." Auf die Entstehungsgeschichte in Deutschland weisen hin: Boehmer-Christiansen, The Precautionary Principle in Germany - enabling Government, in: O'Riordan/Cameron (Hrsg.), Interpreting the Precautionary Principle, London 1994, S. 3159, und Grandjean, Implication of the Precautionary Principle for Primary Prevention and Research, Annual review of Public Health, Vol. 25, 2004, S. 199-223 (201), und sehen die Anfänge des Prinzips im Deutschland der 1930er Jahre: „The modern PP has emerged from the German Vorsorgeprinzip, which was introduced in a social context during the 1930s".

81 S. Fisher u. a., ebda. (Fußn. 75), S. 4 ff., und von Schomberg, The precautionary principle and its normative challenges. In: ebda., S. 19-42. Aus dem deutschen Recht seien hier (ohne Anspruch auf Vollständigkeit) genannt: $\S 1$ des „Gesetzes zur Förderung der Kreislaufwirtschaft und Sicherung der umweltverträglichen Beseitigung von Abfällen“ (KrW-/AbfG): „Zweck des Gesetzes ist die Förderung der Kreislaufwirtschaft zur Schonung der natürlichen Ressourcen und die Sicherung der umweltverträglichen Beseitigung von Abfällen“. Einhellig als „Ausdruck des Vorsorgeprinzips“ interpretiert, s. Beckmann/Kersting, in: Landmann/Rohmer, Umweltrecht, 52. Ergänzungslieferung, München 2007, Rdnr. 18 zu KrW-/AbfG. Im „Gesetz zum Schutz vor schädlichen Bodenveränderungen und zur Sanierung von Altlasten“ (BBodSchG) heißt es in $\S 1$ : „Zweck dieses Gesetzes ist es, nachhaltig die Funktionen des Bodens zu sichern oder wiederherzustellen. Hierzu sind schädliche Bodenveränderungen abzuwehren, der Boden und Altlasten sowie hierdurch verursachte Gewässerverunreinigungen zu sanieren und Vorsorge gegen nachteilige Einwirkungen auf den Boden zu treffen.“ Hier findet sich neben der Vorsorge also auch das Adjektiv „nachhaltig“. Im „Gesetz über die Durchführung von Maßnahmen des Arbeitsschutzes zur Verbesserung der Sicherheit und des Gesundheitsschutzes der Beschäftigten bei der Arbeit“ (ArbSchG) ist nach $\S 3$ für ,angemessene arbeitsmedizinische Vorsorge zu sorgen“. Schließlich im „Gesetz zur Sicherstellung des Verkehrs“ (Verkehrssicherstellungsgesetz, VSG) ist $§ 17$ mit „Vorsorge“ überschrieben; danach haben „der Bund, die Länder, die Gemeinden und Gemeindeverbände [haben] die personellen, organisatorischen und materiellen Voraussetzungen zur Durchführung der Maßnahmen zu schaffen, die für die in $\S 1$ genannten Zwecke erforderlich sind“. Dabei geht es primär um die zur „Verteidigung erforderlichen lebenswichtigen Verkehrsleistungen“". 
Dies ist um so mehr zu hoffen, wenn die zum Vergleich stehenden nationalen Rechtsordnungen die von EU-Mitgliedstaaten sind: Dann bietet sich der „vertikale“82 Rechtsvergleich mit dem ja für alle Mitgliedstaaten verbindlichen supranationalen Recht der EU geradezu an.

\section{b) Supranationales Recht}

Die Hinwendung der Europäischen Gemeinschaft zum Umweltschutz ${ }^{83}$ steht in engem nicht nur zeitlichen Zusammenhang mit den Initiativen aus dem System der Vereinten Nationen: Wie die Stockholm-Konferenz der Vereinten Nationen fand die Gipfelkonferenz der Staats- und Regierungschefs der Mitgliedstaaten im Jahr 1972 statt. In ihrer Schlusserklärung betonen diese die Bedeutung des Umweltschutzes und fordern die Organe der Gemeinschaft auf, ein entsprechendes Aktionsprogramm auszuarbeiten. ${ }^{84}$ Eine primärrechtliche Verankerung des Umweltschutzes (Vorbeugegrundsatz) erfolgte dann durch die Einfügung der Art. $130 \mathrm{r}$ - t in der Einheitlichen Europäischen Akte. Mit dem Vertrag über die Europäische Union (Maastricht) wurden die Inhalte der Grundsätze 15 und 16 der Rio-Deklaration (Vorsorgeprinzip) in das EG-Recht aufgenommen und eine eigene Kompetenzgrundlage für eine Umweltpolitik der EG eingeführt. 85 Seit dem Amsterdamer Vertrag wird in Art. 2 als eines der Ziele der Union die „Herbeiführung einer ausgewogenen und nachhaltigen Entwicklung“ (,a harmonious, balanced and sustainable development"/,un développement harmonieux, équilibré et durable“) genannt. In Art. 174 Abs. 2 (ex-Art. 130 r) heißt es zur Umweltpolitik der Gemeinschaft: 86

82 Zacher, Vorfragen zu den Methoden der Sozialrechtsvergleichung, in: v. Maydell/Eichenhofer (Hrsg.), Abhandlungen zum Sozialrecht (Fußn. 1), S. 329-472 (332): ,horizontale Rechtsvergleichung (zwischen nationalen Rechtsordnungen) und vertikale Rechtsvergleichung (zwischen internationalem/supranationalem Recht und nationalem Recht) ergänzen einander.“ Zur Umsetzung von EU-Vorgaben in das deutsche Recht s. Debus, Vom Wert einer Kodifikation des Umweltrechts, in: Verwaltungsarchiv, Bd. 100 Heft 1 2009, SW. 21-39.

83 Eine knappe Übersicht über den Beginn (Euratom-Vertrag) gibt Becker, Der Gestaltungsspielraum der EG-Mitgliedstaaten im Spannungsfeld zwischen Umweltschutz und freiem Warenverkehr, Baden-Baden 1991, S. 13-19.

84 S. mit Nachweisen ders., ebda., S. 13.

85 Kahl, in: Streinz (Hrsg.), EUV/EGV, Kommentar, München 2003, Art. 174 EGV Rdnr. 1-8, spricht von vier Phasen der Rechtsentwicklung, deren zweite (1972-1987) und vierte (seit 1993) Ergebnisse der VN-Konferenzen aufnahmen. Zu den bis dahin zu klärenden Kompetenzfragen s. Becker (Fußn. 83), und Streinz, Europarecht, 8. Aufl. Heidelberg 2008, Rdnr. 1110, 1124.

86 Nach Art. 314 EGV ist der Wortlaut in diesen Sprachen (und den weiteren darin aufgeführten Sprachen), ,gleichermaßen verbindlich“. Zum Rechtsproblem, dass alle unterschiedlichen Textversionen des EGV als „Originaltext“ gelten, s. Luttermann, Juristische Übersetzung als Rechtspolitik im Europa der Sprachen, EuZW 1998, S. 151 ff., und aus nordischer Perspektive Kjoer, Ret og sprog i EU: Mangfoldighed, sprogforbistring - og grænser for integration?, Retfærd, 21. Jg. 1998, Nr. 83, S. 4 ff., und dies., The Eyery-Day Miracle of Legal Translation, International Journal for the Semiotics of Law, (2008) 21, S. 67-72; darin die Bemerkung: „Especially, the process of European inte- 
„Sie beruht auf den Grundsätzen der Vorsorge und Vorbeugung ... sowie auf dem Verursacherprinzip.“
„It shall be based on the precautionary principle and on the principles that preventive action should be taken, ... and that the polluter should pay."
„Elle est fondée sur les principes de précaution et d'action préventive, ... et sur le principe du pollueur-payeur.'

Die Texte gelten hinsichtlich des rechtlichen Inhalts als gleich und sind doch nicht identisch - sie könnten beispielhaft für die Übersetzungsprobleme sein, die sich selbst in rechtlich mehrsprachigen Institutionen wie der EU permanent stellen: ${ }^{87}$ Im Deutschen bezieht sich Vorsorge und Vorbeugung auf die gemeinschaftliche Umweltpolitik, im Englischen und Französischen wird bezüglich der Vorbeugung auf einzelne Maßnahmen abgestellt.

Man kann vertreten, dass die beiden Begriffe „rechtlich kaum von einander zu tren-

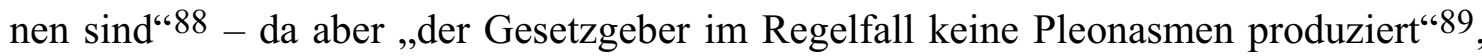
scheint doch eine Differenzierung geboten. Darauf wurde auch ,im Schrifttum (...) viel Scharfsinn verwandt“. 90 Für die Frage nach dem Inhalt eines „Prinzips Vorsorge“ lässt sich dieser Diskussion entnehmen, dass „Vorbeugen“ nur „die Abwehr von Gefahren [bildet]“, „Vorsorge“ demgegenüber „früher ansetzt, (...) neben der Gefahrenabwehr zusätzlich die Vermeidung von Risiken [verlangt]“. ${ }^{91}$ Es geht um „Risikovorsorge und

gration has provoked an intense debate on the commensurability of legal cultures (...) some assert that Civil Law and Common Law traditions are converging, and that it happens faster than one wants to believe" (S. 70). Im Vertragsentwurf zu einer Verfassung für Europa, Abschnitt 5, Umwelt, Art. III-233 Abs. 2, finden sich Vorsorge-, Vorbeugungs- und Verursacherprinzip textidentisch zu Art. 174 Abs. 2 EGV.

87 S. Koziol, Sprachliche Aspekte der Auslegung von internationalen Rechtstexten, JB1 130 (2008), S. 230-241, oder die Beiträge in Pozzo/Jacometti (Hrsg.), Multilingualism and the Harmonisation of European Law, Alphen aan den Rijn 2006, darin insbesondere Pozzo, Multilingualism, Legal Terminology and the Problems of Harmonising European Law, S. 3-20, am Beispiel des deutschen Worts „Eigentum”: „Can the word Eigentum be translated by the words 'proprietè', 'property' or 'proprietà'? In everyday language, they mean 'almost the same thing', as Umberto Eco would have it." Dann reflektiert die Autorin aber über den Eigentumsbegriff des Art. 14 GG und vergleicht ihn mit dem des $\S 903$ BGB, der auf den Begriff „Sache“ des § 90 BGB verweist, erinnert an den Einbezug subjektiver öffentlicher Rechte in den Schutz des Art. 14 GG durch das BVerfG und daran, dass die Gerichte Patent- und Urheberrechte längst wie Eigentum behandeln: „Therefore, even within the German legal system itself, Eigentum is not always Eigentum and translating by ,proprietè', ,property' or ,proprietà' could have problematic aspects, depending on the relevant context" (S. 7-8).

88 Krämer, in: von der Groeben/Schwarze (Hrsg.), Kommentar zum EU-/EG-Vertrag, 6. Aufl. München 2003, Art. 174 Rdnr. 39.

89 Kahl, in: Streinz (Hrsg.), EUV/EGV (Fußn. 85), Art. 174 EGV Rdnr. 70.

90 Krämer, in: von der Groeben/Schwarze (Hrsg.), Kommentar zum EU-/EG-Vertrag (Fußn. 88), Art. 174 Rdnr. 39, der die Feststellung aber ohne Schrifttumshinweise macht; diese gibt dafür Kahl, Kommentar EUV/EGV (Fußn. 83), Art. 174 EGV Rdnr. 71-72, und Nettesheim, in: Grabitz u. a. (Hrsg.), Das Recht der Europäischen Union, Bd. III, EUV/EGV, München, 32. Ergänzungslieferung April 2007, Art. 174 EGV Rdnr. 36-38.

91 Kahl, in: Streinz (Hrsg.), EUV/EGV (Fußn. 85), Art. 174 EGV Rdnr. 71. 
Abgrenzung zur Gefahrenabwehr“, um ein „Verhältnis gradueller Abstufung zu einander.“92 In der Praxis der Umweltschutzpolitik der EG geht freilich meist eines im anderen auf, ein Festhalten an der begrifflichen Unterscheidung erweist sich angeblich als „Zu stark dem deutschen Verständnis verhaftet“. .93

Letzterem kann nicht gefolgt werden: Die Ameise in der in allen europäischen Sprachen geläufigen Fabel sammelt ,so viel sie nur kann“ ja nicht, um dem Eintritt des Winters vorzubeugen - das wäre absurd -, sondern weil sie weiß, dass der Winter kommen wird und sie dann, wenn sie noch lebt, die aus Vorsorge angehäuften Vorräte zum Überleben notwendig brauchen wird. Es scheint, dass wegen der schwierigen Differenzierung zwischen „Risiko“ und „Gefahr“ beide in eins gesetzt werden. Dabei spricht man von Risiko,

„,wenn etwaige künftige Schäden auf die eigene Entscheidung zurückgeführt werden. Wer kein Flugzeug besteigt, kann nicht abstürzen. Bei Gefahren handelt es sich dagegen um von außen kommende Schäden, zum Beispiel, dass man durch herabfallende Flugzeugtrümmer getötet wird. Beide Fälle behandeln die Ungewissheit eines künftigen Schadens, sind also Gegenfälle zur Sicherheit.“94

Die Lexika bestätigen das Abstellen auf die eigene Entscheidung, also beim Tatbestand des ein „Risiko eingehen“ nur teilweise: „Risiko“ bedeutet im Deutschen zwar „Wagnis“, was auf „wagen, sich trauen“" zurückgeht, also auf ein individuelles Tun, aber auch „Gefahr“; 95 das englische „risk“ steht für „the possibility of meeting danger“96, das Antonym ist „safety“; 97 und französisch „risque“, meint „,danger éventuel plus ou moins prévisible“, 98 als Antonym wird „sécurité, tranquillité“ angegeben. ${ }^{99}$ Der primä-

92 Nettesheim, in: Grabitz u. a. (Hrsg.), EUV/EGV (Fußn. 90), Art. 174 Rdnr. 36.

93 Ders., ebda., Art. 174 Rdnr. 36.

94 Luhmann, Verständigung über Risiken und Gefahren, Die politische Meinung 36 (1991) Heft 258, S. 86- 95 (88).

95 S. Duden, Herkunftswörterbuch (Fußn. 34), Lemma: Risiko. Die Herkunft des Wortes ist ungewiss. Taylor-Gooby/Zinn, Risk in Social Science, Oxford 2008, S. 3-4, versuchen, das Wort aus dem Arabischen oder Spanischen und unter Bezug auf Luhman, Risk: a Sociological Theory, New York 1993, aus dem Lateinischen abzuleiten, doch sind dies nur Annäherungen. Erhellend dagegen der Hinweis auf die gemeinsame Geschichte des Begriffs Risiko und dem der Versicherung: ,It entered the world of moneylending and finance more generally, and became a useful tool in the conceptualization of the probable consequences of investment decisions. During the 18th and 19th centuries, the development of mathematics of probability (...) facilitated the application of probabilistic reasoning to risk issues, so that (...) 'results become predictable in accordance with the laws of chance' (Kaplan)"; zu dieser Wechselbeziehung unter wohlfahrtsstaatlichem Aspekt s. Rüb, in: Lessenich (Hrsg.), Wohlfahrtsstaatliche Grundbegriffe (Fußn. 5). S. auch die Zusammenfassung von Greve, Risk and Welfare, Social Policy Administration, Special Issue (Fußn. 14) S. 710-714.

96 Hornby, Oxford Advanced Learner's Dictionary of Current English., 7th imp., Oxford 1999, Lemma: risk.

97 Lindberg, The Oxford American Writer's Thesaurus (Fußn. 41), Lemma: risk.

98 Robert, Le nouveau Petit Robert (Fußn. 42), Lemma: risque.

99 Boussinot, Dictionnaire des synonymes. Analogies. Antonymes, Paris 1991, Lemma: danger. Wie fruchtbar eine begriffsgeschichtliche Analyse von "Sicherheit" und "Abenteuer" sein kann, zeigen 
re Aspekt des Begriffs ist also die Zufälligkeit, die Ungewissheit und Unbeeinflussbarkeit des Eintretens eines (Schadens-)Ereignisses. 100 Davon zu unterscheiden ist die allgemeine Absicherung der Zukunft durch Vorbeugemaßnahmen und Vorsorge, die nicht dem Schadens(einzel)fall geltende „Besorgnis vor Zukünftigem“.

Der Europarat wandte sich im Jahr 2000 mit einer „Resolution on the Precautionary Principle"101 an die World Trade Organization (WTO) mit der Bitte um Verbreitung bei den Mitgliedstaaten, in der die Bedeutung des Prinzips auch für die Arbeit der WTO hervorgehoben 102 und die Initiative der EU-Kommission begrüßt wird, eine Mitteilung betreffend des Vorsorgeprinzips vorzulegen. Darin 103 wird das Vorsorgeprinzip auf „europäischer Ebene über den Bereich des Umweltschutzes hinaus als allgemeines Rechtsprinzip anerkannt"104:

„Although the precautionary principle is not explicitly mentioned in the Treaty except in the environmental field, its scope is far wider and covers those specific circumstances where scientific evidence is insufficient, inconclusive or uncertain and there are indications through preliminary objective scientific evaluation that there are reasonable grounds for concern that the potentially dangerous effects on the environment, human, animal or plant health may be inconsistent with the chosen level of protection." 105

Als Rechtsprinzip gilt das Vorsorgeprinzip europarechtlich gegenwärtig dennoch ganz überwiegend im Umweltschutz:

„Hence this principle has been progressively consolidated in international environmental law, and so it has since become a full-fledged and general principle of international law." 106

die Beiträge in Lindberg (Hrsg), Trygghet och aventyr. Om begreppshistoria. Konferens 59 der Kungl. Vitterhets Historie och Antikvitets Akademien, Stockholm 2005.

100 So Rüb, in: Lessenich (Hrsg.), Wohlfahrtsstaatliche Grundbegriffe (Fußn. 5), S. 310, der dazu noch die Abgrenzbarkeit von Risikofaktoren und die Messbarkeit stochastischer Gesetzmäßigkeiten als Grundlage des aktuarischen Äquivalenzprinzips nennt.

101 S. Doc. WT/CTE/W/147-G/TBT/W137, angenommen vom Europarat im Dezember 2000 in Nizza als Annex III der „Presidency Conclusions“.

102 In der WTO sahen bislang vor allem die USA, in der Anwendung des Vorsorgegrundsatzes einen Versuch, den freien Welthandel einzuschränken“, s. Krämer, in: von der Groeben/Schwarze, Kommentar zum EU-/EG-Vertrag (Fußn. 88), Art. 174 Rdnr. 44.

103 I. e. Communication from the Commission on the Precautionary Principle, Brussels 02.02.2000, $\operatorname{COM}(2000) 1$.

104 Krämer, in: Kommentar zum EU-/EG-Vertrag (Fußn. 88), Art. 174 Rdnr. 40; s. auch Gruszczynski, Science in the Process of Risk Regulation under the WTO Agreement on Sanitary and Phytosanitary Measures, German Law Journal Vol. 7 No. 4, April 2006.

105 COM (2000) 1, S. 10. So hat z. B. der EuGH in der Rechtssache C-236/01 (Monsanto) auch für die VO (EG) Nr. 258/97 (Neuartige Lebensmittel) entschieden, dass dann, wenn vorab von der Unschädlichkeit eines Lebensmittels auszugehen ist, dies im vereinfachten Verfahren in den Verkehr gebracht werden kann: „Etwas anderes gilt jedoch dann, wenn nach den bei der Erstprüfung verfügbaren wissenschaftlichen Erkenntnissen ein Risiko potentiell gefährlicher Auswirkungen auf die menschliche Gesundheit erkennbar ist.“

106 COM (2000) 1, S. 11; in Annex I und Annex II findet sich ein Überblick über das ,precautionary principle“ im europäischen und im internationalen Recht; Krämer, in: von der Groeben/Schwarze (Hrsg.), Kommentar zum EU-/EG-Vertrag (Fußn. 88), Art. 174 Rdnr. 40-42, nennt als Nachweis 


\section{Unsicherheit - ein neues altes Rechtsproblem}

Der Hinweis auf die besonderen Umstände unzulänglicher wissenschaftlicher Klarheit (,specific circumstances where scientific evidence is insufficient"), die wiederum nach der „Rio-Deklaration“ kein Grund dafür sein sollen, „Maßnahmen zur Vermeidung von Umweltverschlechterungen aufzuschieben“, macht den Unterschied zwischen dem spezifisch umweltrechtlichen „precautionary principle“ und „Vorsorge“ deutlich:

„Das Recht ist, von seiner Funktion her, eine Regulierung sozialer Verhältnisse. Umweltprobleme haben gerade diese Qualität zunächst nicht. Es sind psychische, chemische, biologische Fakten und deren Interdependenzen. Die Typik juristischer Problemwahrnehmung - etwa das Schema ,Freiheit versus Zwang' oder ,Erlaubnis und Verbot'- ist darauf nicht eingestellt. (...) Es muss eine Einstellung zu Risiken fixiert werden, für die es keine Berechnungssicherheiten und auch keine sozial konsentierte Risikotoleranz gibt. (...) Auf welche Rechtsprinzipien soll das Recht sich hier stützen?"“107

Umweltrechtliche Vorsorge ist eben (noch) nicht so sehr ein materiellrechtliches Prinzip, sondern ihm kommt „,primär prozessuale Bedeutung“ zu. ${ }^{108}$

Die Behörden können ein Verbot z. B. gegen ein neues technisches Verfahren aussprechen, ohne dass eine davon ausgehende mögliche Schädigung mit vollständiger wissenschaftlicher Sicherheit nachgewiesen ist. Doch darf wissenschaftliche Unsicherheit „nicht als Regel zur Beweisverteilung missverstanden werden“, 109 die politischen Entscheidungsträger (der Gesetzgeber) müssen Entscheidungen finden und sei es die, nicht zu handeln. ${ }^{110}$ Kritiker sprechen daher von einem ,paralyzing principle“:

„The most serious problem with the Precautionary Principle is that it offers no guidance -

not that it is wrong, but that it forbids all courses of action, including inaction" 111

In einer immer komplexer gewordenen Welt kann es „wissenschaftliche Sicherheit” im Sinne von universal und zeitlos geltenden Gesetzen der Naturwissenschaften nicht mehr geben. Kommt es zu Kontroversen, stellt sich die Frage, wer die Entscheidung darüber treffen kann (muss), welches wissenschaftliche Ergebnis das „richtigere“ ist.

dieses Rechtsprinzips die EG-VOen Nr. 178/2002 (Lebensmittelrecht), Nr. 793/93 (chemische Altstoffe) und die diversen EU-VOen dazu. Weiterführende Gedanken z. B. bei Orth, Ein Grundrecht auf Umweltschutz in Europa?, Frankfurt/Main 2007.

107 Luhman, Kann die moderne Gesellschaft sich auf ökologische Gefährdungen einstellen? Opladen 1985, S. 27. S. auch damals viel diskutiert Beck, Die Risikogesellschaft, Frankfurt/Main 1986.

108 Nettesheim, in: Grabitz u. a. (Hrsg.), EUV/EGV (Fußn. 90), Art. 174 Art. 174 Rdnr. 41.

109 Nettesheim, in: Grabitz u. a. (Hrsg.), ebda., (Fußn. 90), Art. 174 Rdnr. 40.

110 COM (2000) 1, S. 4: „In some cases the right answer may be not to act or at least not to introduce a binding legal measure.“

111 Sunstein, The Paralyzing Principle, Does the Precautionary Principle point us in any helpful direction? Regulation, The Cato Review of Business and Government Winter 2002-2003, S. 32-87 (33). Seine Monografie „Laws of Fear: Beyond the Precautionary Principle”, Cambridge UK 2005, wurde eingehend besprochen von Kahan/Slovic/Braman/Gastil, Fear of Democracy: A Cultural Evaluation of Sunstein on Risks, Harvard Law Review Vol. 119, 2006. S. 1071-1109. 
Der EuGH hat sich dem bislang entzogen, ${ }^{112}$ wohl auch aus der Erkenntnis, dass es für eine komplexe Welt eine „einfache Theorie“ nicht geben kann 113 - immerhin hielt das Gericht daran fest, dass wissenschaftliche Ergebnisse Entscheidungsgrundlagen bleiben sollen:

„it still recalled science as a verification of risk, and scientific evidence as grounds for the management of risk." 114

Mit Beschluss vom 12.11.2008115 hat das Bundesverfassungsgericht festgestellt, dass die aus Art. 2 Abs. 2 S. 1 GG herzuleitende Schutzpflicht des Gesetzgebers Vorschriften nicht entgegensteht,

„die insoweit ein Restrisiko in Kauf nehmen, als sie Genehmigungen auch dann zulassen, wenn sich nicht völlig ausschließen lässt, dass künftig durch das Gebrauchmachen von der Genehmigung ein Schaden auftreten wird."116

Nicht nur, dass die „Risiko-Diskussion“ nun höchstrichterlich um das die Angst vor einem unbeherrschbaren Risiko gefühlsmäßig mindernde „Doppelwort“, dem „Restrisiko", angereichert wurde, kommt das Gericht bei der Abwägung, welche Vorsorge getroffen werden muss, auch zurück auf den unbestimmten Rechtsbegriff vom gesunden Menschenverstand, hier in der an Kant gemahnenden Ausdrucksweise ,praktische Vernunft":

„Vom Gesetzgeber im Hinblick auf seine Schutzpflicht eine Regelung zu fordern, die mit absoluter Sicherheit Grundrechtsgefährdungen ausschließt, die aus der Zulassung technischer Anlagen und ihrem Betrieb möglicherweise entstehen können, hieße die Grenzen menschlichen Erkenntnisvermögens verkennen und würde weithin jede staatliche Zulassung der Nutzung von Technik verbannen. Für die Gestaltung der Sozialordnung muss es

112 S. zu T-13/99, Pfizer Animal Health SA v. Council (2002), T-70/99, Alphapharm Inc. v. Council (2002) und C-236/01 (Monsanto) Szawlowska, Risk Assessment in the European Food Safety Regulation: Who is to Decide Whose Science is Better? Commission versus France and Beyond, German Law Journal Vol. 5 No. 10, 1 Oct. 2004. Zur Rechtsprechung in Australien s. Gullett, The threshold test of the precautionary principle in Australian courts and tribunals: lessons for judicial review, in: Fisher u. a. (Hrsg.), Implementing the Precautionary Principle (Fußn. 75), S. 182-201. Der Autor mahnt im Ergebnis ,,a pressing need in Australia for legislative adoption of a more useful definition of the principle" an (S. 199).

113 Quine, On Simple Theories of a Complex World, in: The Ways of Paradox and Other Essays, Cambrige/Massachusetts 1976: „When two theories are equally defensible on other counts, certainly the simpler of the two is to be preferred on the score of both beauty and convenience." (S. 255). Der Autor zeigt dann aber die Gründe auf, warum dies irreführend ist, der erste: „There is wishful thinking" (S. 258). Zu Quine's wissenschaftstheoretischen Ansatz s. die Beiträge in Davidson/Hintikka (Hrsg.), Words and Objections. Essays on the Work of W. V. Quine, Dordrecht 1969, und Davidson, Wahrheit, Sprache und Geschichte, Frankfurt/Main 2008.

114 Speziell zu Monsanto Dabrowska, GM Foods, Risk, Precaution and the Internal Market: Did Both Sides Win the Day in the recent Judgement of the European Court of Justice? German Law Journal, Vol. 5 No. 2-1, Feb. 2004, S. 10.

115 Az.: 1 BvR 2456/06

116 Ebda., Rdnr. 25. 
insoweit mit Abschätzungen anhand praktischer Vernunft sein Bewenden haben (vgl. BVerfGE 49, $89141 \mathrm{ff}$.). “117

Das heißt im Grunde, dass man am Ende wohl der Aufforderung der Wissenschaftstheorie folgen muss, nämlich die ,unausweichliche Unsicherheit anerkennen und damit umgehen."118 Dabei erscheint die Relativität wissenschaftlicher Erkenntnis womöglich als eine neue Ursache von Unsicherheit, diese selbst ist aber ein altes Problem menschlichen Daseins.

\section{Die Unsicherheit des Daseins und die Sicherung des Daseins durch Daseinsvorsorge}

\section{Soziale Unsicherheit: Daseinsangst}

Unsicherheit macht den Menschen Angst. Sie wird als soziales Phänomen, als existenzielle „Daseinsangst“" seit dem frühen 19. Jahrhundert konstatiert und von Kierkegaard mit „Schwindligsein“ verglichen:

„Derjenige, dessen Auge plötzlich in eine gähnende Tiefe hinunterschaut, der wird schwindlig. Aber was ist der Grund dafür? Es ist ebensosehr sein Auge wie der Abgrund; denn was, wenn er nicht hinabgestarrt hätte! So ist Angst der Schwindel der Freiheit, der entsteht, indem der Geist die Synthese setzen will und die Freiheit nun hinabschaut in ihre eigene Möglichkeit..."119

Der dänische Philosoph prognostizierte damit hellsichtig120 eine Existenzangst, die Jahrzehnte später in ganz Europa die Menschen „verunsichern“ sollte. Ein Grund dafür

117 Ebda., Rdnr. 25.

118 Mitchell, Komplexitäten, Warum wir erst anfangen, die Welt zu verstehen, Frankfurt/Main 2008, S. 129. Aufgrund der verloren gegangenen wissenschaftlichen Gewissheiten kommt die Autorin zu einem „Vorsorgeprinzip“ des ,,anpassungsorientierten Managements (...) einem fortlaufenden, endlosen Prozess [aus] Vorhersagen, handeln, einen Maßstab für erfolgreiches Handeln aufstellen, handeln, Daten über die Folgen sammeln, neu vorhersagen“, also eine „stark von Rückkopplungen geprägte Strategie der Entscheidungsfindung“ (S. 122-123). Zur ethischen Dimension s. Jonas, Das Prinzip Verantwortung, Versuch einer Ethik für die technologische Zivilisation, Frankfurt/Main 1979, abgedruckt auch in der Textsammlung von Böhler, Hans Jonas - Leben, Wissenschaft, Verantwortung, Stuttgart 2004, S. 87-200.

119 Kierkegaard, Der Begriff Angst, Kopenhagen 1844. Hier zitiert nach der deutschen Übersetzung von Richter, Reinbek 1960, S. 57. Darin auch der Essay von Richter, Zum Verständnis des Werkes, S. $148-177$.

120 Kierkegaards Schriften wurden ab 1860 ins Deutsche übersetzt, fanden aber erst vor dem 1. Weltkrieg größere Aufmerksamkeit. Mit der Jenaer Ausgabe der Gesammelten Werke 1909-1920 setzte die „Kierkegaardrenaissance“ ein, insbes. durch Jaspers, Psychologie der Weltanschauungen, Berlin 1919, und Heidegger, Sein und Zeit, Halle 1927; s. Richter, ebda., S. 169 ff., oder Stenström, Existensialismen i Sverige. Mottagende och inflytande 1900-1950, Uppsala 1984, der auf die ungefähr gleichzeitige Zuwendung der Theologie zum Denken Kierkegaards, etwa in der von Georg Merz und Karl Barth 1922 gegründeten Zeitschrift „Zwischen den Zeiten“ hinweist. 
waren „die Verelendungsängste des in eben jenen Jahren entstehenden Marxismus“, 121 ein anderer das als Katastrophe erlebte Ende des 19. Jahrhunderts im 1. Weltkrieg und dessen Folgen: Nach dem finalen Höhepunkt der Industriellen Revolution durch einen Krieg, dessen Materialschlachten man auch als „vierjährige Standardisierungskampagne"122 treffend beschreiben kann, trat eine neue Produktionsweise neben die inzwischen schon gewohnte Industrieproduktion:
„Die Maschine des 19. Jahrhunderts, Watts Dampfmaschine mit ihren Regulatoren, Dia- grammen und energetischen Gleichungen, generierte und implementierte geschlossene, in sich zurücklaufende Kreise. Maschinengewehre dagegen operieren in allen Dimensionen und an allen Fronten auf unabgeschlossenen, gleichförmigen Serien diskreter Elemente. (...) Als Funktion läuft das Maschinen[gewehr]schloß 08/15 im Gleichtakt mit Telegra- phen, Schreibmaschinen, Nähmaschinen, Kameras, Projektoren und, selbstreferentiell, Werkzeugmaschinen." 123

Es zeigte sich, dass Technologie den Code gesellschaftlicher Strukturen trägt, also mehr ist, als eine ansonsten „neutrale“ Art der Produktionsweise: ${ }^{124}$ Die Spezialisten der Unfallversicherung waren bald dazu aufgerufen, sich mit ihrem aus langer Erfahrung mit Industrieunfällen gewonnenem know how um die Kriegskrüppel zu sorgen. ${ }^{125}$ Ein Vorstandsmitglied der Arbeiterunfallversicherungsanstalt für das Königreich Böhmen sah die Zusammenhänge:

„Die Toten und Verwundeten eines schrecklichen Krieges, wie ihn die Weltgeschichte noch nicht kannte, sind wie die auf dem fruchtbaren Felde der gewerblichen und land-

121 Leisner, Existenzsicherung im Öffentlichen Recht. Minimum - Grundlagen - Förderung, Tübingen 2007, S. 22.

122 Berz, 08/15 Ein Standard des 20. Jahrhunderts, München 2001, S. 55; Vec, Recht und Normierung in der Industriellen Revolution, Neue Strukturen der Normsetzung in Völkerrecht, staatlicher Gesetzgebung und gesellschaftlicher Selbstnormierung, Frankfurt/Main 2006, insbes. Kap. III 6: „Der Erste Weltkrieg als Normungsbeschleuniger“ (S. 371 ff.). Zum neuen „Gefahrenspektrum“ des auf Massenproduktion angewiesenen Kriegs und dessen Fortwirken s. Encke, Augenblicke der Gefahr, Der Krieg und die Sinne 1914-1934, München 2006. Zum Aspekt des „Ingenieurskrieges“ s. Ernst (Hrsg.), Aggression und Katharsis, Wien 2004.

123 Berz, 08/15 Ein Standard des 20. Jahrhunderts (Fußn. 122), S. 9.

$124 \mathrm{Zu}$ den daraus rührenden Problemen des „Technologietransfers“ s. Köhler, Sozialversicherung Pfade der Entwicklung, in: Köhler/Zacher (Hrsg.), Ein Jahrhundert Sozialversicherung in der Bundesrepublik Deutschland, Frankreich, Großbritannien, Österreich und der Schweiz, Berlin 1981, S. 13-41.

125 Schon 1916 stellte sich den Berufsgenossenschaften im Deutschen Reich die Herausforderung, die Kriegsbeschädigten wieder arbeitsfähig zu machen, s. Krais, Die Verwendungsmöglichkeiten der Kriegsbeschädigten in der Industrie, in Gewerbe, Handel, Handwerk, Landwirtschaft und Staatsbetrieben. Stuttgart 1916. Zum Versuch, die 2,7 Millionen Kriegsinvaliden nach dem 1. Weltkrieg gesellschaftlich „zu verbergen“, s. Lethen, Verhaltenslehren der Kälte. Lebensversuche zwischen den Kriegen. Frankfurt/Main 1994, S. 245 ff. (Kriegskrüppel). Eine eingehende regionalgeschichtliche Darstellung der „Reintegrations“-Versuche gibt Rudloff, Die Wohlfahrtsstadt, Kommunale Ernährungs-, Fürsorge- und Wohnungspolitik am Beispiel Münchens 1910-1933, Göttingen 1998, insbes. Kap. V 4.: „Es gibt kein Krüppeltum, wenn der eiserne Wille besteht, es zu überwinden.“ (Teilband I S. 289 ff.). S. a. Sloterdijk, Kritik der zynischen Vernunft, Bd. II, Frankfurt/Main 1983, Kap. „Prothesen - vom Geist der Technik. Funktionalistischer Zynismus II.“, S. 791-807. 
wirtschaftlichen Arbeit Verunglückten die Opfer desselben technischen Fortschritts, welcher die Produktivität der menschlichen Arbeit fast ins Unglaubliche gesteigert, aber auch in ungeheurem Maße ihre Gefahren und ihr Risiko erhöht hat." 126

Der nach der Anfangseuphorie bald vollkommen romantikfrei industriell geführte Krieg nahm diesem die ihm bis dahin zugesprochene „Katharsis-Funktion“ zur Verbesserung des Volksganzen. Der „Große Krieg“ ist deshalb als eugenische „Auslesemethode" abgelehnt worden, er

„ermöglichte in Europa den Schritt von einer rein intellektuellen Auseinandersetzung über die Rassenaufartung hin zu einer konkreten Umsetzung eugenischer Konzepte in die politische Praxis." 127

Kein Wert blieb unangefochten: In der vom Krieg erzwungenen Massenproduktion setzte sich eine neue „Meßordnung“ durch: Beim Bau von Maschinen (oder der in Milliarden zu zählenden Munitionsproduktion) wurden ,absolute Werte durch Grenzwerte ersetzt“. 128 Wenn aber überall in den Fabriken „Toleranzsysteme und ihre materiellen Agenten, die Grenzlehren"129 einen neuen, jetzt von Ingenieuren ausgerechneten und faktisch ausgeübten Typ von Kontrolle erschaffen, verliert die überkommene, wesentlich auf Genauigkeit beruhende Arbeit der Meister und Facharbeiter ihren Wert. Die Abwesenheit verbindlicher Normen in der Arbeitswelt musste von den Betroffenen auch als Relativierung der Werte allgemein empfunden werden. ${ }^{130}$ Derartige Verschiebungen betreffen ganze Gesellschaftsschichten und verändern die Gesellschaft. Was Ernst Jünger als Versuch abtat, „das Schicksal durch Wahrscheinlichkeitsrechnung aufzulösen“, 131 wurde für die aus dem Krieg heimkehrenden Arbeiter bald zu einem die Existenz bedrohenden Substanzverlust. Es kam erstmals nicht nur für viele Arbeiter, sondern zunehmend auch für Angestellte zu einer bislang unbekannten Arbeitslosigkeit „aus Altersgründen“, denn die neuen Methoden veränderten die überkommenen Produktionsweisen: Durch Fließband und ,amerikanische“ Organisation wie die Rationalisierung der Arbeitsabläufe in Fabrik und Büro wurden 40-50jährige für den Arbeitsmarkt

126 Zitiert von Hermsdorf, Franz Kafka und die Arbeiter-Unfall-Versicherungs-Anstalt, in: Koch/Wagenbach u. a. (Hrsg.), Kafkas Fabriken, Marbacher Magazin 100/2002, S. 41-78 (68).

127 Peter, Der Einbruch der Rassenhygiene in die Medizin, Auswirkungen rassenhygienischen Denkens auf Denkkollektive und medizinische Fachgebiete von 1918 bis 1934, Frankfurt/Main 2004, S. 18.

128 Berz, 08/15 Ein Standard des 20. Jahrhunderts (Fußn. 122), S. 51, spricht von einer „Neudefinition des Begriffs Identität", denn nicht mehr das möglichst genaue Normalmaß ist formgebend, sondern für ,die modulare Identität von Maschinenelementen“ bedeutet „,identisch austauschbar und modular, das, was zwischen zwei Grenzwerten liegt.“

129 Ders., ebda., S. 52.

130 Adorno, Minima Moralia, Reflexionen aus dem beschädigten Leben, Nachdruck Frankfurt/Main 1970, unter III. Nr. 134.

131 Jünger, Der Arbeiter, Herrschaft und Gewalt, 3. Aufl. Hamburg 1932, S. 49. Zur Interpretation dieses Werks als „Jüngers Fall ins Kristall“ s. Lethen, Verhaltenslehren der Kälte (Fußn. 125), S. $187 \mathrm{ff}$. 
nicht mehr verwendbar, auch wenn sie unter keinerlei körperlichen Gebrechen litten. ${ }^{132}$ Dazu kam, dass die Kriegswirtschaft die Beschäftigung von Frauen in der Rüstungsindustrie erzwungen hatte. Ebenfalls wegen der zunehmend technisierten und damit „leichter“ zu bewältigenden Arbeitsabläufe konnten Frauen auch nach dem Krieg für die Männer zur (geringer entlohnten) Konkurrenz auf dem Arbeitsmarkt werden. ${ }^{133}$ Besonders in Deutschland wurde dieser Modernisierungsschub (nicht nur in einer ,ad hoc herbeigezerrten Pathetik“134) als „Kulturverfall“ beklagt oder auf den „Verlust der Werte" zurückgeführt.

Kierkegaards Angst vor der Freiheit als „Möglichkeit für die Möglichkeit“ sollte in der Atmosphäre eines durch den verlorenen Krieg, Revolutionsangst und politische Unsicherheit, „Verstädterung“ und die sog. „Vermassung“ oder „Nivellierung“ weithin tief beunruhigten Zeitgeists 135 dann besonders vom Existenzialismus aufgenommen werden. Jaspers beschrieb 1931 die geistige Situation der Zeit:

132 S. mit Nachweisen Köhler, Schweden: Der wachsende Anteil alter Menschen an der Bevölkerung und die aktuelle Reform des Systems der Alterssicherung, in: Reinhard (Hrsg.), Demographischer Wandel und Alterssicherung. Baden-Baden 2001, S. 185-226 (194-198).

133 Rouette, Sozialpolitik als Geschlechterpolitik, Frankfurt a. M. 1993. Den gleichen „emanzipatorischen“" Effekt beschreibt Daniel, Lost Revolutions, Chapel Hill 2000, für den Süden der USA in der Zeit während und nach dem 2. Weltkrieg.

134 Jaspers, Die geistige Situation der Zeit, Berlin/Leipzig 1931, S. 69: „wo etwa in der Diskussion zwingendes nicht mehr gesagt werden kann, hilft eine ad hoc herbeigezerrte Pathetik, ,Heiligkeit des Lebens', ,Majestät des Todes', ,Macht des Volkes', ,Volkes Wille ist gleich Gottes Wille', ,Dienst am Volke' u. a. sind Wendungen im Munde derer, die sonst im bloßen Dasein verloren scheinen."

135 Paradigmatisch Spengler, Der Untergang des Abendlandes, Bd. I, München 1920, S. 489: „Die Weltstadt selbst steht als Extrem von Anorganischem inmitten der Kulturlandschaft da, deren Menschentum sie von seinen Wurzeln löst, an sich zieht und verbraucht.“ Freud, Das Unbehagen in der Kultur, Frankfurt 1920. Plessner, Grenzen der Gemeinschaft, Bonn 1924, warnt schon früh (vergeblich) vor „sozialem Radikalismus“. Friedell, Kulturgeschichte der Neuzeit, Die Krisis der europäischen Seele von der schwarzen Pest bis zum Weltkrieg, 3 Bde., München 1927-31. Gerade in Deutschland außerordentlich viel gelesen Ortega y Gasset, dessen „Aufstand der Massen“ (La rebelión de las masas, 1930) die Angst vor der „Vermassung“ zitierbar machte, etwa: „Wie sollte man nicht fürchten, dass der Staat unter der Herrschaft der Massen alle unabhängigen Individuen und Gruppen erdrücken und so die Zukunft zu einer Wüste machen wird!" So nach der Ausgabe Stuttgart 1965, S. 187; zur Wirkung Ortegas s. ausführlich von Beyme, Politische Theorien im Zeitalter der Ideologien, Wiesbaden 2002, S. 280-292; s. a. die Beiträge in Gangl (Hrsg.), Intellektuellendiskurse in der Weimarer Republik, Frankfurt/Main 2007. Auch Jünger, Der Arbeiter, Hamburg 1932, gehört wegen der Diagnose der ,totalen Mobilmachung“ durch den Funktionalismus der totalen Arbeitswelt hierher. Nicht zu vergessen die in den frühen 20er-Jahren erschienene Albtraumprosa von Kafka, deren Protagonisten auf beklemmende Weise anonymen Mächten ausgeliefert sind. Im angelsächsischen Raum war Huxley, Brave New World, 1932 erschienen, im gleichen Jahr die deutsche Übersetzung von $v$. Herlitschka, unter dem zeittypisch fragenden Titel „Welt - wohin? Ein Roman der Zukunft.“ Dazu gehört auch Celine, Voyage au bout de la nuit, Paris 1932, das, wenngleich von den Nazis in ihrem Sinne ,entschärft“, bereits 1933 ins Deutsche übersetzt wurde. Später (1946) spricht Adorno (Fußn. 130), unter III Nr. 131 von einer „Totalstruktur (...) welche die einzelnen Subjekte erst zu bloßen Momenten reduziert, um sie dann, als Ohnmächtige und Abgetrennte, zum Kollektiv zu vereinen.“ 
„Die Angst wirft sich auf alles. Die Unsicherheiten werden von ihr betont, wenn es nicht gelingt, sie zu vergessen. (...) am Maßstab des heute für ein Existenzminimum geltenden ist, was öffentliche und private Vorsorge schafft, immer weniger als das beanspruchte Minimum, auch wenn der Mensch nicht verhungert.“136

Allein ,das Bewußtsein von Gefahr und Verlust" scheint noch als wahrhaft wirklich, „die als Apparat der Daseinsfürsorge neu entstehende Welt zwingt alles, ihr zu dienen."137 Kierkegaards „Schwindelgefühl“ erlebt Jaspers als „Strudel des modernen Daseins“, dem nicht zu entrinnen ist und der uns nur dann, wenn ,wir in ihm mitgerissen werden“" erkennen lässt:

„Dasein wird heute mit einer allverbreiteten Selbstverständlichkeit gesehen als Massenversorgung in rationaler Produktion aufgrund technischer Erfindungen. (...) scheint also die Wirklichkeit des Menschen im Grunde nichts anderes zu sein als Massenordnung in Daseinsfürsorge“. 138

Man kann dies dahin interpretieren, dass ,damit die Verbindung zum Staatsrecht erreicht“ ist, für das zur selben Zeit Carl Schmitt die These aufstellte, ${ }^{139}$

„,souverän sei, wer über den Ausnahmezustand entscheide - ein Staat, dem dabei vor allem die Aufgabe zufällt, mit seinem Recht den Ausnahmezustand der Existenzbedrohung

zu beherrschen, wie wenig später in der ,Machtergreifung' versucht." 140

Oder man kann darin die neue Erfahrung des Wandels des liberalen Rechtsstaates zu einem ,aktiven, Staat und Gesellschaft eng miteinander verzahnenden Interventionsstaat"'141 erkennen.

\section{Daseinsvorsorge und deutsche Verwaltungswirklichkeit der Zwischenkriegszeit}

Diese Entwicklung in den 20er und 30er Jahren des 20. Jahrhunderts war nicht der Effekt erst einer ,Modernisierung durch den NS-Staat“, ${ }^{142}$ sondern nahm ihren Ausgang in der Kriegszwangswirtschaft - nur höchst zurückhaltend kann man daher die Meinung vertreten, der Nationalsozialismus mit seiner Polemik gegen die Republik und

136 Jaspers, Die geistige Situation der Zeit (Fußn. 134), S. 56- 57.

137 Jaspers, Die geistige Situation der Zeit (Fußn. 134), S. 62; zur Wirkung Jaspers' die Beiträge in Saner, Karl Jaspers in der Diskussion, München 1973, darin insbes. Löwith, Die geistige Situation der Zeit, S. 142-152, der auf die Verwandtschaft zu Kierkegaards Gedanken der „Nivellierung“ als überspitzte Idee von „Selbstsein“ im Gegensatz zum „Massendasein“ (S. 149) hinweist.

138 Jaspers, ebda. (Fußn. 134) S. 30-31.

139 Schmitt, Verfassungslehre, München u. Leipzig 1927, insbesondere S. 20 ff.

140 Leisner, Existenzsicherung im Öffentlichen Recht, (Fußn. 121) S. 25.

141 Stolleis, Geschichte des öffentlichen Rechts in Deutschland, 3. Band, Staats- und Verwaltungsrechtswissenschaft in Republik und Diktatur 1914-1945, München 1999, S. 366.

142 Hockerts (Hrsg.), Drei Wege deutscher Sozialstaatlichkeit, München 1998; Prinz/Zitelmann (Hrsg.), Nationalsozialismus und Modernisierung, Darmstadt 1994; Mazerath/Volkmann, Modernisierung und Nationalsozialismus, in: Kocka (Hrsg.), Theorien in der Praxis des Historikers (Geschichte und Gesellschaft, Sonderheft 3), Göttingen 1977, S. 86-116. 
die Idee des Rechtsstaats „öffnete den Blick auf die Verwaltungswirklichkeit und wirkte insoweit befreiend." "143

An dieser Art „Befreiung“ hatte Ernst Forsthoff hervorragenden Anteil. Bis heute wird ihm die Wortbildung "Daseinsvorsorge“ zugeschrieben, ${ }^{144}$ hat er doch diesen Begriff 1938 in seiner Schrift: „Die Verwaltung als Leistungsträger“ geprägt. ${ }^{145}$ Meist wird dazu vermerkt, dass Forsthoff die Vokabel „Daseinsfürsorge“ von Jaspers übernommen und abgewandelt hatte - den verwaltungsrechtlichen Bedeutungswandel von Fürsorge und Vorsorge hatte der Philosoph noch übersehen! - der Staatsrechtslehrer stellte nämlich klar:

„Die soziale Bedürftigkeit ist also in gewisser Weise unabhängig von der ökonomischen

Lage und darf darum mit der sozialen Fürsorge, der Fürsorge in Fällen der Armut, Krankheit und sonstiger Not nicht gleichgesetzt werden." 146

Forsthoff transponiert das Unbehagen in der Kultur einschließlich des daraus entstehenden Wunsches, das politische Handeln anderen zu überlassen, 147 ins Verwaltungsrecht:

143 Stolleis, Geschichte des öffentlichen Rechts in Deutschland (Fußn. 141), S. 367. Zum Staatsrecht im NS-Staat s. Dreier, Die deutsche Staatsrechtslehre in der Zeit des Nationalsozialismus, VVDStRL 60, S. 10-72.

144 Stolleis, ebda., S. 367, der aber darauf hinweist, dass „der Leistungsstaat längst Realität war und dass die einleuchtende Begriffsprägung nur durch einen glücklichen Griff gefunden werden musste.“ Ausdrücklich dieser Beurteilung als „Glücksgriff“ zustimmend Pauly, Die deutsche Staatsrechtslehre in der Zeit des Nationalsozialismus, VVDStRL 60, Berlin 2001, S. 98-100. Nur beispielhaft für die allgemeine Übereinkunft, dass Forsthoff die Daseinsvorsorge als Verwaltungsrechtsbegriff eingeführt hat, s. etwa Ringwald, Daseinsvorsorge als Rechtsbegriff, Frankfurt 2007; Forsthoff, Grundgesetz und Grundversorgung, Frankfurt/Main 2008, S. 30; Bull, Daseinsvorsorge im Wandel der Staatsformen, Der Staat 47 (2008) S. 1-19 (2-5); Tüllmann, Die Finanzierung von Leistungen der Daseinsvorsorge im Kontext des europäischen Beihilfenrechts, ZEuS 2008 Heft 3, S. 470-486 (472); Jellinghaus, Zwischen Daseinsvorsorge und Infrastruktur, Zum Funktionswandel von Verwaltungswissenschaften und Verwaltungsrecht in der zweiten Hälfte des 19. Jahrhunderts, Frankfurt/Main 2006, S. 15. Voßkuhle, Das Arbeiten mit Schlüsselbegriffen und Leitbildern, in: Hoffmann-Riem/Schmidt-Aßmann u. a. (Hrsg.), Grundlagen des Verwaltungsrechts, Bd. I, München 2006, Rdnr. 40-41, spricht vom „Schlüsselbegriff der Forsthoff”schen Daseinsvorsorge“; Kersten, Die Entwicklung des Konzepts der Daseinsvorsorge im Werk von Ernst Forsthoff, in: Der Staat 44 (2005), S. 543-569; Ronellenfitsch, Daseinsvorsorge als Rechtsbegriff - Aktuelle Entwicklungen im nationalen und europäischen Recht, in: Blümel (Hrsg.), Ernst Forsthoff. Kolloquium aus Anlaß des 100. Geburtstags von Prof. Dr. Dr. h. c. Ernst Forsthoff, Berlin 2003, S. 53-114 (59 ff.); Pielow, Grundstrukturen öffentlicher Versorgung, Vorgaben des Europäischen Gemeinschaftsrechts sowie des französischen und des deutschen Rechts unter besonderer Berücksichtigung der Elektrizitätswirtschaft, Tübingen 2001, S. 18.

145 Forsthoff, Die Verwaltung als Leistungsträger, Stuttgart 1938.

146 Forsthoff, ebda., S. 5, Anm. 6. Er fährt fort: „die folgenden Ausführungen haben nicht die Absicht, die soziale Fürsorge (welche ich von der Daseinsvorsorge scharf geschieden wissen möchte), in die allgemeine Verwaltungslehre enger einzubeziehen, (...) sondern sie sollen auf die moderne Daseinsweise des Menschen (...) hinweisen.“

147 Jaspers, Die geistige Situation der Zeit (Fußn. 134), S. 84, erschien es angesichts der Nöte der Zeit begreiflich, ,dass wir alle versagen. Wie Auswege zu leichteren Möglichkeiten erscheinen Bolschewismus und Faschismus. Man kann wieder einfach gehorchen und alles Handeln jeweils dem 
„Diejenigen Veranstaltungen, welche zur Befriedigung des Appropriationsbedürfnisses getroffen werden, bezeichne ich als Daseinsvorsorge. (...) Die Verantwortung für die Befriedigung dieser Appropriationsbedürfnisse nenne ich Daseinsverantwortung. "148

Weiter im Text wird dann klarer, was gemeint ist:

„Daseinsvorsorge als Vorsorge für die Lebensnotwendigkeiten, für die Daseinsmöglichkeiten schlechthin."149

Die Abhängigkeit des Individuums von der Bereitstellung elementarer Lebensgüter ist ihm, wie seinen Zeitgenossen, eine durch Sachzwänge selbstverständlich vorgegebene, außerhalb individuellen Wollens stehende Tatsache. Daraus zieht Forsthoff rechtliche Folgerungen: Das bürgerliche, auf das Individuum abstellende Recht ist für ihn überwunden, „die Grundrechte gehören völlig unbezweifelbar der Vergangenheit an“. 150 Und dem Mitmachen, der notwendigen „Teilhabe“ an den vorsorgenden Einrichtungen und Leistungen der Verwaltung misst er im Vergleich zu individuellen Freiheitsrechten einen höheren Stellenwert zu:

„Im modernen Staate behauptet sich der Mensch nicht durch eine ihm garantierte individuelle Freiheit, sondern durch die Teilhabe." 151

Und diese Teilhabe galt jetzt einer,wirklich konkreten Gemeinschaft, in der der Gegensatz des subjektiven und des objektiven Rechts, des Sollens und des Seins überwun-

Einen überlassen, der das Regiment sich erobert hat.“ Bullinger, Französischer service public und deutsche Daseinsvorsorge, JZ 2003, S. 597-604 (599), führt Forsthoffs Abstellen auf das „Führerprinzip“ darauf zurück, dass „das damals in Deutschland als unantastbar hingenommen werden musste."

148 Forsthoff, Die Verwaltung als Leistungsträger (Fußn. 145), S. 6, Hervorhebungen im Original.

149 Ders., ebda., S. 7.

150 Ders., ebda., S. 43 und S. 46: ,wird klar, dass eine rechtlich gesicherte Teilhabe an der Daseinsvorsorge, funktionell betrachtet, eine Art von Ersatz für jene überholten Sicherungen bietet, welche die Grundrechte in sich beschlossen." Forsthoff unterliefen auch später politische Fehleinschätzungen, wenn er etwa am 9. Januar 1966 an seinen Lehrer Carl Schmitt von der „Tatsache“ schreibt: „dass wir seit zwanzig Jahren keinen Staat mehr haben, sondern demokratischen Nebel, hinter dem sich ein Rangierbahnhof der Interessen notdürftig verbirgt (...)“, s. Mußgnug u. a. (Hrsg.), Briefwechsel Ernst Forsthoff Carl Schmitt [1926 - 1974], Berlin 2007, unter Nr. 202; der Vorwurf, dass aus den „beiden Jasagern von 1933 die Neinsager der Bundesrepublik geworden waren“ (Schlak, Neinsager der Bundesrepublik, SZ Nr. 279 vom 1. Dezember 2008, S. 14), ist nicht unbegründet; zu Forsthoffs Unbehagen am Machtverlust des Staates durch „die Technik“ s. Vec, Aushöhlung des Staates?, Rechtshistorisches Journal 19/2001, S. 517-532. Bisweilen gelang Forsthoff aber, dies mit verwaltungsrechtlichem Weitblick zu verbinden: 1972 beklagt er „,den gegenwärtigen, unübersehbaren Zerfall der Staatlichkeit“" einerseits, tat dies andererseits aber insbesondere deshalb, weil „die immer drängendere Notwendigkeit des Umweltschutzes (...) nicht anders als mit staatlichen Mitteln zu verwirklichen ist.“ S. Forsthoff, Einführung, in: ders. (Hrsg.), Lorenz von Stein. Gesellschaft - Staat - Recht, Frankfurt/Main 1972, S. 19-20. Im gleichen Band meint übrigens Huber, Lorenz von Stein und die Grundlegung der Idee des Sozialstaates, S. 495-512 (498): „Was man in unserer Zeit die ,Daseinsvorsorge' der Verwaltung genannt und als einen neuen Grundzug des gegenwärtigen Verwaltungshandelns hervorgehoben hat, hat Stein schon vor einem Jahrhundert mit Recht als ein wesentliches Moment des damaligen Staates beschrieben.“

151 Forsthoff, Die Verwaltung als Leistungsträger (Fußn. 145), S. 45. 
den wird durch die konkrete Ordnung", was juristisch insoweit korrekt dann auch mit „Ende des subjektiv-öffentlichen Rechts“ überschrieben wurde. ${ }^{152}$

Der „merkwürdige Begriff“153 Daseinsvorsorge ist heute in Deutschland (wenngleich inzwischen rechtsstaatlich korrigiert ${ }^{154}$ ) insbesondere im Kommunalrecht geläufig (wenngleich das Wort in den meisten Gemeindeordnungen der Länder ebenso wenig selbst aufscheint, ${ }^{155}$ wie in der Reichsgemeindeordnung von 1935156) und hat (wenn-

152 Maunz, Das Ende des subjektiven öffentlichen Rechts, Zeitschrift für die gesamte Staatswissenschaft, 96. Bd. 1935, S. 71 ff. (S. 111). Ausführlich dazu s. Stolleis, Gemeinwohlformeln im nationalsozialistischen Recht, Berlin 1974, S. 241-245.

153 So Bull (Fußn. 144), S. 3; weil der Begriffsinhalt so schwer zu fassen ist, verweist der Autor auf die Formulierung von Schmidt, Die Liberalisierung der Daseinsvorsorge, Der Staat 42 (2003), S. 225: Daseinsvorsorge sei ein „metaphysischer Staatszweck“. Dort auch das Verdikt: „Als Rechtsbegriff konnte sich die Daseinsvorsorge nicht etablieren. Zur Begründung von Teilhabeansprüchen ist sie angesichts von Grundrechten als subjektiv-öffentlichen Rechten ungeeignet bzw. überflüssig.“ (S. 229).

154 Diese Korrekturen nahm Forsthoff, in der Neuausgabe: Rechtsfragen der leistenden Verwaltung, Stuttgart 1959, selbst vor. 1959 fehlen Ausführungen zum „Führertum“, zur „Führerpersönlichkeit an der Spitze des Staates“, zur „Daseinsvorsorge, (...) welche die politische Gemeinschaft konstituiert“ aber auch die „Vorstellung des totalen Krieges, der sich ja vor allem gegen die Institutionen der Daseinsvorsorge richten muss“, die ursprünglich in Kap. 2, S. 15 ff., enthalten waren. Das Abstellen auf den ,totalen Krieg“ geht offenbar zurück auf das Pamphlet von Ludendorff, Der totale Krieg, München 1935, das eines der schrecklichsten Stichwörter der nationalsozialistischen Ideologie vorweggenommen hat.

$155 \S 102$ Abs. 1 Ziff. 3 der VwGO lässt wirtschaftliche Einrichtungen der Gemeinden zu, wenn sie zur Daseinsvorsorge gehören; sonst wird Daseinsvorsorge durch Aufzählung von Dienstleistungen beschrieben, etwa in Art. 57 BayGO: Aufgaben des eigenen Wirkungskreises. Dort heißt es: „Im eigenen Wirkungskreis sollen die Gemeinden in den Grenzen ihrer Leistungsfähigkeit die öffentlichen Einrichtungen schaffen und erhalten, die nach den örtlichen Verhältnissen für das wirtschaftliche, soziale und kulturelle Wohl und die Förderung des Gemeinschaftslebens ihrer Einwohner erforderlich sind, insbesondere Einrichtungen zur Aufrechterhaltung der öffentlichen Sicherheit und Ordnung, der Feuersicherheit, der öffentlichen Reinlichkeit, des öffentlichen Verkehrs, der Gesundheit, der öffentlichen Wohlfahrtspflege einschließlich der Jugendhilfe, des öffentlichen Unterrichts und der Erwachsenenbildung, der Jugendertüchtigung, des Breitensports und der Kultur- und Archivpflege; hierbei sind die Belange des Natur- und Umweltschutzes zu berücksichtigen.“

156 In der Deutschen Gemeindeordnung vom 30. Januar 1935, geändert bzw. neu gefasst durch Verordnung Nr. 21 der Militärregierung vom 1. April 1946 (für die britische Besatzungszone) etc. findet sich zwar neben dem Bezug auf den Freiherrn v. Stein die Ideologie der Nazis, etwa in der Präambel: „Die Deutsche Gemeindeordnung will die Gemeinden in enger Zusammenarbeit mit Partei und Staat zu höchsten Leistungen befähigen und sie damit instand setzen, im wahren Geiste des Schöpfers gemeindlicher Selbstverwaltung, des Reichsfreiherrn vom Stein, mitzuwirken an der Erreichung des Staatszieles: in einem einheitlichen, von nationalem Willen durchdrungenen Volke die Gemeinschaft wieder vor das Einzelschicksal zu stellen, Gemeinnutz vor Eigennutz zu setzen und unter Führung der Besten des Volkes die wahre Volksgemeinschaft zu schaffen, in der auch der letzte willige Volksgenosse das Gefühl der Zusammengehörigkeit findet.“ $§ 18$ enthält dann die Aufgabenzuweisung, die zur Daseinsvorsorge gehören, ohne dies auszusprechen! „Die Gemeinde kann bei dringendem öffentlichen Bedürfnis durch Satzung mit Genehmigung der Aufsichtsbehörde für die Grundstücke ihres Gebietes den Anschluß an Wasserleitung, Kanalisation, Müllabfuhr, Straßenreinigung und ähnliche der Volksgesundheit dienende Einrichtungen (Anschlußzwang) und die Benutzung dieser Einrichtungen und der Schlachthöfe (Benutzungszwang) vorschreiben.“ 
gleich nicht wörtlich übersetzt ${ }^{157}$ ) sogar Eingang in Rechtsdokumente der EU gefunden. Die Notwendigkeit, den deutschen Begriff dabei in anderen Sprachen zu umschreiben, lässt es zweifelhaft erscheinen, ob „Daseinsvorsorge“ als juristischer Terminus ein tauglicher Ansatz für einen Rechtsvergleich sein kann.

Unter dem Aspekt eines von der EU ausgelösten Handlungsbedarfs, „dem Gemeinsamen Markt auch große Versorgungsunternehmen zuzuführen“, beschreibt Bullinger den französischen „service public“ und die deutsche „Daseinsvorsorge“. ${ }^{158}$ Dabei stellt er zunächst fest, dass der service public „in anderen Ländern kein einigermaßen exaktes Gegenstück besitzt.“"159 Im Vergleich zu Deutschland werden „Unterschiede in Idee und Dogmatik der leistenden Verwaltung“ konstatiert, „zwei unterschiedliche Staatsideen,“ die den Ausgangspunkt und die weitere Entwicklung der Verwaltungskulturen bestimmten. ${ }^{160}$ Für Frankreich wäre dies, zurückgehend auf Leon Duguit, danach die „bürgerliche Republik als höchste[r] Einheit für sorgsam begrenzte Dienstleistungen“, während er

„bei Forsthoff die konservativ-romantische Idee des Staates als höchster Lebensgemeinschaft mit umfassender Verantwortung für das Wohl ihrer Mitglieder"161

erkennen will. Auch wenn man Forsthoffs Gedankenwelt eher nicht als ,konservativromantisch" interpretieren will, ist Bullinger doch darin zu folgen, dass ein Vergleich der Umsetzung eines amorphen Begriffs wie „Daseinsvorsorge“ in unterschiedlichen Rechtskulturen unvermeidlich auch ein Kulturvergleich sein muss. Dieser hat aber nur Sinn, wenn er den historischen Kontext einbezieht:

„Rechtsgeschichte und Rechtsvergleich sind Holz vom gleichen Stamm. Sie sind Zwillingsschwestern." 162

157 Auf Deutsch werden z. B. in Art. 16 EUV dafür „Dienste von allgemeinem wirtschaftlichen Interes-

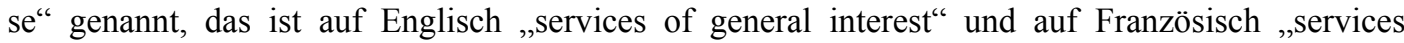
d'intéret général“; laut Mitteilung der Kommission: Leistungen der Daseinsvorsorge in Europa. Kom(2000) 580, S. 3 sind „Leistungen der Daseinsvorsorge ein Schlüsselelement des europäischen Gesellschaftsmodells." Zu diesem s. etwa Mestmäcker, Daseinsvorsorge und Universaldienst im europäischen Kontext, in: Ruland/Maydell/Papier (Hrsg.), Verfassung, Theorie und Praxis des Sozialstaates, Festschrift für Hans F. Zacher zum 70. Geburtstag, Heidelberg 1998, S. 635 ff.

158 Bullinger (Fußn. 147), S. 597; auch Pielow, Grundstrukturen öffentlicher Versorgung (Fußn. 144), der von „Elementarunterschieden zwischen Daseinsvorsorge und service public“ spricht (S. 395).

159 Bullinger, ebda., S. 597. Ebenfalls mit europarechtlichem Ansatz s. Waechter, Verwaltungsrecht im Gewährleistungsstaat, Tübingen 2008, darin ein exemplarisch funktionaler Rechtsvergleich: „Das Konzept des service public in Frankreich“, S. 84 ff.

160 Bullinger, ebda., S. 599.

161 Ders., ebda., S. 599-600.

162 Kötz, Was erwartet die Rechtsvergleichung von der Rechtsgeschichte?, JZ 1992 S. 20. 


\section{Funktioniert der funktionale Rechtsvergleich und wenn ja, warum?}

Unter Kultur ist natürlich ,politische Kultur” zu verstehen, was den Gegenstand zwar überschaubarer, nicht aber sehr viel einfacher macht. ${ }^{163}$ Hier ist auch mehr an das gedacht, was Zacher einmal „Tendenzvergleich“164 genannt hat, etwa eine aus dem Rückblick gewonnene Erkenntnis wie diese:

„Die Zeit zwischen den dem Ersten und Zweiten Weltkrieg war aber auch eine Epoche, in der das Begriffspaar, Security' - ,Insecurity' als zeitdiagnostische Kategorie seinen Höhepunkt erreichte." 165

Darüber hinaus kann ein Vergleich zwischen der politischen Kultur, in der im Deutschland der 1930er Jahre „Daseinsvorsorge“ als Beschreibung der Verwaltungswirklichkeit geprägt worden ist, mit der Situation in einem anderen Land nur als „funktionaler Rechtsvergleich“ erfolgen.

\section{a) Funktionaler, nicht funktionalistischer Rechtsvergleich}

Zuletzt hat Michaels die funktionale Methode des Rechtsvergleichs einer vermeintlich gründlichen Analyse unterzogen. ${ }^{166}$ Er notiert dazu gleich eingangs höchst kritisch:

„This functional method is a chimera, in both theory and practice of comparative law. As theory it hardly exists, at least in an elaborated form. The standard reference text for supporters and opponents alike is a brief chapter in an introductory textbook, a text that in it's original conception is almost half a century of age."167

Der Autor nimmt hier Bezug auf einen kurzen Abschnitt im Einleitungskapitel „Generalia“ in der „Einführung in die Rechtsvergleichung“ von Zweigert und Kötz. ${ }^{168}$ Tat-

163 Jayme, Langue et Droit, Rapport général, Congrès de Droit Comparé, Brüssel 1998, S. 2: „La langue est l'expression primordiale d'une culture. Chaque système juridique développe sa propre langue et dispose des règles sur l'emploi des langues." Aktuell hat Schuppert, Politische Kultur, Baden-Baden 2008, versucht, ,herauszufinden, was Politische Kultur eigentlich ist“ (Vorwort); trotz über 790 Druckseiten lässt sich aus dem Werk dennoch kein irgendwie definitives Ergebnis zitieren! Speziell zu den nordischen Ländern s. Sørensen/Stråth (Hrsg.), The Cultural Construction of Norden, Oslo u. a. 2005. Man kann aber auch die Meinung vertreten, dass „Der Norden“ eine Erfindung „von außen“ ist, s. Henningsen, Der Norden: Eine Erfindung, Das europäische Projekt einer regionalen Identität, Berlin 1993, oder Mjøset, The Nordic Model Never Existed, but Does it Have a Future?, Scandinavian Studies Journal 1992, S. 652-671.

164 Zacher, Vorfragen zu den Methoden der Sozialrechtsvergleichung, in: v. Maydell/Eichenhofer (Hrsg.), Abhandlungen zum Sozialrecht (Fußn. 1), S. 362-363, der freilich anmerkt, dass dies „besonders schwierig“" ist, und „,noch besonderer Untersuchung [bedarf]“.

165 Kaufmann, in: Lessenich (Hrsg.), Wohlfahrtsstaatliche Grundbegriffe (Fußn. 5), S. 73.

166 Michaels, The Functional Method of Comparative Law, in: Reimann/Zimmermann (Hrsg.), The Oxford Handbook of Comparative Law, Oxford 2006, Chapter 10, S. 340-382.

167 Ders., ebda., S. 340.

168 Zweigert/Kötz, Einführung in die Rechtsvergleichung, 3. Aufl. Tübingen 1996 (Erstauflage 1971), $\S 3$ : „Methode der Rechtsvergleichung“. Hervorhebung im Original. 
sächlich gilt selbst in diesem knappen Kapitel der Methode des Rechtsvergleichs eigentlich nur ein Satz:

„Das methodische Grundprinzip der gesamten Rechtsvergleichung, aus dem sich alle anderen Methodenansätze - Auswahl der zu vergleichenden Rechte, Spannweite der Untersuchung, Systembildung etc. - ergeben, ist das der Funktionalität."169

Im Weiteren führen die Autoren primär erklärende Beispiele dafür an, wie diese Funktionalität funktioniert und warum sie für die Verfasser die einzig pragmatische Methode ist. Michaels kritisiert dies als das Postulat eines Anspruchs auf ein methodologisches Monopol, das er als solches sogleich ebenfalls kritisiert:

„Such claims of monopoly suggest a lack of conceptual clarity, or a lack of theoretical "Sophistication, or both." 170

Und obwohl er zugesteht, dass der funktionale Ansatz einigen berühmten rechtsvergleichenden Studien zugrunde lag, führt er deren Berühmtheit gerade nicht auf diesen Ansatz, sondern darauf zurück, dass derartige Studien an sich sehr selten sind. ${ }^{171}$ Dann macht er quer durch Zeit und wissenschaftliche Disziplinen sieben verschiedene Konzeptionen des Funktionalismus aus, die von ,(1) finalism, a neo-Aristotelian functionalism based on inherent teleology“ bis hin zu ,(7) equivalence functionalism“ reichen und schließlich vom „functionalist comparative law" als achtem Konzept ergänzt werden, das alle vorgenannten Konzepte irgendwie nutzt, ohne sich deren Inkompatibilität bewusst zu sein. ${ }^{172}$ Eine Ausnahme von dem Verdikt des Theoriedefizits macht Michaels eigentlich nur für Esser, dessen Werk „Grundsatz und Norm in der richterlichen Fortbildung des Privatrechts" 173 er als „one of the most important works for functionalistic comparative law" hervorhebt und inhaltlich auf den später Zweigert zugeschriebenen Satz bringt:

„Institutions are contingent while problems are universal."174

Esser selbst spricht jedoch in dem zitierten Werk von einer „funktionellen Rechtsvergleichung“, deren Schlüsselsatz lautet:

„erweisen sich also auch historisch und strukturell selbständige Lösungen durch die Ubiquität der ethischen und funktionsbedingten Prinzipien und durch die begrenzte Auswahlmöglichkeit der technischen Bewältigung als überraschend ähnlich."175

169 Zweigert/Kötz, Einführung in die Rechtsvergleichung (Fußn. 168), S. 33. S. a. Strömholm, Gibt es eine komparative Methode?, in: Feuerstein/Parry (Hrsg.) Multum non multa, Festschrift für Kurt Lipstein aus Anlaß seines 70. Geburtstags, Heidelberg 1980, S 279-291.

170 Michaels, in: Reimann/Zimmermann (Hrsg.), The Oxford Handbook of Comparative Law (Fußn. 166), S. 343.

171 Ders., ebda., S. 341: „but they are famous in no small part because they are so rare.”

172 Ders., ebda., S. 345: „Largely oblivious of incompatibilities, functionalist comparative law (8) uses all of these."

173 Esser, Grundsatz und Norm in der richterlichen Fortbildung des Privatrechts, 3. Aufl. Tübingen 1974.

174 Michaels, in: Reimann/Zimmermann (Hrsg.), The Oxford Handbook of Comparative Law (Fußn. 166), S. 346.

175 Esser, Grundsatz und Norm (Fußn. 173), S. 31. 
Vielleicht macht diese Nuance deutlich, weshalb Michaels Kritik zu weiten Teilen fehl geht: Er setzt an den diversen Theorien des Funktionalismus an und vermisst beim funktionellen resp. funktionalen Rechtsvergleich theoretische Tiefe. Dabei hat funktionaler Rechtsvergleich wenig etwa mit den klassischen funktionalistischen Theorien der Politikwissenschaft, wie sie in den USA etwa von Mitrany 176 oder Haas ${ }^{177}$ entwickelt wurde, zu tun - auf diese nimmt aber Michaels ausführlich Bezug, um damit die Defizite des funktionalen Rechtsvergleichs zu belegen. ${ }^{178}$ Mit diesem Ansatz, Recht mit politologischen Theorien verstehen oder erklären zu wollen, steht Michaels freilich nicht allein. Da kommt es dann manchmal zu nicht genau differenzierten Gemengelagen aus „formalism“, „functionalism,“" und „neo-functionalism“, letztere präsentiert „more as a disposition than as the exposition of an alternative social policy."179 Man entdeckt diverse ,ironische Wenden“ des Funktionalismus, für die berühmte (wenn auch an sich schwer nachvollziehbar und für die aktuelle Problemanalyse dann doch ein wenig anachronistische) Zeugen benannt werden:

„Carl Schmitt and Ernst Forsthoff, in Germany constitutional and administrative law, are the most eloquent representatives for this turn of functionalism." 180

Wenn als Ergebnis einer weiteren „Wende” dann festgestellt wird

„In turn, autopoietic law radicalizes the functionalist's instrumentalization of law as a means of social engineering by leaving the driver's seat empty"181,

wird das der post-industrielle Gesellschaft nachgesagte Spezifikum angeblich zunehmender Selbstnormierung von Wirtschaft und Technik ${ }^{182}$ als „Radikalisierung des

176 Mitrany, A Working Peace System, London 1943. Zu dessen Idee, internationale Konflikte durch einen „functional approach“, also durch ideologiefreie Zusammenarbeit am Sachproblem zu überwinden, s. ausf. Köhler, Sozialpolitische und sozialrechtliche Aktivitäten (Fußn. 61), S. 115 ff.

177 Haas, Beyond the Nation State. Functionalism and International Organization, Stanford 1964.

178 Michaels, in: Reimann/Zimmermann (Hrsg.), The Oxford Handbook of Comparative Law (Fußn. 166), S. 349 ff., „Classical Functionalism“.

179 Loughlin, The Functionalist Style in Public Law, Toronto Law Journal 2005, S. 361, zitiert von Zumbansen, Law After the Welfare State: Formalism, Functionalism, and the Ironic Turn of Reflexive Law, The American Journal of Comparative Law, Vol. 56 2008, S. 769-808 (785).

180 Zumbansen, ebda., der für diese Behauptung Schmitt, Staatsethik und pluralistischer Staat (1930) und Forsthoff, The Administration as Provider of Services, anführt, was angeblich die engl. Version von „Der Staat der Daseinsvorsorge (1938)“ ist - eher wahrscheinlich - eine fehlerhafte Rückübersetzung der „Verwaltung als Leistungsträger“. Kaum vorstellbar, dass Zumbansen damit die „teils verblüffenden, teils gespenstischen Kontinuitäten im Staatsdenken, die alle Systemwechsel seit dem späten neunzehnten Jahrhundert überdauert haben" meint.

181 Zumbansen, ebda., S. 807.

182 S. etwa DiFabio, Privatisierung und Staatsvorbehalt, Zum dogmatischen Schlüsselbegriff der öffentlichen Aufgabe, JZ 1999, S. 585-636. Die (nicht nur) von DiFabio für den Bereich der Daseinsvorsorge verfassungsrechtlich unbedenklich erklärte „Aufgabenprivatisierung“ (S. 592) ist im aktuellen Zusammenhang mit der Krise der globalen Finanzmärkte weitgehend aus der Diskussion geraten, s. etwa Fisahn/Viotto, Privatisierung und Public-Private-Partnership, KritV 3/2008, S. 264-283, oder Rügemer, „Heuschrecken“ im öffentlichen Recht, Public Private Partnership - Anatomie eines globalen Finanzinstruments, Bielefeld 2008. 
Funktionalismus“ missverstanden. Das Bild vom „leeren Fahrersitz“ zielt wohl auf eine „Aktualisierung“ des Zauberlehrling-Motivs („Die ich rief, die Geister, Werd ich nun nicht $\operatorname{los}$ "183). Dabei wird verkannt, dass der pragmatisch-funktionale Ansatz des amerikanischen „Legal Realism“ sich ursprünglich als Soziologie des Rechts und dort vor allem der richterlichen Rechtsfindung verstand, ${ }^{184}$ die das „magische Zaubern“ mit Begriffen gerade bekämpfte. Schon seit den 1930er Jahren, also früher als die genannten Politologen, diskutierte man dabei nicht „functionalistic jurisprudence“, sondern „functional jurisprudence“!185 Über einen funktionalen Ansatz wollte man inhaltsleer gewordene rechtliche Konzepte186 überwinden:

„In every field of law we should find peculiar concepts which are not defined either in terms of empirical fact or in terms of ethics but which are used to answer empirical and ethical questions alike, and thus bar the way to intelligent investigation of social facts and social policy." 187

Man hatte erkannt, dass etwa Konzepte wie „corporate entity, property rights, fair value and due process“ begrifflich vom Recht geschaffen werden, „selbst also Rechtskreationen" sind, was unseren Erkenntnisgewinn dann, wenn man sie wiederum mit Rechtsbegriffen näher bestimmen will, nicht weiter voran bringt als die Entdeckung des Arztes bei Moliere, "that opium puts men to sleep because it contains a dormitive principle."188 Dieser „pragmatische Realismus“ hängt ohne Zweifel wiederum mit einem Sprach-, besser: Übersetzungsproblem zusammen. Denn der kontinentale Begriff „Jurisprudenz" ist mit dem angelsächsischen ,jurisprudence“ nicht vollständig deckungsgleich. Die Begriffsinhalte unterscheiden sich vor allem bezüglich der ethischen Reflexion von Werten wie Gerechtigkeit etc.:

„English jurisprudence tends naturally to assume the analytical and historical to the exclusion of the ethical. Continental jurisprudence, on the contrary, tends naturally to assume the ethical form."189

183 Goethe, Berliner Ausgabe, Poetische Werke, Band 1, Berlin 1960 ff., S. 150-154.

184 S. Martin, Legal Realism, American and Scandinavian, New York 1997. Pound schrieb 1908: „The sociological movement in jurisprudence is a movement for pragmatism as a philosophy of law; [...] for putting the human factor in the central place and relegating logic to it's true position as an instrument.”, Mechanical Jurisprudence, Columbia Law Review Vol. 8 (1908), S. 605-623 (609-610). Kritisch Kantorowicz, Some Rationalism about Realism, Yale Law Journal Vol. 43/1934, S. 12411253.

185 S. etwa Cohen, Transcendental Nonsens and the Functional Approach, Columbia Law Review Vol. XXXV No. 6 (1935), S. 809-849, oder ders., The Problems of a Functional Jurisprudence, Modern Law Review June 1937, S. 5-26.

186 Pound (Fußn. 184), Columbia Law Review Vol. 8 (1908), S. 620: „The nadir of mechanical jurisprudence is reached when conceptions are used, not as premises from which to reason, but as ultimate solutions."

187 Cohen (Fußn. 185), Columbia Law Review Vol. XXXV No. 6 (1935), S. 820.

188 Ders., ebda., S. 820.

189 Das Zitat ist dem zeitgenössischen Werk von Salmond, Jurisprudence, 7. Aufl. London 1924, S. 10, entnommen. Appendix I, The Names of the Law, S. 513 ff., ist bis heute gerade für den Rechtsvergleich von großem Nutzen. 
Das hat auch die Konsequenz, dass im angelsächsischen Rechtsdenken „the science of law itself is ready and willing to walk in lowlier paths." 190 Dies erklärt vielleicht sogar die vermeintlich ,theoriefreie” Nüchternheit von „functional jurisprudence”.

\section{b) Form ever follows function}

Und noch früher als die Juristen schrieb der Architekt Louis H. Sullivan auf knapp sieben Seiten seinen Essay, ${ }^{191}$ dem seither, wenn auch selten korrekt (meist verkürzt) zitiert und dadurch den Sinn verändernd, ${ }^{192}$ die Formel „form follows function“ als Erklärung für alles, was gefällt, entnommen wird und auch für das, was nicht gefällt. Sullivan war kein Theoretiker. Er gehörte zu den Baumeistern der ersten „Wolkenkratzer"193 in den USA und folgte damit einem ökonomischen und sozialen Bedarf seiner Zeit:

„The architects of this land and generation are now brought face to face with something new under the sun, namely, that evolution and integration of social conditions, that special grouping of them, that results in a demand for the erection of tall office buildings." 194

Er sieht dies als nicht weiter zu diskutierende Gegebenheiten, die es zu akzeptieren, als Herausforderung, die es zu lösen gilt:

„It is not my purpose to discuss the social conditions; I accept them as the fact, and say at once that the design of the tall office building must be recognized and confronted at the outset as a problem to be solved, a vital problem pressing for a true solution." 195

Es geht also um eine dem Problem angemessene Lösung, über die der berühmte Architekt nachdenkt und dabei seine Gedanken in einer einfachen, bis heute lesenswerten Sprache formuliert, etwa:

„It demands of us, what is the chief characteristic of the tall office building? And at once we answer, it is lofty." 196

Diese Aufgabenstellung fordert natürlich zuerst rein architektonische Antworten, die Sullivan auch eingehend und mit der Kompetenz des erfahrenen Architekten diskutiert. Er weiß aber, dass noch mehr erforderlich ist: Eine umfassende Lösung, die das „Prob-

190 Salmond, ebda., S. 11.

191 Sullivan, The Tall Office Building Artistically Considered, Lippincott's Magazine, March 1896.

192 So auch Michaels, (Fußn. 166), S. 344, der darüber hinaus irrtümlich von einem „functionalist turn“ aller wissenschaftlicher Disziplinen spricht, ,,and beyond, for example in architecture and design.“der Verlauf war gerade umgekehrt!

193 S. etwa die Abbildung des ,Schlesinger-Meyer building, an icon for the idea that Form follows Function“ bei Hjelm, Semiotics in Product Design, CID Report Nr. 175, Stockholm 2002, S. 14.

194 Sullivan, The Tall Office Building Artistically Considered (Fußn. 191), unter I.

195 Ders., ebda.

196 Ders., ebda., unter II. 
lem tatsächlich auflöst“" ${ }^{197}$ verlangt Nachdenken über das rein technisch-handwerkliche hinaus. Dies führt ihn zur Formulierung der Passage mit dem berühmten Zitat:

„It is the pervading law of all things organic and inorganic, of all things physical and metaphysical, of all things human and all things superhuman, of all true manifestations of the head, of the heart, of the soul, that the life is recognizable in its expression, that form ever follows function. This is the law."198

„Form ever follows function” steht also für die Erkenntnis, dass das „Leben in seinem Ausdruck erkennbar ist". Damit war die Art, wie knapp 30 Jahre später das Bauhaus 199 diese Formel besetzte, schon deren erstes Missverständnis. Die „Zweckform“ als Schönheitsideal gerät mit der Gleichsetzung „Schönheit $=$ Funktion $=$ Schönheit“ wieder zum Zirkelschluss.

\section{c) Die Frage nach dem tertium comparationis richtig stellen}

Wie schon erwähnt, wollte man mit dem „functional approach“ in der Jurisprudenz diesem Zirkelschluss entgehen. Unter dem eminenten Einfluss von Justice Oliver Wendell Holmes Jr., ${ }^{200}$ der (mit nicht nur für das amerikanische Recht guten Gründen) Recht und Rechtswissenschaft als Mittel zur Vorhersage von Richtersprüchen definierte, ${ }^{201}$ erhoffte man durch das Stellen der „richtigen Fragen“ die Lösung von Rechts-

197 Ders., ebda., unter III: „Let us seek a comprehensive, a final solution: let the problem indeed dissolve.” Die keine 50 Jahre später geschehene Pervertierung der Formulierung der Forderung, Probleme durch funktionale Technik als solche ,aufzulösen“ als „Endlösung“ hätte sich Sullivan nicht vorstellen können.

198 Ders., ebda., unter III, Hervorhebung im Original.

199 Die Literatur zum Bauhaus ist längst vollkommen unüberschaubar. Eine konzentrierte Übersicht findet sich z. B. bei Scheiffele, Bauhaus, Junkers, Sozialdemokratie: ein Kraftfeld der Moderne, Berlin 2003.

200 S. Holmes, The essential Holmes: Selections from the Letters, Speeches, Judicial Opinions and other Writings of Oliver Wendell Holmes Jr., Chicago (u. a.) 1992; für eine „Verteidigung” von Holmes s. Hart, Positivism and the Separation of Law and Morals, Harvard Law Review Vol. 71 Feb. 1958 Nr. 4, S. 593-629. In diesem Zusammenhang ist auch Hohfeld, Fundamental Legal Conceptions, New York 1919, zu nennen und die umfänglichen zeitgenössischen Literaturangeben bei Cohen (Fußn. 185), Columbia Law Review Vol. XXXV No. 6 1935, Anm. 32.

201 Holmes, Tue Path of the Law, Harvard Law Review Vol. X March 25, 1897 No. 8, S. 457-478: „The primary rights and duties with which jurisprudence busies itself again are nothing but prophecies.” (S. 458) und: „The prophecies of what the courts will do in fact, and nothing more pretentious, are what I mean by the law." Cohen (Fußn. 185), Modern Law Review June 1937, S. 16-17: „Washed in a cynical acid, every legal problem can thus be interpreted as a question concerning the positive behaviour of judges." Umso mehr sollte man aber die Bedenken der Praktiker Ernst nehmen: "Although we should be wary of swallowing the practitioners' assertion: that decisions are made intuitively and afterwards provided with a 'facade legitimation' which fits the rules, we must consider the possibility that judges (like magicians) perform their manipulations with reality, imposing on the parties a false sense of safety through the many precautions available when interpreting the rules of law." Jørgensen, Lawyers and Hermeneutics, Scandinavian Studies in Law, Vol. 40 (2000), S. 188. 
problemen. Man soll also den Rechtsvergleicher nicht, wie Michaels, vorschnell danach beurteilen, welche Theorie des Funktionalismus er verfolgt und ob sein Ergebnis dieser dann auch entspricht, sondern welche Fragen er gestellt hat:202

„Die Ausgangsfrage jeder rechtsvergleichenden Arbeit muss deshalb rein funktional gestellt, das zu untersuchende Problem frei von den Systembegriffen der eigenen Rechtsordnung formuliert werden." 203

Nur wenn es gelingt, das der rechtlichen Regelung gleichsam „vorgelagerte“ tatsächliche Problem ${ }^{204} \mathrm{zu}$ erfragen, können einigermaßen objektiv die in verschiedenen nationalen Rechtssystemen darauf gefundenen Antworten verglichen werden. Dabei muss man sich der Schwierigkeit bewusst sein, dass selbst das nichtrechtliche Sachproblem keineswegs einfach aus der Unendlichkeit der Lebenswirklichkeit zu destillieren ist. Es „ist schwierig, Probleme und Problemlösungen voneinander zu scheiden und einander gegenüberzustellen“. ${ }^{205}$ Dies liegt erfahrungsgemäß auch daran, dass durch

„politisches Handeln im Wohlfahrtsstaat [...] die Verhältnisse, auf die es seine Bemü-

hungen richtet, sich in unerwarteter Weise durch die Bemühungen selbst ändern.“206

Ein praktisches Beispiel aus der Arbeit des Max-Planck-Instituts für ausländisches und internationales Sozialrecht zeigt: Will man etwa die soziale Absicherung des Invaliditätsrisikos in einer Erwerbsgesellschaft rechtsvergleichend untersuchen, so kann man nicht auf einen allgemein geläufigen Lebenssachverhalt abstellen, nicht auf „einen $\mathrm{Zu}$ stand an sich", sondern muss nach dem Ergebnis verschiedener individueller, gesellschaftlicher und indirekt auch rechtlicher Faktoren aus der Arbeitswelt fragen.207 Man kann dann zu dem Ergebnis kommen, dass sich der außerrechtlich definierte Sachverhalt in den diversen untersuchten Rechtsordnungen als „sozialer Sicherungstatbestand“

202 Man sollte also bei einer rechtsvergleichenden Studie nicht fragen: "'What basic theory does it defend?' but rather, ,What basic question does it propound?“, Cohen (Fußn. 185), Columbia Law Review Vol. XXXV No. 6 1935, S. 829.

203 Zweigert/Kötz, Einführung (Fußn. 168), S. 33.

204 S. Zacher, Vorfragen zu den Methoden der Sozialrechtsvergleichung (Fußn. 1), S. 344 ff.: „Sachproblem und rechtliche Regelung“", und ders., (Hrsg.), Alterssicherung im Rechtsvergleich, BadenBaden 1991, S. 16 ff.

205 Zacher (Hrsg.), Alterssicherung im Rechtsvergleich, S. 18. Das sieht auch Michaels ein: „If functions are relations between institutions and problems, then the first task is to find the problem to be solved by legal institutions. And this is itself a problem" Wozu er u. a. Zacher, Vorfragen zu den Methoden der Sozialrechtsvergleichung, in: v. Maydell/Eichenhofer (Hrsg.), Abhandlungen zum Sozialrecht (Fußn. 1), und ders., (Hrsg.), Methodische Probleme des Sozialrechtsvergleichs, Tutzing 1976, zitiert, s. Michaels, (Fußn. 166), S. 366 zu Anm. 142.

206 Luhmann, Politische Theorie im Wohlfahrtsstaat, München 1981, S. 11. Ganz ähnlich Zacher, Der Sozialstaat als Prozeß, in: v. Maydell/Eichenhofer (Hrsg.), Abhandlungen zum Sozialrecht (Fußn. 1), S. 73 ff.

207 S. die Studie aus dem Max-Planck-Institut für ausländisches und internationales Sozialrecht Bd. 18, hrsg. von Reinhard/Kruse/v. Maydell, Invaliditätssicherung im Rechtsvergleich, Baden-Baden 1998. Zur Abgrenzung der Invalidität von Krankheit oder Unfall, um das tertium comparationis eines funktionalen Rechtsvergleichs zu gewinnen, s. Köhler, Einleitung, ebda., S. 10 ff., und Clark, Defining and Assessing Disability under US-Social Security Law from a Comparative Perspective, ZIAS 1992, S. $103 \mathrm{ff}$. 
wiederfindet, dessen rechtliche Ausgestaltung dann verglichen werden kann. In einem zweiten Schritt kann schließlich versucht werden, Ähnlichkeiten (oder Unterschiede) und womöglich sogar deren Gründe zu erkennen. ${ }^{208}$

Dies war nicht nur im Beispielsfall209 das Gegenteil eines Ansatzes an einer (wissenschaftlich zweifelhaften) vorweg gehegten „Vermutung für die Ähnlichkeit der praktischen Lösungen“ oder ,präsumtio similitudinis“,210 sondern erst das Resultat der möglichst objektiven Untersuchung der Rechtslage in zahlreichen Ländern. Es hat allerdings die von Esser erwähnte Wahrscheinlichkeit der Ubiquität der Probleme und der begrenzten Auswahlmöglichkeit der technischen Bewältigung bestätigt.

\section{Att lägga livet till rätta - Sich das Leben zurecht legen in Schweden}

Mit der Hinwendung der Verwaltung zur Daseinsvorsorge, also in der Sicherstellung der für das menschliche Dasein notwendigen Grundversorgung, fanden die sozialen Probleme der Zwischenkriegszeit verwaltungsrechtlich „ihren Ausdruck”: Was wir heute Leistungsverwaltung nennen, war die rechtliche „Form”, die für das Funktionieren des Lebens in den großen Städten der Massengesellschaft erforderlich war. Die Ausgestaltung dieser Form folgte dem Gesetz der nationalen Bedingungen, in denen sie wirken sollte. Mit Sullivan: „This is the Law“. Der Sache nach handelte es sich dabei keineswegs um ein auf Deutschland oder Schweden beschränktes Phänomen, sondern um eine Variante des in den 1930er Jahren in vielen Staaten unternommenen Versuchs, die Mängel des „organisierten Kapitalismus“ zu überwinden. Mit ein wenig rhetorischer Übertreibung lässt sich von einem welthistorischen „Gezeitenwechsel vom liberalen Kapitalismus zum Staatskapitalismus oder kapitalistischem Wohlfahrtsstaat mit seiner Planung und Lenkung der Gesellschaft" ${ }^{\text {211 }}$ sprechen.

208 Reinhard/Kruse/v. Maydell (Hrsg.), Invaliditätssicherung im Rechtsvergleich (Fußn. 207), 3. Teil, S. $711 \mathrm{ff}$.

209 S. als weitere Beispiele Zacher (Hrsg.), Alterssicherung im Rechtsvergleich (Fußn. 204), Köhler/v. Maydell (Hrsg.), Arzthaftung - „Patientenversicherung“ - Versicherungsschutz im Gesundheitssektor, Baden-Baden 1997; Reinhard (Hrsg.), Demografischer Wandel und Alterssicherung, Rentenpolitik in neun europäischen Ländern und den USA im Vergleich, Baden-Baden 2001, oder Schlachter/Becker/Igl (Hrsg.), Funktion und rechtliche Ausgestaltung zusätzlicher Alterssicherung, Reformen in der Schweiz, Schweden, den Niederlanden, Großbritannien und Deutschland mit ihren internationalen und gemeinschaftsrechtlichen Bezügen, Baden-Baden 2005.

210 Zweigert/Kötz, Einführung in die Rechtsvergleichung (Fußn. 168), S. 39; Gegen die ,présomption de similitude“ der „doctrine établie du droit comparé“ wendet sich Jayme, Langue et Droit, Brüssel 1999, S. 5 mit seiner „méthode postmoderne“, die vom Gegenteil, einer „présomption de différence“" ausgeht.

211 Schivelbusch, Entfernte Verwandte, Faschismus, Nationalsozialismus, New Deal 1933-1939, München 2005, S. 169, der das „Regime Roosevelts“ mit dem Hitlers, Mussolinis oder Stalins keinesfalls gleichsetzen will, sondern nur auf die Ähnlichkeiten hinweist. Speziell dazu auch Rodgers, Atlantic Crossings. Social Politics in a Progressive Age, Cambrige/Mass. 1998. Zum Europa der Dik- 


\section{Funktionalismus in Schweden: „Funkis”}

Am 28. Mai 1932 machten André Gide und Harry Graf Kessler in Berlin einen Spaziergang hinaus zu einer der Bauhaus-Siedlungen (Siemensstadt). Gide war beeindruckt und fragte, warum die Franzosen vollkommen den Sinn für Architektur verloren hätten, während er plötzlich in Deutschland aufgeblüht sei. Kessler antwortete:

„man könne diese Architektur nicht verstehen, wenn man sie nur als Architektur, abstrakt, sozusagen als >l'art pour l'art < betrachte. Sie erkläre sich nur als Teil eines neuen Lebensstils, einer neuen Auffassung vom Sinn und Zweck des Lebens, die sich diese Lebensformen schaffe. Übrigens sei jede Architektur, wo und wann auch immer, Ausdruck der herrschenden Lebens- und Weltanschauung gewesen.“212

Die Erklärung, dass Architektur „Ausdruck der Lebensanschauung“ sei, ist funktionalistisch, ohne das Wort zu gebrauchen. Tatsächlich waren die Siemensstadt-Projekte Ergebnis einer bereits mit der Jahrhundertwende einsetzenden Entwicklung,

„when the first avant-garde movements encountered the metropolis as the figure of an impossible promise.“213

Das von Gide bewunderte Aufblühen der Architektur war in Deutschland 1932 schon im Stadium des Verblühens, die Hoffnung, der Mensch könne durch Architektur erzogen werden, ${ }^{214}$ war bereits enttäuscht:

„Wenn Brecht sagt: ,Der Mensch ist der Fehler', dann wiederholt er nur den Stoßseufzer, den die Architekten des Neuen Bauens ausstießen, wenn sie ihre dem Volk zugedachten Wohnungen einige Monate nach Einzug der Mieter wieder besichtigten."215

Anders in Schweden: Nicht zuletzt unter dem Einfluss der im Deutschland der Weimarer Republik realisierten modernistischen Architektur und Formgebung ${ }^{216}$ kam es

taturen s. die Schriftenreihe von Simon (Hrsg.), Das Europa der Diktatur. Wirtschaftskontrolle und Recht, Frankfurt/Main 2002; zum New Deal s. Cohen, Nothing to Fear. FDR's Inner Circle and the Hundred Days that Created Modern America, New York 2009; Badger, FRD: The First Hundred Days, New York 2008 (darin S. ix ff. eine "Time Line" der politischen Entscheidungen 1932/33); Alter, The Defining Moment. FDR's Hundred Days and the Triumph of Hope, New York 2007; Lawson, A Commonwealth of Hope: The New Deal Response to Crisis, Baltimore 2006; Davis, FDR. The New Deal Years 1933 - 1937, A History, New York 1986; kritisch Zinn, Eine Geschichte des amerikanischen Volkes, Hamburg 2007, und die Beiträge in Winkler (Hrsg.), Die große Krise in Amerika, Vergleichende Studien zur politischen Sozialgeschichte 1929 - 1939, Göttingen 1973, darin insbes. Hawley, New Deal und „Organisierter Kapitalismus“ in internationaler Sicht, S. 9-40. Zur Entwicklung in der Sowjetunion s. aktuell Schlögel, Terror und Traum, Moskau 1937, München 2008.

212 Pfeiffer-Belli (Hrsg.), Harry Graf Kessler, Tagebücher 1918-1937, Frankfurt/Main, Eintrag vom 28.05.1932. Mies van der Rohe prägte den Satz: „Architecture is the will of an epoch translated into space.“ Zitiert in New York Times vom 19. Aug. 1969: Obituary - Mies van der Rohe Dies at 83; Leader of Modern architecture.

213 Mattson/Wallenstein, Swedish Modernism at the Crossrads, in: SITE, Stockholm 01.12.2007, S. 3.

214 Taut, Die neue Wohnung, Die Frau als Schöpferin, 5. Aufl. Leipzig 1928, der deshalb forderte: „Zu der Körperhygiene muss die Gehirnhygiene dazukommen." (S. 60).

215 Lethen, Verhaltenslehren der Kälte (Fußn. 125), S. 167. 
dort zu einer Aufbruchsstimmung, deren sichtbares Zeichen eine nationale Industrieausstellung war, die international viel beachtete „Stockholm-Ausstellung“ von 1930. Sie war auch ein bis dahin in Schweden nicht gekannter Publikumserfolg:217

„Die Ausstellung war ein Ausdruck für Optimismus, Zukunftsglauben, Demokratie und Gemeinschaft aller Menschen, den Glauben an den Kollektivismus. [...] Das alles kam einem vor wie eine Straße, die direkt in die Zukunft führte." 218

Gezeigt wurden in zehn Abteilungen, was man für die nationalen Errungenschaften aus Industrie, Technik, Design und Kultur ${ }^{219}$ hielt. Am meisten Aufsehen machte die Abteilung, in der junge Architekten ihre Konzepte vom Wohnen vorstellten. Sie zeigten, wie eine moderne Wohnung funktionieren kann - vergleichbar einer Maschine mit genormten Teilen und speziellen Funktionen für Kochen, Essen und Schlafen. Das Streben nach Hygiene, Gesundheit, frischer Luft und Reinlichkeit, der lange Kampf gegen Tuberkulose und andere Volkskrankheiten werden in den hellen und lichten Räumen der funktionalistischen Architektur reflektiert. Gleiches gilt für die leicht zu pflegenden Küchen und Badezimmer. Fällt Licht in das Zimmer, kann man den Schmutz besser sehen und wegputzen. ${ }^{220}$ Dies war freilich vielen Besuchern wohl ein zu schneller

216 Hier sei nur an den 1907 gegründeten „Deutschen Werkbund“ (DWB) erinnert, dessen Arbeiten die frühe Internationalität des Funktionalismus belegt. Einige Höhepunkte (nach DWB e. V., Chronik des Werkbundes. Darmstadt 2007): DWB-Ausstellung in Köln, u. a. mit Musterfabrik von Gropius und Glashaus von Taut. Dabei kommt es zu einer Grundsatzdiskussion zwischen van de Velde und Muthesius über Normung: van de Velde vertritt die Position der individuellen Formgebung, während Muthesius die weitreichende Typisierung zur Qualitätshebung befürwortet; 1919 Gründung des „Bauhaus“ in Weimar; 1929 Zweite DWB-Ausstellung in Köln; „Wohnung und Werkraum“; „Film und Foto"-Ausstellung in Stuttgart. Mit dieser wohl wichtigsten Schau der avantgardistischen Fotografie der zwanziger Jahre, die einen internationalen Querschnitt von der UdSSR (Lissitzky, Rodtschenko) bis zu den USA (Weston) vorstellt, gelangen die visuellen Medien stärker ins Blickfeld des DWB; 1933/34 Gleichschaltung des DWB gegen die Stimmen von Wagner, Wagenfeld und Gropius. Ausführlich zum deutschen Einfluss Eriksson, Den moderna staden tar form. Arkitektur och debatt 1910-1935, Stockholm 2001, insbes. S. 46 ff.

217 Die Literatur dazu ist überwiegend architekturhistorisch und international längst unüberschaubar. Hier nur einige deutschsprachige Veröffentlichungen: Küster-Schneider, Schaufenster Zukunft, Die Stockholmausstellung 1930 als literarisches und gesellschaftliches Ereignis, Freiburg 2002; Larsson (Hrsg.), Wege nach Süden, Wege nach Norden, Aufsätze zu Kunst und Architektur, Kiel 2002; Henze, Der schwedische Wohlfahrtsstaat, Zur Struktur und Funktion eines politischen Ordnungsmodells, „Gemeinschaften“ Bd. 19, Florenz u. a., European University Institute 1999; Köhler, Det svenska folkhem - vom „Volksheim“ zum Wohlfahrtsstaat Schweden, ZIAS 1987, S. 203-213, und, immer noch in weiten Teilen aktuell, Henningsen, Der Wohlfahrtsstaat Schweden, Baden-Baden 1986. Zu den 1930er Jahren in Schweden s. das Sonderheft von ord \& bild, 81. Jg. 1-2/1972: „30talet: folkhem - fascism - folkfront.“ Darin insbes. den Beitrag von Sjödin, Funktionalismens dilemma, S. 4-10.

218 Johansson, schwedischer Arbeiterschriftsteller, zitiert und übersetzt bei Henze (Fußn. 217), Anm. 158. Ausführlich zu Johansson s. Lönnroth/Delblanc, Den Svenska Litteraturen, Bd. V, Modernisterna och arbetardiktare 1920-1950, Stockholm 1989, S. 135-142.

219 Bis hin zur Rassenhygiene, s. u. unter IV, 3, a), (2).

220 So Rudberg, Vardagens Utopi, Svenskt och asvensk i funktionalismens arkitektur, in: Moderna Museet (Hrsg.), Uutopi och Verklighet, Svensk Modernism 1900-1960, Stockholm 2000, S. 150 ff. 
Sprung in die Zukunft und sicher zu ungemütlich, ${ }^{221}$ weshalb die fünf wichtigsten Architekten der Ausstellung 222 ein Jahr später ein reich bebildertes „Debattbok“ („Buch zur Debatte") herausgaben, das seinerseits dann berühmte Manifest „acceptera!“ (,akzeptiere!")223. Schon der Titel nimmt ein wichtiges Wort aus dem oben zitierten Essay von Sullivan auf:

„It is not my purpose to discuss the social conditions; I accept them as the fact (...)”

Auf dem Buchumschlag findet sich dann in zeitgemäß progressiver Grafik ${ }^{224}$, das „schwedische Manifest des Funktionalismus” in Kurzform:

,akzeptiere die vorliegende Wirklichkeit - nur dadurch hast du eine Aussicht, sie auch zu beherrschen, ihr überlegen zu sein, um sie zu verändern und eine Kultur zu schaffen, die dem Leben dienen kann. [...] Wir können nicht anders, als der Wirklichkeit ins Auge zu schauen und sie zu akzeptieren, um sie zu beherrschen. [...] Es sind die müden und pessimistischen Menschen, die behaupten, dass wir es darauf anlegen, eine Maschinenkultur zu schaffen, die ihr eigenes Ziel ist." 225

Die Autorin weist darauf hin, dass damit auch schwedische Traditionen reflektiert wurden: „So finden wir in der Bauordnung der Stadt Stockholm aus dem 17. Jahrhundert die Vorschrift, dass Fenster möglichst außen an der Fassade angebracht werden, um das Tageslicht reflektieren zu können und in die dunklen Stuben einzulassen. Nach dem 1. Weltkrieg setzt sich die Standardisierung auch in der Bauindustrie durch. Die in den 1920er Jahren in Schweden entwickelte Einrichtungskunst ,Swedish Grace' wurde auch auf den ,Charme der schwedischen Armut' (svenska fattigdomens betydelse) zurückgeführt.“ (S. 153). Eriksson, Modernismens rötter i svensk arkitektur, ebda., S. 139 ff., erinnert daran, dass bereits seit dem 18. Jahrhundert „hygienische und sanitäre Fragen in die Stadtplanung eingingen.“ (S. 141). S. a. Karlsson, Arbetarfamiljen och Det Nya Hemmet, Om bostadskultur och klasskultur i mellankrigstidens Göteborg, Stockholm 1993, insbes. S. 171 ff.: „Den nya människans stad“.

221 Henze, Der schwedische Wohlfahrtsstaat (Fußn. 217), S. 6. anders Larsson/Schulz, Befolkningen vänjer sig snabbt vid nya lägenheter, in: ord \& bild, 81, Jg. 3/1972, S. 127-134, die das Mitwirken der „Hyresgäströrelse“, der Mieterbewegung, untersuchen mit dem Ergebnis, dass das Neue Bauen von den Menschen, die in diesen Wohnungen lebten, als große Verbesserung des Lebens empfunden wurde.

222 Das waren Sven Markelius, Uno Åhrén, Gunnar Asplund, Wolter Gahn, Eskil Sundahl und der Kunsthistoriker Gregor Paulsson, von denen einige bis in die 1960er Jahre bedeutenden Einfluss auf Architektur, Kunst und Design haben sollten.

223 Asplund et al, Acceptera!, Stockholm 1931. Zu diesem s. ausführlich Kuchenbuch, Gläserne Stadt Gläserner Mensch, Architektur, Literatur und Transparenz in den 1930er Jahren in Schweden, Denkräume, Fastforeword magazin 1 2007; Mattson/Wallenstein, Swedish Modernism at the Crossrads (Fußn. 213); Hjelm, Semiotics in Product Design (Fußn. 193); Henningsen, Der Wohlfahrtsstaat Schweden (Fußn. 217), S. 50 ff.

224 S. Lönnroth/Delblanc, Den Svenska Litteraturen (Fußn. 218), S. 13, und Bury, Breaking the Rules, The Printed Face of the European Avant Garde 1900-1937, London 2007, insbes. S. 16 ff.: The Manifesto.

225 Übersetzung vom Verf., der ungekürzte Originaltext lautet: „Acceptera den föreliggande verkligheten - endast därigenom har vi utsikt att behärska den, att rå på den för att förändra den och skapa kultur som är ett smidigt redskap för livet. Vi har inte behov av en gammal kulturs urvuxna former för att uppehåller vår självakning. Vi kan inte smyga oss ur vår egen tid bakåt. Vi kan inte heller hoppar förbi något som är besvärligt och oklart in i en utopisk framtid. Vi kan inte annat än att se verkligheten i ögonen och acceptera den för att behärska den. Vad som är medel och vad som 
Mit eindrucksvollem Bildmaterial wird ein „A-Europa“ einem „B-Europa“ gegenübergestellt. ${ }^{226}$ Bei „A“ handelt es sich um ein hochindustrialisiertes Land mit perfekten Kommunikationsverläufen für die schnelle Zirkulation von neuen Ideen oder Waren und Moden:

„ein großer Organismus, in dem alles gleichermaßen spezialisiert und zentralisiert funktioniert und alle Zellen vom einsam gelegenen Bauerngarten bis zur großen Fabrik oder Bank aufeinander angewiesen sind."227

Demgegenüber gibt es in „B“ zwar vereinzelt auch neue Techniken, aber alle Teile der Gesellschaft verhalten sich zueinander wie ,isolierte Inseln“. Die Botschaft war klar: In Schweden fanden sich ebenso Beispiele für die Kategorie „A“, wie für die nach „B“, die „entweder entwickelt werden müssten oder bedeutungslos werden würden.“228

Dies nahm auch die Politik ernst: Als im „Wendejahr“1933229 Per Albin Hansson, der daraufhin bis zu seinem Tod 1946 Regierungschef, i. e. „Statsminister“, bleiben sollte, ${ }^{230}$ die erste sozialdemokratische Regierung bildete, war dies unmittelbar mit der Initiative zu einem forcierten sozialen Wohnungsbau verbunden. Das Wahlkampfmotto der Sozialdemokraten: „Wir bauen das Land“, dem Text eines Lieds der Arbeiterbewegung entnommen, ${ }^{231}$ war ursprünglich ganz wörtlich gemeint. Durch die funktionalistische Konzeption des normierten Reihenhausbaus war das Versprechen menschenwürdiger Wohnverhältnisse für alle jetzt auch technisch einlösbar geworden. Das den Funktionalismus verkürzende schwedische Wort „funkis“ wurde bald populäres Alltagskürzel für alles, was funktionierte. ${ }^{232}$

är mål i våra dagars kulturliv har det aldrig varit någon tvekan om. Det är de trötta och pessimistiska, som påstår att vi håller på att skapa en maskinkultur, som är sitt eget ändamål."

226 S. Mårald, Synen på natur och miljö under den högindustriella epoken, in: Geijerstam (Hrsg.), Industriland, Tolv forskare om när sverige blev modernt, Stockholm 2008, S. $221 \mathrm{ff}$.

227 Asplund et al,Acceptera! (Fußn. 223), S. 16 (Übers. vom Verf.).

228 Asplund et al,Acceptera! (Fußn. 223 S. 16: „utvecklas eller bli betydelselösa.“ Die Einteilung fand wenig später Verwendung bei der rassenhygienischen Bewertung von A- und B-Menschen, s. mit Faksimiles der diversen Wettbewerbe in der Presse unter dem Motto: „Ist Dein Kind ein A-Kind oder ein B-Kind?“ Runcis, De som inte fick plats - att hålla måttet, in: Gejerstam (Hrsg.), Industriland, Tolv forskare om när Sverige blev modernt, Stockholm 2008, S. 101-120.

229 So nennt Schivelbusch, Entfernte Verwandte (Fußn. 211), S. 39, das Jahr 1933: ,in dem mit Ausnahme der Tschechoslowakei die meisten der nach dem I. Weltkrieg [...] gegründeten ostmitteleuropäischen Staaten autoritär-diktatorisch regiert wurden. Der italienische Faschismus feierte sein elfjähriges Jubiläum, und mit der nationalsozialistischen Machtergreifung erlitt die liberale Demokratie [...] ihre bedeutsamste Niederlage.“ Im gleichen Monat (März 1933) erfolgte der Amtsantritt Franklin D. Roosevelts und die Regierungsübernahme der Sozialdemokraten in Schweden.

$230 \mathrm{Zu}$ Hansson s. die dreibändige Biografie von Isaksson, Per Albin, Bd. I, Vägen mot folkhemmet, Stockholm 1985, II. Revolutionären, Stockholm 1990, und III. Partiledaren, Stockholm 1996.

231 „Vi är tusenden, som bygger landet [... ] nu bygger vi den nya tid...“, s. Hirdmann, Vi bygger landet, Den svenska arbetarrörelsens historia fråm Per Görtel till Olof Palme, Stockholm 1980.

232 Björk, Ett 30-tal, Minnesbilder, Stockholm 1984, S. 14, und ausführlich ders., Folkhemsbyggare, Stockholm 2008. 


\section{2. „Folkhem” und ,Volksgemeinschaft”}

„Folkhem“, das „Volksheim“ lässt (in deutschen Ohren) das verwandte Wort „Volksgemeinschaft“" anklingen. Auf inhaltliche Parallelen der beiden Begriffe ist auch seit den 1930er Jahren vielfach hingewiesen worden; aus heutiger Sicht fällt auf,

„dass Volksgemeinschaft und Volksheim strukturell ähnliche Begriffe sind, die in derselben Zeitperiode ihre entscheidende Prägung erfahren haben." 233

\section{a) In Schweden: „Folkhem“}

Das „folkhem“ 234 begann mit dem sozialen Wohnungsbau. Wie kam es zu einer derartigen politischen Konzentration auf den Bau von Wohnungen, dass „folkhem“ (Volksheim) ${ }^{235}$ zum Oberbegriff für den „Middle Way“236 Schwedens werden konnte? Dafür gibt es mehrere Gründe: Ein nicht zu unterschätzender kultureller Hintergrund war die in Schweden seit jeher „passionierte Beziehung“ zum Heim. ${ }^{237}$ Die in ihrer Zeit höchst einflussreiche Reformpädagogin (und spätere Reichstagsabgeordnete) Ellen $K e y,{ }^{238}$ deren umfangreiches Oeuvre stets sofort ins Deutsche übersetzt worden ist, predigte schon um die Jahrhundertwende engagiert, was man in den 1930er Jahren dann praktisch umsetzen wollte:

„Das am stärksten ,konstruktive’ Moment bei der Erziehung des Menschen ist die feste ruhige Ordnung des Hauses, sein Friede und seine Schönheit.“239

Dabei war in Wirklichkeit die Wohnungssituation im Vergleich etwa zu Deutschland erheblich schlechter, insbesondere Arbeiterwohnungen waren trotz relativ hoher Mieten meist nur Einraumwohnungen. Wohnungsbau war also an sich notwendig und politisch nicht kontrovers. ${ }^{240} \mathrm{Um}$ das ambitionierte Ziel politisch auch durchsetzen zu können,

233 Götz, Ungleiche Geschwister, Die Konstruktion von nationalsozialistischer Volksgemeinschaft und schwedischem Volksheim, Baden-Baden 2001, S. 15.

234 Das Wort ist nicht schwedischen Ursprungs, sondern wurde um 1860 in Norwegen geprägt, s. Götz, Ungleiche Geschwister (Fußn. 233), S. 206.

235 Auch zu diesem Begriff ist die internationale Literatur längst völlig unübersehbar geworden. Auf Deutsch s. statt vieler Götz, ebda.; Henze, Der schwedische Wohlfahrtsstaat (Fußn. 217), und Henningsen, Der Wohlfahrtsstaat Schweden (Fußn. 215).

236 Diese Wortschöpfung war ein ebenfalls „glücklicher Griff“, hier von Childs, Sweden, The Middle Way, London 1936, mit dem die Versuche einsetzten, das ominöse „schwedische Modell“ (meist von außen) zu analysieren; s. die Übersicht bei Henningsen, Der Wohlfahrtsstaat Schweden (Fußn. 217), S. 43 ff.

237 S. für die Zeit ab 1900 Björk/Kaijser, Svenska hem, En passionerad affair, Stockholm 2005, oder die Beiträge in Broberg/Wikander/Amark (Hrsg.), Bryta, bygga, bo, Stockholm 1994.

$238 \mathrm{Zu}$ dieser zuletzt Mann, Ellen Key, Ein Leben über die Pädagogik hinaus, Darmstadt 2004.

239 Key, Das Jahrhundert des Kindes, 7. Aufl. Berlin 1905, S. 163. Dieses Werk und noch fünf weitere (darunter Key's Briefwechsel mit Rilke, Frankfurt 1993) sind noch heute auf Deutsch erhältlich.

240 S. SOU (= Statens offentliga utredningar) 1933:14, Undersökning rörande behovet av en utvidgning av bostadsstatistiken jämte vissa därmed förbundna bostadfspolitiska frågor. (Verfasser u. a.: Åhrén 
änderten die Sozialdemokraten ihr Programm von einem „ideellen“ zu einem „pragmatischen" Sozialismus. Hirdmann weist dabei darauf hin, dass der Sozialismus zuvor auf die Arbeitswelt insbesondere in den Fabriken zielte, sich jetzt aber pragmatisch der Gestaltung des Wohnens im privaten Heim zuwandte. ${ }^{241}$ Aus Deutschland übernahm man die Faszination von der Idee, dass die „Gestaltung von Lebensvorgängen“ 242 durch „schrankenlose Integration und der Herstellung einer größtmöglichen solidarischen Öffentlichkeit“ 243 möglich sei. Vom neuen Leben möglichst vieler Menschen in den neuen funktionalistisch durchgeformten und normierten ${ }^{244}$ Häusern in begrünten Wohnanlagen erhoffte man sich, konfliktfrei da unbemerkt „sozialistische Lebensformen in die kapitalistische Gesellschaft einzuschmuggeln". 245 Insofern war der pragmatische Kurs der Sozialdemokraten, das „Leben im kleinen zurecht zu legen“, auch ein Wiederaufgreifen vormarxistisch utopischer Gedanken, radikale gesellschaftliche Veränderung durch Planung des Alltagslebens zu erreichen.

Die Sozialdemokraten hatten schon in der Opposition eine neue Wirtschaftspolitik eingefordert: Gerade angesichts der weltweiten Wirtschaftskrise sollte der Staat nicht sparen, sondern ein kraftvoller Akteur sein, um die Volkswirtschaft voranzubringen. Schweden war bald das erste Land, das eine Wirtschafts- und Sozialpolitik nach den Theorien von Keynes in die Praxis umsetzte, noch bevor diese formuliert waren. ${ }^{246}$ Insbesondere die Wirtschaftspolitik war durchweg in hohem Grad wissenschaftlich begründet ${ }^{247}$ und „on more than a tentative trial and error basis“. 248 Die Sozialdemokraten wurden in den 30er Jahren

und Myrdal); SOU 1935:2 Bostadssociala utredningen. Zum etwa zeitgleichen deutschen Ansatz, u. a. auch über Genossenschaften den Wohnungsbau zu fördern, s. Rudloff, Die Wohlfahrtsstadt (Fußn. 125), Kap. X: Öffentliche Bauprogramme (Teilband II S. 769 ff), zum „Gemeindebau“ in Wien s. reich dokumentiert Riedl, Jüdisches Museum (Hrsg.), Wien, Stadt der Juden, Wien 2004.

241 Hirdmann, Att lägga livet till rätta - studier i svensk folkhemspolitik, Stockholm 1989, S. 96; s. a. Lundberg/Amark, Social Rights and Social Security: The Swedish Welfare State, 1900-2000, Scandinavian Journal of History Vol. 26 (2001), S. 157-176, insbes. S. 160 ff.: Building the peoples' home 1932-1950.

242 Mattson/Wallenstein, Swedish Modernism at the Crossrads (Fußn. 213), S. 2.

243 Kuchenbuch, Gläserne Stadt - Gläserner Mensch (Fußn. 223), S. 3.

244 Zur Industrialisierung des Bauens (Gropius) s. Scheiffele, Bauhaus (Fußn. 199), S. 124 ff., Rudberg, Vardagens Utopi (Fußn. 220), S. 159 ff., und zum 50jährigen Jubiläum der Errichtung des ersten Reihenhauses 1936 in Stockholms Vorort Hjorthagen das Sonderheft der Zeitschrift Arkitektur, Heft 4/1986.

245 Hirdmann, Att lägga livet till rätta (Fußn. 241), S. 96: ,att smuggla in socialistiska former i det kapitalistiska samhället..." Larsson/Schulz, Befolkningen (Fußn. 221), weisen daraufhin, dass die sozialistisch geprägte Mieterbewegung in den neuen Miethäusern auch kulturell wirkte, Büchereien einrichtete, bei der Wohnungseinrichtung künstlerisch beriet, Hygiene propagierte, Gartenfeste veranstaltete etc.

246 Keynes, The General Theory of Employment, Interest and Money, erschien erst 1936, im gleichen Jahr wie Wicksell, Interest and Price.

247 Dies besorgte die einflussreiche sog. „Stockholm Schule”, zu der Gunnar Myrdal, Bertil Ohlin, Dag Hammarskjöld u. a. gehörten, alle beeinflusst von den Theorien des Ökonomen und Sozialreformers Knut Wiksell; zu diesem s. Samuelson, Wicksell's Werk und Persönlichkeit, Düsseldorf 1988, und 
,the first socialist party in the world to be able to increase gradually the power of the state in economic life without revolution or large-scale nationalization." 249

Für den sozialdemokratisch regierten Staat stand wirtschafts- und sozialpolitisch die Bekämpfung der Arbeitslosigkeit im Vordergrund. ${ }^{250}$ Daneben dominierte für die ,neue Art Politiker, die Sozialingenieure“ 251 der Ansatz am privaten Heim, um dadurch ein dem privaten übergeordnetes ,Volksheim“ für das ganze Volk zu schaffen:

„So wurden Politiker zu Architekten und Architekten zu Politikern und für beide galt der "wissenschaftliche Imperativ." 252

Ein bis heute beeindruckendes Beispiel der spezifisch schwedischen Ambivalenz dieses Zusammenwirkens ist das 1932 fertig gestellte Verwaltungsgebäude der (damaligen) Unfallversicherung. Der funktionalistische Rundbau wird international bewundert. Praktiker der deutschen Sozialversicherung heben hervor:

„Die großen Arbeitsräume liegen sämtlich nach den Lichtseiten des Innenhofes. Akten-
aufzüge sind auf den gleichen Arbeitsrhythmus eingestellt und arbeiten in einer Art selb-
ständig laufenden Bandes. [...] Der Rundbau ist im Inneren des Gebäudes vollkommen
geschlossen. Die Arbeitstische liegen in der Regel unmittelbar bei den Fenstern. Mit we-
nigen Blicken kann sich der Chef des Hauses über die Besetzung der Arbeitsstätten unter-
richten und so eine beinahe völlige Kontrolle über das ganze Haus ausüben.“ 253

Das Engagement der Sozialingenieure machte aber nicht bei perfekt (kontrollierbaren) funktionalistischen Arbeitsabläufen halt. Man glaubte daran, wissenschaftlich herausarbeiten zu können, welche Operationen der Gesamtgesellschaft sozial notwendig sind, und man glaubte auch daran, dass diese Operationen mit einem funktionalistischen Instrumentarium auch erfolgreich durchgeführt werden können:

Steiger, Studien zur Entstehung der neuen Wirtschaftslehre in Schweden, Berlin 1977; zu Wicksell's Einfluss auf die Wirtschafttheorie im Norden während der 1930er Jahre s. Andvig, Wicksells Influence on Frisch's Macroeconomics in the Thirties, The Scandinavian Journal of Economics Vol. 80, No. 2, S. 148-167.

248 So Childs, The Middle Way on Trial, Yale 1980, S.18; s. a. Esping-Andersen, Jämlikhet, effektivitet och makt, Socialdemokratisk välfärdpolitik, in: Misgeld u. a. (Hrsg.), Socialdemokratins samhälle, SAP och Sverige under 100 År., Stockholm 1988.

249 Koblik (Hrsg.), Sweden's Development from Poverty to Affluence, 1750-1970, Ontario 1975, S. xii.

250 So im Rückblick Möller, De planerade socialreformerna, Tiden, Stockholm 1946, inbes. S. 70 ff., und Therborn, Arbetarrörelsen och välfärdstaten, Lund, Arkiv nr. 41-42.

251 Hirdmann, Att lägga livet till rätta (Fußn. 241), S. 11 ff. Die Autorin diskutiert hier auch den Begriff „Sozialingenieur“. Sie weist (unter Verweis auf McClymer, War and Welfare, Social Engineering in America 1890-1925, New York 1980) die Herkunft des Wortes aus den USA nach, inhaltlich differenziert sie den ,svensk socialingenjör“ aber wegen dessen engerer Relation zum Staat.

252 Hirdmann, ebda., S. 101.

253 S. den Bericht (mit Bild und Grundriss): Neuzeitliche Bauformen eines Verwaltungsgebäudes, in: Die Reichsversicherung 7. Jg. 1933, Heft 10/11, S. 339-341; die deutschen Besucher weiter: „Das Gebäude kann beim Haupteingang vor Beginn der Bürozeit betreten werden. Danach sind diese $\mathrm{Zu}-$ gänge in der Regel versperrt und es bleibt nur ein Zugang auf dem anderen Ende des Innenhofs. Jeder verspätete Angestellte [...] ist während des Durchgangs der Beobachtung von den Arbeitssälen aus freigestellt. Zuspätkommen der Angestellten soll es in diesem Verwaltungsgebäude nicht geben." 
„The social engineer does not ask any questions about historical tendencies or the destiny of man. He believes that man is the master of his own destiny and that, in accordance with our aims, we can influence or change the history of man just as we have changed the face of the earth." 254

Damit wird neben dem Reichstag und der Verwaltung die Autorität von Experten installiert, deren Kompetenz und Berechtigung zur Inspektion und Kontrolle gesellschaftlicher Mangellagen als quasi überparteiliche erst einmal außer Zweifel steht ${ }^{255}$ und von Regierung und Verwaltung auch bei der Bestimmung und Umsetzung sozialpolitischer Ziele ganz selbstverständlich eingesetzt wird.

\section{b) In Deutschland: „Volksgemeinschaft“}

Im Wort „Volksgemeinschaft“ steckt, wenngleich extrem komprimiert, ein wesentlicher Teil der deutschen Geschichte des 20. Jahrhunderts. Geht man dem Inhalt der beiden Teile dieses „Doppelworts“ nach, so führt die Zeitreise noch viel weiter zurück. ${ }^{256}$ Deshalb muss hier genügen, darauf zu verweisen, dass „Volksgemeinschaft“ erst ein „Schlüsselbegriff der Weimarer Republik“ war und dann ausgeweitet wurde zu einem „Universalbegriff im Nationalsozialismus“. 257

In der oben erwähnten Atmosphäre der Daseinsangst war die ungeliebte Weimarer Republik für weite Teile der Menschen in Deutschland kein Staat, der dieser Angst hätte abhelfen können. Der von Tönnies viel früher formulierte Gegensatz von „Gemeinschaft und Gesellschaft" ${ }^{258}$ wurde jetzt geradezu sprichwörtlich für die auf das „Hauptübel der deutschen Nationalgeschichte, der ,Zerrissenheit'“259 zurückgeführten Gegensätze, etwa dem von „Parteienstaat" und „Volksgemeinschaft“.

Die Nationalsozialisten versuchten dann auch, den Begriff „Volksgemeinschaft“ im Zuge der „Umwertung aller Werte“ als in der Idee des Führertums enthalten zu usurpie-

254 Popper, The Open Society and It's Enemies, I. The Spell of Plato, London 1944, S. 22; Hirdmann, Att lägga livet till rätta (Fußn. 241), S. 101, nennt Poppers Definition des Sozialingenieurs kongruent mit der Selbstbeschreibung der socialingenjöre in Schweden: „Mit anderen Worten, Popper und Gunnar und Alva Myrdal können der gleichen Kategorie zugerechnet werden.” (S. 12).

255 Kuchenbuch, Gläserne Stadt - Gläserner Mensch (Fußn. 223), Teil 1, S. 10.

256 S. Götz, Ungleiche Geschwister (Fußn. 233), S. 63 ff.: „Das Chaos der Begriffsverwendung“; dort auch eine etymologische Analyse von „Volk“ versus (s) „folk“ und „Gemeinschaft“ versus (s) ,gemenskapen“. Historisch noch weiter führt Koselleck, Volk, Nation, Nationalismus, Masse, in: Brunner/Conze/Koselleck (Hrsg.), Deutsche Verwaltungsgeschichte Bd. 7, Stuttgart 1992, S. 141-431. Aktuell hebt Baumann, Gemeinschaften. Auf der Suche nach Sicherheiten in einer bedrohlichen Welt. Frankfurt/Main 2009 (in der engl. Originalfassung 2001 steht der Singular: „Community“), wieder das Sicherheitsgefühl hervor, das mit dem Privileg, in einer Gemeinschaft leben zu dürfen, entsteht, das aber notwendig einen Preis hat, den Verzicht auf Freiheit.

257 Götz, Ungleiche Geschwister (Fußn. 233), S. 83, resp. S. 110; Süß/S̈̈ß $\beta$, Volksgemeinschaft“ und Vernichtungskrieg, in: Dies. (Hrsg.), Das „Dritte Reich“, Eine Einführung, München 2008, S. 7883.

258 Toennies, Gemeinschaft und Gesellschaft, Leipzig 1878.

259 Stolleis, Geschichte des öffentlichen Rechts in Deutschland (Fußn. 141), S. 108. 
ren. ${ }^{260}$ Tatsächlich wurde der Begriff aber wohl mehr als „überzeugungsstiftende Beschwörungsformel“"261 eingesetzt,

„ein zumeist handlungsleitender [...] Kollektivsingular, dessen Nutzen es durch organisatorische Maßnahmen, insbesondere durch eine zweckentsprechende Gestaltung von Staat und Politik durch die Inpflichtnahme des Einzelnen zu maximieren galt."262

Wegen der inhaltlichen Unbestimmtheit hatte der Appell an die „Volksgemeinschaft“ erhebliche Mobilisierungskraft. Denn wegen der allem übergeordneten Projektion der „Volksgemeinschaft“ in den Wertehimmel konnten sich im Nationalsozialismus auch alle heimisch fühlen: Innerhalb der jetzt nationalsozialistischen Volksgemeinschaft konnte man Bürger sein, Bauer oder Arbeiter. Man konnte radikal sein, nationalistisch oder sozialistisch, alle, die dazu gehörten, waren „mit neuer Identität im neu geborenen Deutschland in einem 1000jährigen Reich." 263 Insbesondere wegen der darin auch enthaltenen (und propagandistisch ebenso gern wie unverbindlich bedienten) sozialromantischen Sehnsüchte, lag in der Bezugnahme auf die „Volksgemeinschaft“ in allen Politikbereichen eine Möglichkeit, das Fehlen rationaler Argumente zu verschleiern. So auch im Recht und in der Rechtswissenschaft. „Gemeinschaftszwecke“ oder die Belange der „Volksgemeinschaft als Geltungsgrund, unübersteigbarer Schranke und letztem Ziel [...] der gesamten Verwaltungstätigkeit" 264 wurden zum obersten Wert allen staatlichen Lebens, ${ }^{265}$ zu gewichtigen Gründen bei der Gesetzesauslegung und beim Verwaltungshandeln. ${ }^{266} \mathrm{Im}$ Staatsrecht galt:

260 Reinhardt, Vom Wesen der Volksgemeinschaft, Grundlagen, Aufbau und Wirtschaftsordnung des nationalsozialistischen Staates, Bd. I, Berlin 1936, ausführlich zitiert bei Götz (Fußn. 233), S. 110; Majer, „Fremdvölkisches“ im Dritten Reich, Boppard 1981, S. 82 ff.: Das Prinzip der ,,völkischen Ungleichheit“ (Sonderrecht) - „Volksgemeinschaft“ als Grundlage der ,völkischen Gleichheit“.

261 Koselleck, in: Brunner/Conze/Koselleck, Deutsche Verwaltungsgeschichte (Fußn. 244), S. 419.

262 Götz, Ungleiche Geschwister (Fußn. 233), S. 112; aufgrund einer Analyse des Vorkommens des Begriffs in Hitlers Mein Kampf. Götz weist auch nach, dass Hitler das Wort „Volksgemeinschaft“ schon mindestens seit 1920 in Wahlkampfreden verwendet hat (S. 111).

263 Thörn, Rörelser i det moderna, Politik, modernitet och kollektiv identitet i Europa 1789-1989, Stockholm 1997, S. 221. Süß/Süß, in: dies., (Hrsg.), Das „Dritte Reich“ (Fußn. 257), S. 79: „es geht um völkische Versprechen und ihre soziale Wirklichkeit, um die Ambivalenz von Teilhabe und Ausgrenzung im Zeichen von Rassismus und Vernichtungspolitik an der ,inneren Front' des ,Dritten Reiches." "

264 S. die Beiträge in Jeserich/Pohl/v. Unruh (Hrsg.), Deutsche Verwaltungsgeschichte Bd. 4, Stuttgart 1985, Teil 2: Die Zeit des Nationalsozialismus, darin Stolleis, II. Kap. I. 1.:,,Der ,Umbruch’ des Jahres 1933 “(S. 708).

265 Majer, „Fremdvölkisches“ im Dritten Reich (Fußn. 260), S. 83; Zitat Scheuner, Der Gleichheitsgedanke in der völkischen Verfassungsordnung, ZStW 1939, S. 255; für das Strafrecht wies Ogorek, „Rassenschande“ und juristische Methode, Die argumentative Grammatik des Reichsgerichts bei der Anwendung des Blutschutzgesetzes von 1935, in: Dies., Aufklärung über Justiz, 1. Halbband, Frankfurt/Main 2008, S. 287-310, nach, dass das Reichsgericht mit „ausnahmsloser Konsequenz (...) im Bereich des Blutschutzgesetzes alle strafrechtsdogmatischen Limitierungen mühelos in der Entgrenzungssemantik der nationalsozialistischen Ideologie aufgehen ließ““ (S. 310).

266 Rüthers, Die unbegrenzte Auslegung, Heidelberg 1991; Stolleis, Gemeinwohlformen im nationalsozialistischen Recht (Fußn. 152), S. 234 ff. 
„An Stelle des individualistischen Prinzips ist heute ein anderes getreten, das Prinzip der Gemeinschaft. Nicht mehr die juristische Staatsperson ist Grund- und Eckstein des Staatsrechts, sondern die Volksgemeinschaft ist der neue Ausgangspunkt." ${ }^{\text {267 }}$

Das Zitat macht einen wesentlichen Unterschied zwischen den so gleich klingenden Wortbildungen „Volksheim“" und „Volksgemeinschaft“ deutlich. Geht es in Schweden (keineswegs den Sozialdemokraten allein) darum, das unwürdige Dasein der unteren Schichten der Gesellschaft in Armut und mangelnder Bildung zu überwinden und allen Menschen (auch den davon nicht so begeisterten) zu einem ,anständigen Leben“ zu verhelfen,

„... es wird allzu leicht vergessen, dass Armut in den nordischen Ländern lange weit verbreitet war und dass der Kampf für ein Existenzminimum auch für ein im einfachsten Sinn anständiges Leben lange Zeit sehr hart war.“268

so wurde im Nazi-Deutschland der 1930er Jahre ,Volksgemeinschaft" im schlimmsten Sinne zum Schlagwort: Es diente zur nach Belieben der Machthaber anwendbaren Begründung für die Eingrenzung der „Volksgenossen“ und der Ausgrenzung der anderen:

„Von den ersten Stunden der nationalsozialistischen Herrschaft an wurde die Inlandgesellschaft gespalten: In Eingeschlossene und Ausgeschlossene. [...] Der Einschluss hieß ,Volksgemeinschaft"“269

\section{Vorbeugende Daseinsvorsorge: Volksgesundheit und Homogenität des Volkes}

Mit den Fortschritten der Naturwissenschaften im 19. Jahrhundert ging lange Zeit auch der Glaube einher, dass sich eines Tages alle Probleme naturwissenschaftlich würden lösen lassen. ${ }^{270}$ Diesem Fortschrittsglauben unterlagen auch Wissenschaftler wie der englische Mathematiker Francis Galton, 271 ein Vetter Darwins, dessen Evolutions-

267 Höhn, Vom Wesen der Gemeinschaft, Berlin 1934, zitiert bei Stolleis, Geschichte des öffentlichen Rechts in Deutschland (Fußn. 141), S. 327.

268 Amark, Trygghet och tvång - två teman i aktuell nordisk välfärdsstatshistorisk forskning, in: Arkiv nr. 91 2004, S. 1-18 (17): „Det är lätt att glömma bort att fattigdomen länger var utbredd i de nordiska länder och att kampen för existensminimum och för ett i den enklaste meninegn anständigt liv länge varit hård (...)" (Übers. vom Verf.); s. a. Ambjörnsson, Den skötsame arbetaren. Idéer och ideal i ett norrländskt sågverkssamhälle 1880-1930, Stockholm 1989.

269 Zacher, Deutschland den Deutschen?, Die wechselvolle Geschichte des sozialen Einschlusses im Deutschland des 19. und 20. Jahrhunderts, Stimmen der Zeit Bd. 221, Heft 4 April 2003, S. 233 ff. (241).

270 Dieser Fortschrittsglaube hatte schon damals seine düsteren Seiten, s. den 1818 erschienenen ersten „Science Fiction“-Roman von Wollstonecraft-Shelley, Frankenstein: The Modern Prometheus.

271 In diesem Zusammenhang zu nennen: Galton, Natural Inheritance, London 1889; zu Galton s. Schmitt, Francis Galton, Menschenproduktion zwischen Technik und Fiktion, in: KaupenHaas/Saller (Hrsg.), Wissenschaftlicher Rassismus: Analysen einer Kontinuität in den Human- und Naturwissenschaften, Frankfurt/Main 1999, S. 327-345, zu dessen historischer „Fernwirkung“ s. 
theorie er bekämpfte. Galton prägte den Begriff ,eugenics“ für die von ihm begründete "Science of human improvement", dem Versuch, der Sozialpolitik eine biologische Grundlage zu geben. Er zielte damit auf

,a society that recognized inherited ability, so that social affairs were to be managed by an expert elite." 272

Sein doppelter Ansatz, dabei nicht nur Erbkrankheiten auszumerzen, sondern auch positiv auf die Gesellschaft einzuwirken, etwa durch Schulspeisung und Schulhygiene für alle Kinder, ${ }^{273}$ liest sich wie eine Vorwegnahme des funktionalistischen Ansatzes der Sozialingenieure. Seine Gedanken fanden im Übrigen in Schweden weite Verbreitung durch Key, für die „Veredelung der Rasse“ eine wissenschaftlich begründete $\mathrm{Zu}$ kunftshoffnung war:

„Galton, der aus einem griechischen Worte einen Namen für die Wissenschaft von der

Veredelung der Rasse geschaffen hat, ,eugenics' (...)“274

„Eugenics“ war nur eine der Reaktionen darauf, dass das uralte Wissen von der Ungleichheit der Menschen nunmehr statistisch (wissenschaftlich) erfassbar und damit „objektiv“ bewertbar geworden war. So begannen die privaten Lebensversicherungen ${ }^{275}$ versicherungsmathematisch wertfrei, ${ }^{276}$ den Abschluss von Verträgen für „,minderwertige Leben“" abzulehnen. In der Fachliteratur war dieser Rückzug -nicht das Wort vom minderwertigen Leben!- umstritten: Empfohlen wurde demgegenüber, die ökonomische und sozialpolitische Seite des Problems zu überwinden:

„Wenn es wünschenswert erscheint, dass die Versicherung Abnormer möglichst sich ausdehne und sich insbesondere auch auf die stärkeren Grade der Minderwertigkeit miterstrecke, so muss man sich die Frage vorlegen, wie die Kosten einer solchen Versicherung möglichst gemindert werden können, ohne dass doch die Solvenz der Gesellschaft dabei gefährdet wird.“277

Weindling, International Eugenics: Swedish Sterilization in Context, Scandinavian Journal of History Vol. 24:2, 1999, S. 179-197 (181).

272 Weindling, ebda., S. 181.

273 Ders., ebda., S. 182, unter Bezug auf Cowan, Nature and Nurture: the Interplay of Biology and Politics in the Thought of Francis Galton, in: Studies in the History of Biology Vol. 1, 1977, S. 133208.

274 Key, Das Jahrhundert des Kindes (Fußn. 239), S. 19; Zaremba, De rena och de andra, Om tvångssterilisering, rashygien och arvsynd, Stockholm 1999, S. 52, nennt den ersten Teil des Werkes von Key mit guten Gründen ein „Manifest der Rassenhygiene”.

$275 \mathrm{Zu}$ deren Rolle bei der Entstehung von Sozialversicherung s. Maurer, Bedingungen für die Entstehung und Entwicklung von Sozialversicherung: Zusammenhänge mit der Entwicklung der Privatversicherung, in: Zacher (Hrsg.), Bedingungen für die Entstehung und Entwicklung von Sozialversicherung. Berlin 1979, S. 355-384.

276 Blaschke, Denkschrift zur Lösung des Problems der Versicherung minderwertiger Leben, Wien 1895, führt gewissermaßen beruhigend aus, ,dass die hereditäre Veranlagung im allgemeinen für den Versicherer die geringste Gefahr und zwar eine geringere Gefahr, als die Disposition zu oder die Erkrankung an irgendeiner Todesursache bilde“ (S. 34), zitiert bei Kehm, Über die Versicherung minderwertiger Leben. Staatswissenschaftliche Studien Bd. 6, Jena 1897, S. 62.

277 Kehm, ebda., S. 63. 
Es galt also nicht zuletzt, Vorsorge auch für die Solvenz der Gesellschaft zu treffen. Dazu wurden Wahrscheinlichkeitsrechnungen nach Maßgabe der insbesondere in England weit entwickelten ,Sterbetafeln“ empfohlen, ${ }^{278}$ aber (im wohlverstandenen Eigeninteresse) auch an die sozialpolitische Verantwortung des Staates erinnert:

„... wenn ein Eingriff des Staates überhaupt wünschenswert erschiene, [könnte] nur eine

Form desselben in Frage kommen: die Errichtung einer oder mehrerer staatlicher Monopolanstalten für abnorme Leben mit freiem Beitritt..."279

Ökonomisch vernünftiger als die Versicherung musste, da in den Augen der Zeitgenossen so vieles wissenschaftlich machbar wurde, aber die Beseitigung der Ursachen der Herausbildung „minderwertiger Leben“ erscheinen.

\section{a) Der Ansatz der ,Sozialingenieure“}

\section{(1) Die Myrdals}

1932 erschien in der radikalen Zeitschrift „Spektrum“ Gunnar Myrdals Aufsatz „Socialpolitikens dilemma“, 280 in dem er für eine eigentlich unlösbare Situation ${ }^{281}$ dennoch gleich eine Lösung anbot: Dabei baute er auf der Prämisse auf, „dass alle ,eigentlich' ein Recht darauf hätten, gleich gut zu leben.“282 Da eine Gesellschaft mit großen Klassenunterschieden nicht ,vernünftig funktionieren kann“ (,kan helt enkelt inte fungera förnuftigt"), hat man in einer vernünftigen Gesellschaft gegen Armut, Kriminalität und andere Verwerfungen vorzusorgen (,,forebygga och förhindra“) und der Weg dazu ist eine „prophylaktisch vorbeugende Sozialpolitik“ (,profylaktisk-förebyggande socialpolitik"). Es gelte, die immer nur ,nachbessernde“ Sozialpolitik zu überwinden, einzugreifen, bevor es zu sozialen Schäden kommt, „radikal“, also an den Wurzeln des Übels anzusetzen. ${ }^{283}$

278 Ders, ebda., führt die bereits erstaunlich vollständigen, die Gesamtbevölkerung erfassenden englischen Statistiken über Todesursachen und altersbezogener Sterbewahrscheinlichkeit an. Versicherungsgeschichtlich wird bestätigt: „Die Industrielle Revolution war ein englisches Ereignis. Marktwirtschaft, Freihandel und Goldstandard waren englische Erfindungen.“ Polanyi, The Great Transformation, Politische und ökonomische Ursprünge von Gesellschaften und Wirtschaftssystemen, Frankfurt/Main 1978, S. 55 (Engl. Originalausgabe 1944).

279 Kehm, Über die Versicherung (Fußn. 276), S. 72.

280 Spektrum 2/1932 und 4/1932, ausführlich zitiert bei Hirdmann, Det tänkande hjärtat, Boken om Alva Myrdal, Stockholm 2006, S. 187 ff. Zu Myrdals frühen Schriften s. Nilsson, Den sociala ingenjörskonstens problematik, En orättfärdig dissektion av den unge Gunnar Myrdal, in: Nilsson, Den lycklige humanisten, Tio offensiva essäer, Stockholm 1990, S. 19-47.

281 Dilemma, aus griech. $\delta \imath \lambda \varepsilon \mu \mu \alpha=$ Doppelfang, Zwiegriff, bezeichnet eine insofern ausweglose Situation, als zwei Wahlmöglichkeiten, von denen eine ergriffen werden muss, jede zu einem unerwünschten Resultat führen. Zum logischen und moralischen Dilemma s. Honderich (Hrsg.), Philosophy, Oxford 1995, Lemma: dilemma.

282 „alla ha ,egentligen’ rätt att liva lika bra”, s. Hirdmann, Det tänkande hjärtat (Fußn. 280), S. 187.

283 Hirdmann, ebda., S. 187: „Det är att ingripa radikalt. Dra upp met roten.” 
1934 erschien dann das Buch, das eine ganze Epoche prägen sollte, das von den Myrdals gemeinsam geschriebene „Kris i befolkningsfrågan”. ${ }^{284}$ Es handelte sich um ein soziologisches Porträt des schwedischen Volkes, über 320 Seiten Text, belegt mit Ziffern, Tabellen und Fakten. Beschrieben wurde ein kinderloses Volk, das daran sei, auszusterben, wenn nicht schnell Hilfe geleistet würde. Aus dem „Dilemma“ war eine „Krise“ geworden und, kein Zweifel möglich: „Krise“ verlangt nach sofortigem Handeln. ${ }^{285}$ Die dafür ausgebreiteten sozialpolitischen Maßnahmen lassen sich in drei Gruppen teilen, ${ }^{286}$ nämlich Maßnahmen zur Unterstützung für die Väter, Hilfen für die Mütter und „prophylaktische“ Sozialpolitik:

„Den profylaktiska socialpolitikens direkta uppgift är att framskapa ett bättre människomaterial.“287

Trotz dieser befremdlichen Wortwahl (,Menschenmaterial“) geht es nicht (unmittelbar) um Eugenik, „Rassenhygiene“ oder gar Rassismus - die Myrdals sind zuvörderst Ökonomen und Soziologen, die an der Annahme gesellschaftlicher Ursachen sozialer Schäden festhalten:

„Wenn Neger in Amerika oder Juden in Polen im Durchschnitt gewisse Rassencharakteristika in ihrem Handeln zeigen, erklärt sich das vor allem daraus, dass sie seit der Kindheit gestempelt wurden, behandelt und gezwungen, genau wie Neger in Amerika und Juden in Polen zu reagieren." 288

Sie grenzen sich ausdrücklich von der politischen „ras- och klassbarbari” (Rassenund Klassenbarbarei) ab, die sie in Deutschland (schon vor 1934!) beobachten und führen diese „spekulativen biologischen Ramschladenweisheiten in sozialen Fragen“ darauf zurück, dass

„dieses unglückliche Land seit zwei Generationen fast ganz auf eine kritische sozialwissenschaftliche Forschung internationalen Standards hat verzichten müssen“.289

284 Alva \& Gunnar Myrdal, Kris i befolkningsfrågan, Stockholm 1934, im folgenden zitiert nach dem Nachdruck, Falun 1997.

285 Hirdmann, Det tänkande hjärtat (Fußn. 280), S. 191: „Das Wort Krise erzeugt den Eindruck, dass es nun zu handeln gilt. Keine Zweifel, kein ,parlamentieren'“. Zu dieser „Botschaft“ des Wortes s. Koselleck, Some Questions Concerning the Conceptual History of „Crisis“, in: Witoszek/Trädgårdh (Hrsg.), Culture and Crisis, The Case of Germany and Sweden, New York/Oxford 2002, S. 13: „'Crisis' belongs among those fundamental concepts of the Greek Language for which there are no substitutes. Derived from 'krino' - to separate [...] 'crisis' tended to indicate a final, irrevocable decision."

286 Hirdmann, Det tänkande hjärtat (Fußn. 280), S. 193 ff.: „Bistå pappa [...] bistå mamma [...] fler barn - av högre kvalitet" (= mehr Kinder von höherer Qualität).

287 Myrdal, Kris i befolkningsfrågan (Fußn. 284), S. 205: „Die direkte Aufgabe der prophylaktischen Sozialpolitik ist es, besseres Menschenmaterial hervorzubringen” (Übers. v. Verf.).

288 Dies., ebda., S. 76: „Om negrer i Amerika eller judar i Polen ådagaläggar vissa genomsnittliga raskaraktäristika i sin handlingar, förklaras det framför allt därigenom, att de sedan barndomen stämplats, behandlats och tvungits att reagera just som negrer i Amerika eller judar i Polen.”

289 Dies., ebda., S. 78: „Till nazismens förhistoria hör även, att detta olyckliga land under två generationer nära nog saknat en kritisk socialvetenskaplig forskning på internationell standard.” 


\section{(2) Die Stockholm-Ausstellung 1930}

Wenn Verhaltensunterschiede milieubedingt sind, so die Soziologen, kann man die „Qualität der Masse der Bevölkerung durch Veränderung des Milieus für einzelne Individuen verbessern. Sind sie aber von Natur aus erblich, sind die Möglichkeiten begrenzt". 290

Für die Zeitgenossen in ganz Europa und den USA gab es aber unbegrenzte Möglichkeiten und zwar sogar auf vermeintlich wissenschaftlicher Basis: ${ }^{291}$ Gleichzeitig, im Jahr 1905, wurde in London am University College das Francis Galton „Laboratory for the Study of National Eugenics“ gegründet und die „Internationale Gesellschaft für Rassenhygiene“ in Berlin, 1927 dann das Kaiser Wilhelm Institut für Anthropologie, Erbkunde und Eugenik. ${ }^{292}$ Weitere wissenschaftliche Institute wurden eingerichtet - u.a. 1906 in Norwegen, 1910 in New York, 1921 in Leningrad, 1938 in Kopenhagen und 1922 in Uppsala.293 In diesem letztgenannten Institut arbeiteten international führende Wissenschaftler, die auch eine Abteilung in der „Stockholm-Ausstellung“ unter dem Titel „Svea Rike“, das „Reich Schweden“ mit Parolen von Blut, Boden und Rasse als lebensspendende Kräfte ausrichteten. ${ }^{294}$ In den 1930er Jahren vermischten sich also auch in Schweden nationales mit nationalistischem und dieses dann mit rassenbiologischem Denken. 295 Recht als Teil der Kultur konnte davon nicht frei bleiben.

290 Dies., ebda., S. 66: „Äro de åter av ärftlig natur äro möjligheter mera begränsade”.

291 „Im historischen Rückblick [...] wurde die Rassenforschung geradezu zum Inbegriff von Pseudowissenschaft.“ So Lipphardt, Das „schwarze Schaf“ der Biowissenschaften, Marginalisierung und Rehabilitierungen der Rassenbiologie im 20. Jahrhundert, in: Rupnow u. a. (Hrsg.), Pseudowissenschaft. Konzeptionen von Nichtwissenschaftlichkeit in der Wissenschaftsgeschichte. Frankfurt/Main 2008, S. 223-250; im gleichen Band auch die Beiträge von Schleiermacher/Schagen, Medizinische Forschung als Pseudowissenschaft (S. 251-278), und Rupnow, „Pseudowissenschaft“ als Argument und Ausrede, Antijüdische Wissenschaft im „Dritten Reich“ und ihre Nachgeschichte (S. 279-307).

$292 \mathrm{Zu}$ diesem s. Schmuhl (Hrsg.), Rassenforschung an Kaiser-Wilhelm-Instituten vor und nach 1933, Göttingen 2003, darin insbes. Massin, Rasse und Vererbung als Beruf, Die Hauptforschungsrichtungen am KWI für Anthropologie, menschliche Erblehre und Eugenik im Nationalsozialismus, S. 190-244; Weindling, Weimar Eugenics, The Kaiser Wilhelm Institute for Anthropology, Human Heredity and Eugenics in Social Context, in: Annals of Science 42/1985, S. 303-318.

293 S. die vollständige Aufzählung bei Weindling (Fußn. 271), S. 185; zur Entwicklung in den USA s. Dowbiggin, Keeping America Sane: Psychiatry and Eugenics in the United States and Canada 18801940, Ithaca 2003, und Black, War against the Weak, Eugenics and America's Campaign to Create a Master Race, Four Walls 2003; Finzsch, Wissenschaftlicher Rassismus in den Vereinigten Staaten, in: Kaupen-Haas/Saller (Hrsg.), Wissenschaftlicher Rassismus (Fußn. 271), S. 84-110; zum Institut in Uppsala, wo Rassenhygiene erstmals als staatlich anerkannte Wissenschaft betrieben wurde, s. Broberg, Statlig ras forskning, En historisk över Rasbiologiska institutet, Lund 1995, und Zarem$b a$, De rena och de andra (Fußn. 274), S. 78 ff.

294 S. Almgren, Illusion und Wirklichkeit, Individuelle und kollektive Denkmuster in nationalsozialistischer Kulturpolitik und Germanistik in Schweden 1928-1945, Stockholm 2001, S. 69-70.

295 Trädgårdh, Crisis and the Politics of National Community, Germany and Sweden 1933/1994, in: Culture and Crisis, S. 75 ff., insbes. S. 80 ff.: The Swedish Social Democrats and the Turn towards a National Socialism. 


\section{(3) Die Sterilisierungsgesetze von 1934 und 1941}

Dieser Zeitgeist entwickelte sich auch in Schweden nicht über Nacht: So wurden staatliche Zuschüsse zur Anstaltsunterbringung von Geistesschwachen schon mit Gesetz 1897:50 geregelt, ein Eheverbot aus Gesundheitsgründen erging 1915 (Lag 1915:426) und in Örebro wurde 1931 die erste staatliche Anstalt zur Unterbringung von Geisteskranken errichtet. ${ }^{296}$ Bei der Begründung des Immigrationsgesetzes von 1927 durch die liberale Regierung kommt rassistisches Denken dann wie ganz selbstverständlich zum Ausdruck:

„Die großen Schwierigkeiten, mit denen Länder mit gemischten Volkselementen kämp-
fen, haben diese Frage [i. e. der, Rassengesichtspunkt”] in hohem Maße aktualisiert. Daß
die Bevölkerung unseres Landes aus einer besonders einheitlichen, unvermischten Rasse
besteht, ist nicht hoch genug einzuschätzen.“297

Im Januar 1935 trat schließlich das Sterilisierungsgesetz ${ }^{298}$ in Kraft. Nach dessen $\S 1$

\section{S. 1 konnte}

„bei begründeter Annahme, dass jemand an Geisteskrankheit, Geistesschwäche oder anderer seelischer Zerrüttung leidet, aufgrund derer er zukünftig Kinder nicht aufziehen kann oder dass jemand Geisteskrankheit oder -schwäche durch Vererbung an seine Abkömmlinge weitergeben kann, kann an ihm auch ohne Einwilligung die Sterilisierung dann vorgenommen werden, wenn er aufgrund der seelischen Zerrüttung tatsächlich nicht in der Lage ist, eine Einwilligung rechtsgültig zu erteilen.“299

Eine auf sonstige Weise medizinisch begründete Sterilisation kam nicht in Betracht. ${ }^{300}$ Die für die Entscheidung zuständige Behörde war das Gesundheitsamt (medi-

296 S. z. T. mit den Gesetzestexten im Anhang Andersson/Malm, Synen på moderskap och utvecklingsstörning, En historisk studie som omfattar 1930-och 1940-talen, Växjö 2008. Die Vererbungslehre von Hofsten, Ärftlighetslära, erschien bereits 1919, 1926 wurde er zum Direktor an das Statens institut för rasbiologi (Uppsala) berufen, wo er die wissenschaftlichen Grundlagen des Sterilisierungsgesetzes legte, s. Catomeris, Det ohyggliga arvet, Sverige och främlingen genom tiderna, Stockholm 2004, S. 249.

297 Zitat und Fundstelle des Protokolls bei Almgren, Illusion und Wirklichkeit (Fußn. 294), S. 70-71.

298 Lag 1934. Nr 171 om sterilisering av vissa sinnessjuka, sinnesslöa eller andra som lida av rubbad själsverksamhet. Zu diesem s. Catomeris, Det ohyggliga arvet (Fußn. 296), insbes. S. 247 ff., Steriliseringens praktik; Runcis, Steriliseringar i folkhemmet, Stockholm 1998; dies., Sinnesslöhet som samhällsproblem, Historisk Tidskrift Vol. 1998, S. 547-567; dies., I skuggan av välfärdsstaten, Steriliseringarna och vetenskapen, in: Hallberg/Lernestedt (Hrsg.), Svenska värderingar?, Stockholm 2002; Zaremba, De rena och de andra (Fußn. 274), und Broberg/Tydén, Oönskade i folkhemmet. Rashygien och sterilisering i Sverige, Stockholm 1991.

299 Übers. v. Verf., § 1 S. 1: „Kan med skäl antagas att någon som lider av sinnessjukdom, sinnesslöhet eller annan rubbning av själsverksamheten är på grund för framtiden ur stånd att handhava vårdnaden om sina barn eller kommer genom arvsanlag på avkomlingar överföra sinnessjukdom eller sinnesslöhet, må utan hans samtycke sterilisering enligt denna lag å honom företagas, där han på grund av sin rubbade själsverksamhet varaktigt saknar förmåga att lämna giltigt samtycke till åtgärden."

300 § 1 S. 2: „Å sterilisering på grund av medicinska skäl äger lagen icke tillämpning.” 
cinalstyrelse, § 2), bei Schwachsinn genügte das Gutachten zweier Ärzte. Der Antrag301 auf Sterilisierung war schriftlich mit einem speziellen Formular zu stellen und vom Antragsteller zu unterzeichnen. Die Entscheidung erfolgte nach obligatorischer Begutachtung des sozialen Umfelds des Betroffenen und ärztlichem Gutachten über die Krankheit und deren Vererblichkeit. Die verwaltungsrechtlichen Vorgaben verhinderten nicht, dass es bis 1941 zu vielen Eingriffen kam, die außerhalb der gesetzlich zulässigen Sterilisationen lagen, insbesondere im Bereich der „sozialen Indikation“.302 1941 wurde (auch deshalb) ein zweites „Sterilisierungsgesetz“303 erforderlich. Jetzt wurden von der eugenischen Indikation nicht mehr nur Erb(geistes)krankheiten erfasst, sondern auch „andere schwere Krankheiten oder schwere Fehler." ${ }^{304}$ Die soziale Indikation kam auch für den Fall in Betracht, dass die Kinderaufzucht wegen ,asozialer Lebensweise“305 gefährdet erscheint. Die Einwilligung dazu war schon dann entbehrlich, wenn jemand aufgrund „seelischer Zerrüttung“ dazu nicht in der Lage war - das im Erstgesetz einschränkend verlangte „tatsächlich“ (= varaktigt) fiel ersatzlos weg. Für Frauen wurde die medizinische Indikation eingeführt, wenn die Gefahr bestand, dass eine Schwangerschaft Leben oder Gesundheit gefährden würde. ${ }^{306}$ Gegen den Sterilisierungsbeschluss des Gesundheitsamts war Beschwerde „,beim König vor zwölf Uhr des 20sten Tages nach Zugang des Beschlusses“" möglich. ${ }^{307}$

Dieses Gesetz galt bis 1975, wobei seit 1950 Eingriffe fast nur noch freiwillig und aufgrund medizinischer Indikation vorgenommen wurden. 308 Unter dem Erstgesetz, also bis ins Jahr 1941, kam es zu ca. 3.200 Sterilisationen, von da an bis 1975 waren es ca. 60.000 Eingriffe. Betroffen davon waren zu ca. 90 \% Frauen, seit der Strafrechtsänderung von $1938^{309}$ sehr viele im Zusammenhang mit einem ärztlich vorgenommenem Abort.

301 Zum Antrag und zum weiteren Verfahren s. Andersson/Malm, Synen på moderskap och utvecklingsstörning (Fußn. 296), S. 36 ff.

302 Andersson/Malm, Synen på moderskap och utvecklingsstörning (Fußn. 296), S. 37, und SOU 2000:20 Steriliseringsfrågan i Sverige 1935-1975.

303 Lag 1941:282 Om sterilisering.

304 § 1 S. 1: „Kan någon med skäl antagas komma att genom arvsanlag på avkomlingar överföra sinnessjukdom eller sinnesslöhet eller ock svårartad sjukdom eller svårt lyte av annat slag (...)."

305 § 1 S. 2: ,på grund av asocialt levnadssätt (...)" Von der ,asozialen Lebensführung” waren vor allem Zigeuner betroffen.

$306 \S 1$ S. 3: „Är på grund av sjukdom, kroppsfel eller svaghet hos kvinna påkallat att hon steriliseras för att förebygga havandeskap som skulle medföra allvarlig fara för hennes liv eller hälsa, må ock med hennes samtycke sterilisering enligt denna lag företagas å henne."

$307 \S 6$ : „,besvär anföras hos Konungen före klocken tolv å tjugonde dagen från den då beslutet meddelas.“

308 S. hierzu und zu den folgenden Zahlen SOU 2000:20 Steriliseringsfrågan i Sverige 1935-1975, Bilage 1-3.

309 Lag (1938:566) om upphävande av 18 kap. 13 § 2 Strafflagen. 


\section{b) Der Ansatz im Maßnahmestaat}

Die oben unter zeittypische Denkmuster subsumierte Begründung des schwedischen Immigrationsgesetzes von 1927 findet in einer 1926 veröffentlichten Studie ${ }^{310}$ von Carl Schmitt eine beklemmende Parallele. Der Lehrer Forsthoffs reflektiert darin, dass der Parlamentarismus zur Gedankenwelt des Liberalismus, nicht aber zur Demokratie gehört, weshalb man beide trennen muss,

„damit das heterogen zusammengesetzte Gebilde erkannt wird, das die moderne Massendemokratie ausmacht." “311

Weil Demokratie für ihn die „Identität von Regierenden und Regierten“ ist, 312 sieht er einen

„in seiner Tiefe unüberwindlichen Gegensatz von liberalem Einzelmensch-Bewußtsein und demokratischer Homogenität. “313

Die Konsequenzen, die Schmitt aus seiner Annahme eines „in seiner Tiefe“ unüberwindlichen Gegensatzes zieht, beschränken sich aber nicht auf ordnungsrechtliche Maßnahmen zur Steuerung von Einwanderung:

„Zur Demokratie gehört also notwendig erstens Homogenität und zweitens - nötigenfalls

- die Ausscheidung und Vernichtung des Heterogenen."314

Zur Vernichtung des Heterogenen als Staatsaufgabe sollte es alsbald kommen. Ein erster praktischer Schritt dazu war der Erlass des noch aus Weimarer Zeit stammenden 315 Gesetzes zur Verhütung erbkranken Nachwuchses vom 14. Juli 1933.316 Dessen $\S 1$ Satz 1 lautete:

„Wer erbkrank ist, kann durch chirurgischen Eingriff unfruchtbar gemacht (sterilisiert) werden, wenn nach den Erfahrungen der ärztlichen Wissenschaft mit großer Wahrscheinlichkeit zu erwarten ist, daß seine Nachkommen an schweren körperlichen oder geistigen Erbschäden leiden werden.“

310 Schmitt, Die geistesgeschichtliche Lage des heutigen Parlamentarismus, 2. Aufl. Berlin, 1926.

311 Ders., ebda., S. 13.

312 Ders., ebda., S. 19.

313 Ders., ebda., S. 23.

314 Ders., ebda., S. 14. Er fährt fort: „Zur Illustration dieses Satze sei an zwei verschiedene Beispiele moderner Demokratien erinnert: an die heutige Türkei mit ihrer radikalen Aussiedlung der Griechen und ihrer rücksichtslosen Türkisierung des Landes - und an das australische Gemeinwesen, das durch Einwanderungsgesetzgebung unerwünschten Zuzug fernhält.“ Dass Schmitt neben sonstigen Fehleinschätzungen auch hochgestimmte Nonsense-Sätze unterliefen, zeigt der darauf folgende Satz: „Bei der Frage der Gleichheit handelt es sich nämlich nicht um logischarithmetische Spielereien, sondern um die Substanz der Gleichheit.“ (Hervorhebungen und „Doppeladjektiv“ im Original).

315 Zur Gesetzgebungsgeschichte, ,einer eigenartigen Kombination von Öffentlichkeit und Geheimhaltung“, s. Bock, Zwangssterilisation im Nationalsozialismus, Studien zur Rassenpolitik und Frauenpolitik, Opladen 1986, S. 79 ff. (80).

316 RGBl. I 1933, 529; zu diesem s. ausführlich Majer, „Fremdvölkisches“ im Dritten Reich (Fußn. 260), S. 181 ff. 
In $\S 1$ S. 2 werden die Erbkrankheiten i.S.d. Gesetzes aufgezählt. $317 \S 1$ S. 3 sieht „ferner“ vor, dass auch unfruchtbar gemacht werden kann, ,wer an schwerem Alkoholismus leidet". Wie in Schweden war ein bis in die Details geregeltes Verfahren auf Antrag vorgesehen; zuständig für die Entscheidung waren die bei den Amtsgerichten „,anzugliedernden“ ( $§ 6$ Abs. 1 S. 1) „Erbgesundheitsgerichte“. Diese waren besetzt mit einem Amtsrichter (Vorsitzender), einem beamteten Arzt und einem weiteren Arzt, ,der mit der Erbgesundheitslehre besonders vertraut ist" (§ 6 S. 2). Das Gericht hatte den Sachverhalt von Amts wegen zu ermitteln ( $\$ 7$ Abs. 2); es entschied durch Beschluss, gegen den binnen einem Monat 318 Beschwerde zum ,Erbgesundheitsobergericht“ möglich war. Hatte das Erbgesundheitsobergericht entschieden, so war die Unfruchtbarmachung auch

„gegen den Willen des Unfruchtbarzumachenden auszuführen [...] Soweit andere Maßnahmen nicht ausreichen, ist die Anwendung unmittelbaren Zwanges zulässig." (§ 12 Abs. 1)

1935 wurde (neben den ohnehin gegebenen strafrechtlichen Zwangsmaßnahmen) eine freiwillige Sterilisation von Männern mit „entartetem Geschlechtstrieb“ in das Gesetz eingefügt. 319

Das Gesetz wurde mit dem statistischen Geburtenrückgang und der ,hemmungslosen Vermehrung von Minderwertigen“ begründet, die das Erbgesundheitsgesetz zur ,,bevölkerungspolitischen Notwendigkeit" machten. ${ }^{320}$ Für die Ausgrenzung und dann Ausmerzung der „Minderwertigen“ gab es bald einen vielfältigen untergesetzlichen ,Maßnahmekatalog“‘ 321 ergänzt durch ,fürsorgerische Disziplinierung“.322 In den Jahren

317 Das war gegeben bei „1. angeborenem Schwachsinn, 2. Schizophrenie, 3. zirkulärem (manischdepressivem) Irresein, 4. erblicher Fallsucht, 5. erblichem Veitstanz (Huntingtonsche Chorea), 6. erblicher Blindheit, 7. erblicher Taubheit, 8. schwerer erblicher körperlicher Mißbildung.“

318 Die Notfrist wurde mit Gesetz vom 26. Juni 1935 (RGB1. I. S. 773) auf zwei Wochen verkürzt.

$319 \S 14$ Abs. 2, eingefügt mit Gesetz vom 26. Juni 1935: „Eine Entfernung der Keimdrüsen darf beim Manne mit seiner Einwilligung auch dann vorgenommen werden, wenn sie nach amts- oder gerichtsärztlichem Gutachten erforderlich ist, um ihn von einem entarteten Geschlechtstrieb zu befreien, der die Begehung weiterer Verfehlungen im Sinne der $\S \S 175$ bis 178, 183, 223 bis 226 des Strafgesetzbuchs befürchten läßt. Die Anordnung der Entmannung im Strafverfahren oder im Sicherungsverfahren bleibt unberührt.“

320 Begründung zum Gesetz zur Verhütung erbkranken Nachwuchses (Berlin, 26. Juli 1933), Deutscher Reichsanzeiger und Preußischer Staatsanzeiger 1933 Nr. 172, S. 1-2.

321 Auch durch Gesetze, etwa das „Blutschutzgesetz“ (Gesetz zum Schutze des deutschen Blutes und der deutschen Ehre, RGB1 I 1935, S. 1176, oder das „Ehegesundheitsgesetz“ (Gesetz zum Schutze der Erbgesundheit des deutschen Volkes, RGBl I 1935 529), zu diesem s. Majer (Fußn. 260), S. 189 ff.; s. die umfangreiche Dokumentation von Ayaß, "Gemeinschaftsfremde", Quellen zur Verfolgung von "Asozialen" 1933-1945, Bundesarchiv Koblenz 1998 (= Materialien aus dem Bundesarchiv Nr. 5); Roth, Schöner neuer Mensch, in: Kaupen-Haas (Hrsg.), Der Griff nach der Bevölkerung, Aktualität und Kontinuität nazistischer Bevölkerungspolitik, Nördlingen 1986, S. 11-63 (40 ff.); zur Pervertierung des „Bewahrungsgedankens“ der Fürsorge im Nationalsozialismus s. Lehnert, Die Beteiligung von Fürsorgerinnen an der Bildung und Umsetzung der Kategorie ,minderwertig““ im Nationalsozialismus, Frankfurt/Main 2003; Sachße/Tennstedt, Der Wohlfahrtsstaat im Nationalsozialismus, Geschichte der Armenfürsorge in Deutschland, Bd. 3, Stuttgart 1992. 
von 1933 bis 1945 wurden etwa 350.000 Menschen sterilisiert. ${ }^{323}$ Allein 1935 waren 73.174 Personen betroffen, davon 37.834 Männer und 35.340 Frauen. Mehr als die Hälfte aller Sterilisierungen erfolgte aufgrund ,angeborenen Schwachsinns“, ein Viertel aufgrund „Schizophrenie“. Nach Angaben des Reichsinnenministeriums sind 1934 7,7\%, 1935 8,4\% und 1936 9,4\% der Betroffenen gegen ihren ausdrücklichen Willen zwangssterilisiert worden, die übrigen beugten sich der Maßnahme. Dafür wurden über 200 Erbgesundheitsgerichte und 30 Erbgesundheitsobergerichte eingerichtet, mit Richtern und Ärzten besetzt und entsprechend ausgestattet.

Wie in Schweden wollte man die „negative“ Bevölkerungspolitik nach dem Erbgesundheitsgesetz aber durch eine ,positive“ Sozialpolitik eines Familienlastenausgleichs zugunsten der erbgesunden deutschen Mehrkinderfamilie ergänzen. ${ }^{324}$ Auf der ersten Sitzung des Sachverständigenbeirats für Bevölkerungs- und Rassenpolitik ${ }^{325}$ am 28. Juni 1933 stellte der Reichsminister des Innern Dr. Frick klar:

„seien wir uns dessen bewußt, daß mit der Ausmerze und Auslese, die durch unsere rassenhygienische und rassenpolitische Gesetzgebung eingeleitet werden, noch nichts erreicht ist, wenn wir nicht durch positive bevölkerungspolitische Maßnahmen die Familiengründung und die ausreichende Fortpflanzung der wertvollen erbgesunden deutschen Menschen erreichen ... Ich sehe es als die größte Aufgabe und Pflicht der Regierung der nationalen Revolution an, die Aufartung und Bestandserhaltung unseres deutschen Volkes im Herzen Europas zu gewährleisten." 326

\section{c) „Wie konnte das nur geschehen?“}

Diese Frage kann schon deshalb nicht auf Deutschland beschränkt werden, weil sie „nicht nur die Geschichtsschreibung, sondern unsere zivilisatorische Gewissheit so strapaziert“ und weil sie auch die spezifische Enttäuschung darüber enthält, ,vom Prozess der Zivilisation mehr erwartet zu haben, nämlich eine Sicherheit, dass derlei Rückfälle in barbarische Zeiten nicht mehr vorkommen könnten." 327 Der elementare Unterschied zwischen der „Veredelung des Volkes“ in Schweden und der „Vernichtung des Hetero-

322 Ayaß, „Asozial“ im Nationalsozialismus, Stuttgart 1995, insbes. Kap. 5, „Asoziale Familien“ zwischen rassenhygienischer Ausmerzung und fürsorgerischer Disziplinierung, S. $105 \mathrm{ff}$.

323 S. hierzu und zu den folgenden Angaben Ganssmüller, Späte Entschädigungsregelungen für die Opfer des Sterilisierungsgesetzes vom 14.7.1933, NJW 1988, S. 2867 ff.

324 Kaupen-Haas, Die Bevölkerungsplaner, in: ders. (Hrsg.), Der Griff nach der Bevölkerung (Fußn. 321), S. 103 ff. (104).

$325 \mathrm{Zu}$ den z. T. prominenten Mitgliedern dieses Beirats und den Arbeitsschwerpunkten auf dessen Tätigkeitsgebieten I: Finanzen, Steuerpolitik, Statistik und Siedlung, II: Rassenhygiene und Rassenpolitik und III: Erziehungs- Frauen- und Mütterfragen, s. Kaupen-Haas, ebda., S. 90 ff.

326 Die Rede, in der Frick auch ,die Einschränkung übertriebener sozialer Fürsorge für lebensunwerte Existenzen“ fordert, ist vollständig abgedruckt in: Die Reichsversicherung, 7. Jg. 1933, Heft 8, S. 209 ff., und z. T. dokumentiert bei Reidegeld (Hrsg.), Staatliche Sozialpolitik in Deutschland, Band II: Sozialpolitik in Demokratie und Diktatur 1919-1945, Frankfurt/New York 2006 (Dok. 11).

327 S. Reemtsma, Vertrauen und Gewalt, Versuch über eine besondere Konstellation der Moderne, Hamburg 2008, hier: Einleitung: Das Rätsel, S. 13 ff. 
genen“ in Deutschland muss dennoch nicht eigens belegt werden. ${ }^{328}$ Trotzdem - eine geradezu idyllische Gleichsetzung dieser dunklen Seite des schwedischen Volksheimbaus mit landwirtschaftlichen Gepflogenheiten

„Aufpfropfen von Apfelbäumen, die Züchtung besserer Kühe, Hunde oder Pferde - warum also nicht auch Menschen?"329

verdeckt das menschliche Elend der oft allzu schnell als „asozial“ eingestuften und dann zwar ohne unmittelbare Gewalt, aber durch erheblichen Druck der Behörden zur Sterilisation gebrachten Menschen. ${ }^{330}$ Beiden Ländern ist (jedenfalls bis Kriegsbeginn) gemeinsam, dass etwa zeitgleich massive Eingriffe in die menschliche Integrität auf verwaltungsrechtlich geregelter Verfahrensgrundlage mit gesetzlich vorgesehenem Rechtsweg vorgenommen worden sind. Der Vergleich der beiden Sterilisierungsgesetze hat die Ähnlichkeit der rechtlichen Gestaltung aufgezeigt. Zu fragen bleibt, ob es rechtliche Gründe dafür gab, die Vorsorge zur menschenfeindlichen Maßnahme für bestimmte Gruppen werden ließen.

\section{(1) Alle machten mit}

Boréus $^{331}$ hat für Schweden die Argumente, die im Gesetzgebungsverfahren für und wider das schwedische Sterilisierungsgesetz geäußert worden sind, gesammelt und analysiert. Schon ein Auszug daraus zeigt die Ähnlichkeit zum damals verbreiteten Meinungsstand der Zeitgenossen in Deutschland.

Primär wurde „eugenisch“ argumentiert:

328 „Im schwedischen Wohlfahrtsprojekt folkhemmet war gerade die Fürsorge für die Schwachen und Benachteiligten zentral im Gegensatz zu der Betonung des starken in der NS-Volksgemeinschaft.“ Almgren, Illusion und Wirklichkeit (Fußn. 294), S. 71.

329 Hirdmann, Det tänkande hjärtat (Fußn. 280), S. 197, beschreibt so den von den Rassehygienikern Schwedens als beruhigend empfundenen subjektiven Unterschied zur deutschen „Rassenmythologie“ der NS- Zeit. Dabei war der Einfluss Nazi-Deutschlands auf Schweden direkt und indirekt durchaus nicht marginal, s. für die Frauenbewegung Bokholm, I otakt med tiden, Om rösträttsmotstånd, antipacisfism och nazism bland svensk kvinnor, Stockholm 2008; für die kulturelle Zusammenarbeit Almgren, Illusion und Wirklichkeit (Fußn. 294); in Schweden wird dieses Kapitel seit der Kultur/Special-Beilage in Dagens Nyheter, 21. Oktober 1997: „Vem tjänade pengar på andra värlskriget? Naziguldet, Sveriges riksbank och svenska företag agerade hälare i historiens störsts rån.“, intensiv diskutiert, s. Håbinette/Böhme, Den svenska nationalsocialismen. Medlemmer och sympatisörer 1931- 1945, Stockholm 2002, worin auf über 500 Seiten die Namen von Parteimitgliedern, Sympathisanten und Mitläufern der schwedischen NS genannt werden; aktuell s. die Beiträge in Andersson/Tydén (Hrsg.), Sverige och Nazityskland. Skuldfrågor och moraldebatt, Stockholm 2007 und Östling, Nazismens sensmoral. Svenska erfarenheter i andra världkrigets efterdyning. Stockholm 2008.

330 S. die Darstellung der „Einzelfälle“ (meist Zigeuner oder ledige Mütter) in SOU 2000:20, Bilag 4.

331 Boréus, Discursiv Discrimination, European Journal of Social Theory, Vol. 9, No. 3, 2006, S. 453, Table 1, Central arguments regarding the need for a sterilisation law targeting the 'mentally deficient' in the Swedish parliamentary discussion 1922-1934. 
„By sterilising the bearers of bad genes in large enough numbers, the proportion of the inferior could be reduced in coming generations. Many mentally deficient people give birth to children who are themselves abnormal."

Sozialpolitische Argumente wurden mit dem Hinweis auf die Belastungen der Gesellschaft vermischt:

„The existence of a large number of psychologically inferior individuals is a burden to society. Such individuals are usually not of any social value. They must usually be supported by society and result in substantial costs for society. The care that they require ties up large amounts of labour. They are a burden to their relatives and others around them. They are often criminal. They often have children who are themselves defective and thus become a burden to society. A normal child born to mentally deficient parents has a cruel and tragic fate. From an ethical point of view it is unacceptable that the mentally deficient have children."

Die Sterilisierung wurde als das gegenüber der Anstaltsunterbringung kleinere Übel hingestellt, sowohl für den Betroffenen, wie auch für das Anstaltspersonal und nicht zuletzt für die Fürsorgekassen:

„Sterilisation is in many cases a better alternative to institutionalisation. In particular, male adults who are mentally deficient but capable of working could be allowed to live outside institutions, were they sterilised first. Some people could have a freer life since they would not have to be institutionalised. They would have to live in institutions anyway, since they might live depraved lives or be dangerous if let out. The staff at the institutions would have a good chance of judging whether a particular individual could live outside an institution without becoming criminal or depraved. It would often be more acceptable to the public sense of justice to have a person sterilised than to keep her or him in detention for the sole reason of stopping her/him from procreating. Sterilisation is cheaper than keeping people in institutions."

Demgegenüber gab es wenig rechtliche Einwände; sie wurden nicht gehört:

„A sterilisation law would be a deviation from the rule of protection of the bodily integrity of the individual. Sterilisation could be seen as causing the 'mentally deficient' person severe bodily harm (in the sense of the law). The adoption of a sterilisation law is a step on the way towards killing people."

Die Reaktionen der Fachwelt, die bei der Ausarbeitung der „Staatlichen Öffentlichen Untersuchung"332 zur Bevölkerungsfrage 1936 mit einbezogenen war, lassen die Mentalität der Zeit erkennen: Über 60 Behörden, Verbände etc., also das ,ganze Sozialschweden" 333 war mit der Untersuchung befasst, fast alle Stellungnahmen enthielten Vorschläge zur „Verbesserung“ des Sterilisierungsgesetzes, insbesondere zur sozialen Indikation. Der Ärzteverband empfahl sogar die Erleichterung der Möglichkeiten der zwangsweisen Sterilisierung. ${ }^{334}$ Allein dem Gesundheitsamt schien eine entsprechende Gesetzesänderung vorläufig nicht opportun - man empfahl statt dessen „Änderungen der Praxis“, etwa bei der Beurteilung des Grades der seelischen Zerrüttung. ${ }^{335}$ Ein Arzt,

332 SOU (1936:46) Betänkande angivet av Befolkningskommissionen.

333 Zaremba, De rena och de andra (Fußn. 274), S. 229: ,praktiskt taget hela Socialsverige” (= praktisch das ganze Sozialschweden).

334 S. mit Fundstelle ders., ebda., S. 230.

335 S. mit Fundstelle ders., ebda., S. 232. 
der seinerzeit über 5.000 Sterilisierungsbeschlüsse unterschrieben hatte, antwortete auf die Frage, warum er so gehandelt hat:

„Ich habe das Gesetz oder die Vorarbeiten dazu nie gelesen (...) ich glaube aber, dass alle der Meinung waren, dass dies Maßnahmen waren, die richtigen Prinzipien folgten, dass dies notwendig war $(\ldots)^{\text {“336 }}$

In Deutschland glichen die sozial- und gesundheitspolitischen Argumente ${ }^{337}$ denen in Schweden, verschärft noch durch die rassistische Propaganda. Wenn die geringe am „Erbgesundheitsgesetz“ laut gewordene Kritik zum Teil auch auf die Situation in einem bald totalitären Staat zurückgeführt werden kann, so bestätigen eingehende Untersuchungen aber dennoch, dass eigentlich allein die katholische Kirche dezidiert gegen die Sterilisierung Stellung nahm. ${ }^{338}$

Für die Berechtigung des Vorwurfs, dass ,alle mitmachten“, spricht indirekt die Art, wie deutsche Behörden nach dem Krieg auf Sterilisierungen reagierten: In der Wiedergutmachungsrechtsprechung ging man jahrzehntelang von der Rechtmäßigkeit des Sterilisationsgesetzes aus; die Frage, ob es mit rechtstaatlichen Grundsätzen vereinbar sei, „wurde entweder bejaht oder für belanglos erklärt.“339 Es sollte bis zum 5. Mai 1988 dauern, dass der Bundestag durch Entschließung der Feststellung zustimmte,

336 Zitiert ders., ebda., S. 234. Zum Einfluss protestantischer Traditionen s. Stenius, The Good Life is a Life of Conformity: The Impact of the Lutheran Tradition on Nordic Political Culture, in: Sørensen/Stråth (Hrsg.), The Cultural Construction of Norden, S. 161-171; s. a. Strömholm, Uppsalaskolan och konstitutionens normativitet, in: Smith (Hrsg.), Grundlagens makt. Konstitutionen som politisk redskap och som rättslig norm, Stockholm 2002, S. 25-42, S. 25 erklärt die „missgestimmte Arbeitslust” der Schweden mit dem Satz: „Det är Luther” (,das liegt an Luther").

337 Merkel, „Tod den Idioten“ - Eugenik und Euthanasie in juristischer Rezeption vom Kaiserreich zur Hitlerzeit, Berlin 2006, insbes. Kap. 2: „Lebenswert - Null“, S. 102 ff., und Kap. 5, III 2: „Die Mischung aus Mitleid und Kosten - Nutzen - Rechnung“, S. 218 ff.; Weingart/Kroll/Bayertz, Rasse, Blut und Gene, Geschichte der Rassenhygiene in Deutschland, Frankfurt/Main 1988, insbes. Kap. IV „Grundzüge der Menschenökonomie - Kalküle des ,lebenden Volksvermögens'“, S. 254 ff., weisen nach, dass die Frage „Was kosten die Minderwertigen dem Staat“ schon seit vor dem 1. Weltkrieg öffentlich immer häufiger gestellt wurde.

338 Bock, Zwangssterilisation im Nationalsozialismus (Fußn. 315), S. 289 ff., weist aber auch darauf hin: „Der gravierendste Kompromiss der katholischen Hierarchie mit der weltlichen Obrigkeit betraf indessen nicht das Gewissen der Betroffenen, sondern das Gewissen derjenigen Katholiken, die ihres Berufs wegen zu den Anzeigenden und Antragstellern gehörten [...] die Bischöfe präzisierten, dass zwar die Antragstellung, nicht aber die Anzeige eine ,Mitwirkung' am Gesetz bedeute und also Sünde sei (...).“ Zur Rolle der evangelischen Kirche s. Ayaß, „Asozial“ im Nationalsozialismus (Fußn. 322), zu der der öffentlichen Fürsorge Lehnert, Die Beteiligung von Fürsorgerinnen (Fußn. 321), S. $175 \mathrm{ff}$.

339 Bock, Zwangssterilisation im Nationalsozialismus (Fußn. 315), S. 245, mit Nachweisen. Eine Entschädigung gab es nur, wenn ,der Antragsteller nicht erbkrank i.S.d. Gesetzes war, wenn das Sterilisationsgesetz nicht ,korrekt' angewandt worden war (...)“; s. auch Weingart/Kroll/Bayertz, Rasse, Blut und Gene (Fußn.337), Kap. VI, S. 562 ff.: „Kontinuität und Diskontinuität eugenischen Denkens. Eine ,Stunde Null' hat es nicht gegeben.“ 
„daß die in dem Gesetz zur Verhütung erbkranken Nachwuchses vom 14. 7. 1933 vorgesehenen und auf der Grundlage dieses Gesetzes während der Zeit von 1933 bis 1945 durchgeführten Zwangssterilisierungen nationalsozialistisches Unrecht sind.“340

Den Opfern wurde Achtung und Mitgefühl bezeugt und die Behörden wurden aufgefordert, die „einmalige Entschädigung von 5.000 DM für die noch lebenden Opfer rasch und unbürokratisch“ auszuzahlen. In der Begründung zu der Entschließung stellte die Mehrheit des Rechtsausschusses fest:

„Das Gesetz ist in seiner Ausgestaltung und Anwendung nationalsozialistisches Unrecht: Wenn auch die NSDAP und die in der Wissenschaft international diskutierte Lehre der Eugenik auf Vorarbeiten in Deutschland und in anderen Ländern und selbst auf gesetzliche Regelungen anderer Staaten zurückgreifen konnte, so sind doch die im Verhältnis zu anderen Staaten außerordentlich intensive Planung und die sehr hohe Zahl von Zwangssterilisierten eindeutig Äußerungen nationalsozialistischer Rassenpolitik. Das Gesetz war Unrecht!“

Die darin enthaltene Relativierung durch den (auf vage Weise entschuldigenden) Bezug auf das Ausland, durch die das massenhaft aktive Tun herunterspielende Hervorhebung der ,außerordentlich intensiven Planung“ und durch das Bedauern der ,außerordentlich hohe[n] Zahl von Zwangssterilisierten" (wäre eine niedrigere Zahl vertretbar gewesen?) zeigt, dass man selbst über 54 Jahre nach Erlass des Gesetzes den darin liegenden Menschenrechtsverstoß noch nicht als solchen erkannte. ${ }^{341}$

\section{(2) Daseinsvorsorge statt Grundrechtsschutz}

Man wird nicht überrascht sein, dass die Grundrechte dem Einzelnen im NS-Staat keinen Schutz gegen Eingriffe aufgrund unfreiwilliger Teilhabe an Maßnahmen boten, die für den Beginn des „Wandels des Objekts sozialpolitischer Intervention vom Individuum zum ,Volkskörper'“342 standen. Noch einmal dazu Forsthoff:

„es wird klar, dass eine rechtlich gesicherte Teilhabe an der Daseinsvorsorge, funktionell betrachtet, eine Art von Ersatz für jene überholten Sicherungen bietet welche die Grundrechte in sich beschlossen." 343

Diese „funktionelle Betrachtung“ bedeutet nicht, dass das Recht überhaupt keine Rolle gespielt hätte:

„Differenzierte Organisationen wie die modernen Staaten sind in denjenigen Funktionen, welche der Daseinsvorsorge gewidmet sind, notwendig rationale Gebilde, das heißt, sie fungieren nach rationalen Regeln. [...] Die Beherrschung solcher Organisationen setzt

340 Text der Entschließung bei Ganssmüller, Späte Entschädigungsregelungen, NJW 1988, S. 2867.

341 Nicht ohne Signifikanz ist wohl auch, dass in dem sonst umfassenden Werk „Deutsche Verwaltungsgeschichte“, Boelcke in Bd. 4, Kap. IV § 4, Arbeit und Soziales unter Ziff. 3 Wohlfahrtspflege, zwar knappe Zahlen über die Belegung der ,geschlossenen Anstalten für Geisteskranke, der Krüppelanstalten und der Alten- und Siechenheime“ angibt, außer dem Hinweis auf „Hitlers EuthanasieErlaß vom 1. September 1939“ der Komplex der rassenbiologischen Eugenik überhaupt nicht erwähnt wird.

342 Sü $\beta$, Der „Volkskörper“ im Krieg, Gesundheitspolitik, Gesundheitsverhältnisse und Krankenmord im nationalsozialistischen Deutschland 1939- 1945, München 2003, S. 21.

343 Forsthoff, Die Verwaltung als Leistungsträger (Fußn. 145), S. 46. 
notwendig voraus, dass der Herrschende eine durch rationale Normen ausgewiesene Zuständigkeit zur Befehlsgewalt in Anspruch nehmen kann. [...] Wer diese Organisationen der Daseinsvorsorge in die Hand bekommen will, muss einen Rechtstitel vorweisen, der ihm Eintritt in die Befehlsgewalt gestattet, das heißt, er muss die Legalität für sich haben." 344

Schon ein ganz kursorischer Blick in beliebige Jahrgänge juristischer (Fach-) Zeitschriften, hier als Beispiel in die ,Arbeiter=Versorgung“345 zeigt, wie genau man die Einhaltung der verwaltungs- und sozialversicherungsrechtlichen Regeln unterhalb der Eingriffsnorm nahm. Die Absicht dahinter war klar:

„Die gerichtliche Feststellung dessen, was als legitim zu gelten habe, nimmt unzähligen Opfern die Furcht vor Repressalien oder vor dem Liquidiert werden und fördert bei den Untertanen eine verständnisvolle und freundliche Haltung gegenüber den Sicherheitsbedürfnissen der Machthaber." 346

So wird etwa im 53. Jg. 1938 den fachlich interessierten Lesern erst einmal die sozialverwaltungsrechtliche Reform mitgeteilt, dass nämlich durch das Gesetz zur Verhütung erbkranken Nachwuchses die Leistungspflicht der Träger der gesetzlichen Krankenversicherung erweitert worden ist:

„Es hat den Krankenkassen Leistungen für solche Veranlagungen ihrer Mitglieder und deren bezugsberechtigten Familienangehörigen auferlegt, die auf Ererbung beruhen und keine Krankheit im Sinne des Zweiten Buches der RVO sind.“347

Sodann wird eine Entscheidung des Reichsversicherungsamtes begrüßt, mit der die Streitfrage geklärt wurde, ob die Reisekosten des Unfruchtbarzumachenden und seiner notwendigen Begleitung in die Anstalt, wo der Eingriff durchgeführt wird, in jedem Fall von den Krankenkassen zu tragen sind:

„Das Reichsversicherungsamt weist darauf hin, dass es sich nach dem allgemeinen Sprachgebrauch, von dem bei der Auslegung des Wortlauts [...] auszugehen ist, um eine

344 Ders., ebda., S. 9. Zuvor heißt es für den Staat insgesamt: „Man muss ihn in die Hand bekommen. Aber man darf ihn nicht zerstören. Die Revolution ist nur noch als Machtübernahme, das heißt in legalen Formen möglich.“ Die Parallelen zu den Vorstellungen vom Staat als „funktionierendem Organismus" in Acceptera! liegen auf der Hand - obwohl die Autoren sicher nicht von einander gewusst haben. Zumbansen, Kumpfmüllers Staat und Ackermanns Markt. Anmerkungen zur Wirkung von Recht am Ende des Wohlfahrtsstaats, in: Zeitschrift für Rechtssoziologie. Bd. 29/Heft2 2008, S. 281-294 (285) spricht von in großzügiger Vereinfachung von der „dienenden Rolle des Rechts" bei der Forsthoffschen Versachlichung der Industriegesellschaft".

345 Die Arbeiter=Versorgung, Zeitschrift für die gesamte Sozialversicherung im Deutschen Reich, Gegründet 1884. Einen Überblick über die Methoden der Rechtsfindung durch die Erbgesundheitsgerichte bei $A y a \beta$, ,Asozialer Nachwuchs ist für die Volksgemeinschaft vollkommen unerwünscht.“, Die Zwangssterilisationen von sozialen Außenseitern, in: Hamm (Hrsg.), Lebensunwert - zerstörte Leben, Zwangssterilisation und „Euthanasie“, Frankfurt/Main 2005, S. 111-119. Exemplarisch daraus (S. 112) das Zitat aus der Begründung eines Beschlusses des Hamburger Erbgesundheitsgerichts: „Zusammenfassend ist Frau N. als eine schwachsinnige, charakterlich haltlose, minderwertige Frau zu bezeichnen, deren Fortpflanzung für die Volksgemeinschaft unerwünscht ist."

346 Kirchheimer, Politische Justiz, Verwendung juristischer Verfahrensmöglichkeiten zu politischen Zwecken, Hamburg 1993, S. 26.

347 Kadgiehn, Grundsätzliches zum Gesetz zur Verhütung erbkranken Nachwuchses, Die Arbeiter=Versorgung 53. Jg./1936, S. 408-412 (409). 
,Reisebegleitung' schon dann nicht handelt, wenn eine Person, die nicht infolge ihres geistigen Zustands willensunfähig ist, im Wege polizeilichen Zwanges zur Durchführung öffentlich-rechtlicher Vorschriften in eine Krankenanstalt, in die sie sich freiwillig nicht begeben will, überführt wird."348

Es ging also nicht darum, ob es rechtens sei, eine Person zwecks Unfruchtbarmachung in eine Krankenanstalt zu überführen, in die sie sich zu dem Zweck freiwillig nicht begeben will, sondern darum, wann eine von der Krankenkasse zu erstattende „Reisebegleitung“ vorliegt. Am 17. Dezember 1936 hatte das RVA zu entscheiden, wann dies der Fall war:

„Dies setzt voraus, dass die Unfruchtbarmachung verfahrensrechtlich überhaupt zulässig ist. Vorliegend war dies zur Zeit der Einlieferung in die Anstalt noch nicht der Fall, da damals der Beschluß des Erbgesundheitsgerichts noch nicht rechtskräftig war."349

Die Einweisung vor Rechtskraft des Gerichtsbeschlusses erfolgte deshalb, weil man der Gefahr vorbeugen wollte, dass der Erbkranke in der Zeitspanne bis zum Eintritt der Rechtskraft seinen Aufenthalt verändert und sich so dem ,weiteren Verfahren“ entzieht.

„Hieraus ergibt sich, dass nicht die Verhütung der Fortpflanzung, sondern allein die Sicherstellung der Persönlichkeit für das Verfahren Anlass für die Verwahrung war.“

Eine Kostenpflicht der Krankenkasse war danach zu verneinen. ${ }^{350}$ Diese formaljuristisch beklemmend korrekten Verfahren sind Teil des Bildes vom „Doppelstaat“, das Ernst Fraenkel 351 für das nebeneinander von „Normenstaat“ und „Maßnahmestaat“ gezeichnet hat. Weil ideologische Diktaturen ihre Legitimation aus der Ideologie und gerade nicht aus Normen oder anderen, der Ideologie vor- oder übergeordneten Instanzen beziehen, wird der maßnahmestaatliche Eingriff zum vermeintlich legalen Instru-

348 Ders., ebda., S. 409, unter Verweis auf die Entscheidung des RVA vom 4. April 1936.

349 Entsch. des RVA 5051, Amtl. Nachr. 1937, Die Arbeiter=Versorgung 54. Jg./1937, S. 160 ff.

In Art. 3 Abs. 4 der Sechsten Verordnung zur Ausführung des Gesetzes zur Verhütung erbkranken Nachwuchses vom 23.12.1936 (RGBl. I 1149) gehörten später die Reisekosten auch die einer „Begleitung, die notwendig ist, wenn ohne sie eine Anordnung nicht oder nicht zur festgesetzten Zeit durchgeführt werden könnte. Das RVA hat dann im Februar 1938 entschieden, dass nunmehr auch die Kosten der Polizeibegleitung von den Krankenkassen zu tragen waren, s. Die Arbeiter=Versorgung 55. Jg./1938, S. $239 \mathrm{ff}$.

350 Auch die mit der Unterbringung ,zugleich erreichte Verhütung der Fortpflanzung“ änderte nach Ansicht des RVA daran nichts, ebda., S. 161: „Der mittelbar erreichte Erfolg der Verhütung der Fortpflanzung kann die [Kostenpflicht] nicht auslösen; denn dieser mittelbare Zweck wohnt allen Maßnahmen inne, die irgendwie der Durchführung des Verfahrens dienen.“

351 Fraenkel, Der Doppelstaat. Frankfurt/Main 1974. Weite Teile der Justiz handelten dabei freilich so, dass das auch der „Normenstaat“ der Rassenideologie zu einer „Maßnahme“ werden ließ. Siehe zur Rechtsprechung des RGSt zum „Blutschutzgesetz“ Ogorek, in: Dies., Aufklärung über Justiz (Fußn. 265), S. 309: „Die empathische Adaption der Rassenideologie, der grenzenlose Erfindungsreichtum bei der Ausdehnung nicht nur der Tatbestandsmerkmale, sondern auch des personellen und räumlichen Anwendungsbereichs des Gesetzes, der geradezu durchgängige Verzicht auf eine seriöse Rückbindung an dogmatische und methodologische Regeln, an deren Stelle die Topoi der NSIdeologie traten, und ein maßloses Strafbedürfnis werden in fast jeder Wendung der Entscheidungen sichtbar." 
ment der Machtausübung. 1955 findet Forsthoff dafür die dann auch nach dem Grundgesetz annehmbare juristische Begründung:

„Das Maßnahmegesetz ist dahin zu kennzeichnen, dass es logisch vom Ziel und Zweck zum Mittel gelangt. Es ist Aktion, die nichts konstituieren soll und kann, sondern Regelungen trifft, die einer Zweckverwirklichung dienen und untergeordnet sind. Das Maßnahmegesetz entwächst deshalb einer bestimmten Situation und steht zu ihr in einem überschaubaren und logisch vollziehbaren Verhältnis.“"352

Die starken Worte, mit denen gerade führende Juristen zuvor aber das Recht des liberalen Staats als „formal-positivistisches“ Recht im Sinne des „Paragraphenstaates“ ablehnten, 353 entfalteten ihre zerstörerische Tendenz vor allem gegen die Rechtstellung des Einzelnen. Auf diese Weise schufen sie die Voraussetzungen dafür, dass Daseinsfürsorge Mittel zur ideologischen Disziplinierung werden konnte und dass „Disziplinierung gleichsam biologisiert" 354 wurde.

In Schweden waren es andere Gründe, weshalb man sich durch, wie man in Deutschland sagte, ,formelle juristische Bedenken nicht aufhalten“355 ließ, darunter das Paradoxon der Ausweitung des Angebots sozialer „Mitbürgerrechte“356 in den Gemeinden: Weil es nun das Recht der Gemeindebürger auf verbesserte Wohnungen zu realisieren galt, auf Gesundheitsversorgung, auf Schulmahlzeiten für die Kinder etc., lag es nahe,

352 Forsthoff, Über Maßnahmegesetze, in: Bachof u. a. (Hrsg.), Forschungen und Berichte aus dem öffentlichen Recht, Gedächtnisschrift für Walter Jellinek. München 1955. S. 221-236 (226); auf S. 224 findet sich aber die Einschränkung: „Das Maßnahmegesetz kann nicht von den formalen Merkmalen des rechtsstaatlichen Gesetzesbegriffs, sondern nur vom Begriff der Maßnahme aus präzisiert werden.“ Er verweist dann auf die Probleme der Staatsrechtslehre, den Begriff „Maßnahme“ unter der Weimarer Reichsverfassung zu klären, und zitiert Carl Schmitt, der die rechtliche Unbestimmtheit damals praktikabel machte: Im Gegensatz zu dem in einem geregelten Verfahren ergangenen formgerechten Urteil wie auch zur Gesetzesnorm genügt es danach für eine Maßnahme, „wenn sie wesentlich ein Rechtsprinzip zum Ausdruck bringen, d. h. vor allem gerecht, von der Rechtsidee beherrscht sein will.“ (VVdStL Heft 1/1924, S. 95 ff.). Angesichts derartiger Ausführungen wird plausibel, dass man gesagt hat, die Bundesrepublik sei erst 1958 mit dem Lüth-Urteil des BVerfG „,aus der Taufe gehoben worden“, weil dieses erst die „verfassungsrechtliche Durchdringung der überkommenen Rechtsordnung" einleitete. S. Hofmann, In Europa kann's keine Salomos geben, Zur Geschichte des Begriffspaars Recht und Kultur, JZ 2009/1, S. 1-10 (7), unter Verweis auf Schaefer, 1958 - Schicksalsjahr der Rechtsentwicklung in beiden deutschen Teilstaaten, JZ 2008, S. $703 \mathrm{ff}$.

353 Forsthoff, Der totale Staat, Hamburg 1933, S. 13, zitiert mit zahlreichen weiteren Beispielen von Scheuner, Huber, Kollreuther, Schmitt u. a. bei Majer, „Fremdvölkisches“ im Dritten Reich (Fußn. 260), S. 87.

354 Sachße/Tennstedt, Der Wohlfahrtsstaat im Nationalsozialismus (Fußn. 321), S. 15.

355 So die Aufforderung aus dem Reichsinnenministerium: „Die Hauptsache ist die Einigkeit in der Auffassung, das deutsche Volk von erbbiologisch unerwünschtem Nachwuchs zu befreien. Auf diesem Weg dürfen uns formelle juristische Bedenken nicht aufhalten." S. mit Nachweisen Ayaß, in: Hamm (Hrsg.), Lebensunwert - zerstörte Leben (Fußn. 345), S. 119.

356 Runcis, De som inte fick plats (Fußn. 228) S. 117: „definerades som medborgerliga rättigheter vidgades emellertid successivt under 1940-talen." 
dort zu „sparen“, wo sozialpolitischer Fortschritt nicht erreichbar schien, also bei den „B-Menschen“.357

Schwerer wiegt aber, dass der vom Glauben an die wissenschaftliche Planbarkeit gesellschaftlicher Entwicklungen getragene Sprung in die Moderne in einem Staat gewagt wurde, der dafür noch keine rechtlichen Steuerungsinstrumente entwickelt hatte. Die Sterilisierungen waren ja nicht die einzigen (vorsorglichen) Eingriffe aus „sozialpolitischen" Motiven - im gleichen Zeitraum kam es alljährlich zur (fürsorglichen) unbefristeten Einweisung von ca. 5.000 Personen in geschlossene Anstalten aufgrund etwa von Alkoholmissbrauch, Arbeitsscheu oder Geistesverwirrung. ${ }^{358}$ All dies konnte gleichsam außerhalb des Rechts ablaufen, weil es de facto keine verfassungsrechtlichen Bremsen für die schnell wachsende Macht einer zentralisierten Verwaltung gab: In der seit 1809 (bis 1974!) geltenden Verfassung war weder eine Überprüfung der Rechtmäßigkeit von Gesetzen durch Gerichte vorgesehen, noch der Schutz von Grundrechten, weshalb man in Schweden von einem „verfassungslosen halben Jahrhundert“359 spricht. Eine Rechtskontrolle des Reichstags oder der nur dem König verantwortlichen Minister erfolgte allein durch den vom Reichstag gewählten „Kontrollausschuss“ im Wege des sog. „Bemerkungsverfahrens“360: Diese schwedische Besonderheit hatte über Jahrzehnte den Effekt, dass eine Regierungspraxis, gegen die dieser Ausschuss keine „Bemerkung“ zu Protokoll gab, durch diese quasi „positive Kontrolle“ gut geheißen wurde und so die „successive Stabilisierung der Praxis zum Gewohnheitsrecht“361 ermöglichte. Es lassen sich aber auch Beispiele kritischer „Bemerkungen“ anführen, die zwar nicht unmittelbar zu Rechtsänderungen geführt haben, sich aber doch auf die Praxis auswirkten. ${ }^{362}$ Die Zeitgenossen rühmten dieses Verfahren als „eine der besten Formen der schwedischen Rechtskontrolle“.363 1866 wurde die ständische Struktur des Reichstags

357 Dies., ebda., die dabei die besondere Hinwendung der Kommunen zur Verbesserung der Lebensumstände der Kinder als Konsequenz der „Bevölkerungskrise“ hervorhebt.

358 Zaremba, De rena och de andra (Fußn. 274), S. 235.

359 Sterzel, Ett kvartsekel efter „det författingslösa halvseklet“: Har Sverige nu en författning?, in: Smith (Hrsg.), Grundlagens makt, (Fußn. 336), S. 77 ff.; zur Verfassungsentwicklung s. WarnlingNerep/Lagerqvist/Reichel, Statsrättens grunder, Stockholm 2005; Jermsten, Konstitutionell rätt, in: Strömholm (Hrsg.), Svensk rätt, En översikt, Uppsala 2001, S. 27-44; Holmberg/Stjernquist, Vår författning, 13. Aufl. Stockholm 2003; Strömberg, Sveriges författning, 19. Aufl. Lund 2004. Auf Deutsch s. Call, Grundrechtsschutz in Schweden unter rechtsvergleichenden Gesichtspunkten, Berlin 2003; Engl. Scheinin (Hrsg.), Welfare state and constitutionalism, Copenhagen 2001.

$360 \mathrm{Zu}$ diesem s. ausführlich Reuterskiöld, Rechtskontrolle im Staat nach schwedischem Staats- und Verwaltungsrecht, Königsberg 1931.

361 Ders., ebda., S. 10.

362 Ders., ebda., S. 16, nennt diverse Bemerkungen aus den 1920er Jahren, darunter die 1922 formulierte Kritik an der Gewohnheit, dass die Höchsten Richter Aufträge als Schiedsrichter gegen hohe Honorare annahmen, die, nachdem die Richter selbst nicht reagierten, 1926 zu einem ausdrücklichen Verbot dieser Praxis in den Dienstbestimmungen führte. 
durch ein Zweikammersystem ersetzt, mit den Wahlrechtsreformen 1907/09 und 1918/21 wurde das allgemeine und gleiche Wahlrecht in Staat und Kommunen eingeführt. Bis weit in die 1930er Jahre blieb jedoch der Umfang des rechtsstaatlich-normativ geregelten Bereichs minimal und selbst diesen ließen die „Sozialingenieure“ des Funktionalismus weitgehend unbeachtet. ${ }^{364}$ Man ging davon aus, dass es bei der Durchsetzung administrativer Maßnahmen einer gesetzlichen Grundlage dann nicht bedürfe, wenn das wohl verstandene „Interesse der Gesellschaft“ diese erforderte. ${ }^{365}$

Die Rechtswissenschaft war vom skandinavischen Rechtsrealismus beherrscht, der eng mit der angelsächsischen ,functional jurisprudence“ verbunden war:

„English and Scandinavian legal theory have long shared many points of view. Among these are the belief that law is something man-made and made for men; hostility or indifference to doctrines of natural law at least in the scholastic form." 366

Die semiotische Unterscheidung zwischen Wort, Begriff und Anschauung367 erfährt über die Auseinandersetzung mit Ogden / Richards, The Meaning of Meaning, großen Einfluss in Schweden: ${ }^{368}$ Danach hat etwa der Ausdruck ,good“ keine ethische Funktion, er ist lediglich ,an emotive sign expressing an attitude to something “369 mit der

363 Ders., ebda., S. 16; ganz ähnlich Herlitz, Charakteristische Züge des schwedischen öffentlichen Rechts, ZaöRV 1932/33, S. 95-117 (114): „Die bloße Bemerkung des Ausschusses, daß in dieser oder jener Richtung unrichtig gehandelt wurde, übt manchmal eine nicht unerhebliche moralische Wirkung aus."

364 Petersson, Svensk politik, 7. Aufl. Stockholm 2007, S. 25 ff.: „Modernisering: ingenjörskunst.”

365 S. Lundberg/Amark, Social Rights and Social Security: The Swedish Welfare State, 1900 - 2000, Scandinavian Journal of History Vol. 26 (2001), S. 157-176, insbes. S. 160 ff.: Building the peoples's home 1932 - 1950; Zaremba, De rena och de andra (Fußn. 274), S. 233; Nilsson, Den sociala ingenjörskonstens problematik, in: Den lyckliga humanisten, Tio offensiva essäer, Stockholm 1990, S. 19-46; Hirdmann, Att lägga livet till rätta (Fußn. 241).

366 Hart, Scandinavian Realism, The Cambridge Law Journal, April 1959, S. 233-241 (233); zum skandinavischen Realismus s. Björne, Realism och skaninavisk realism. Den nordiska rättsvetenskapens historia, Del IV 1911-1950, Stockholm 2007; darin der Befund, dass sich seit den 1920er Jahren der deutsche Einfluss auf die schwedische Rechtswissenschaft zugunsten der Hinwendung zum anglo-amerikanischen Recht minderte (S. 563); Lyle, A Call for Scientific Purity: Axel Hägerström's Critique of Legal Science, Stockholm 2006; Blandhol, Nordisk rettspagmatisme. Savigny, Ørsted og Schweigaard om vitenskap og metode, Kopenhagen 2005; Strömholm, Uppsalaskolan och konstitutionens normativitet, in: Smith (Hrsg.), Grundlagens makt (Fußn. 338), S. 25-42; Cassirer, Axel Hägerström, Eine Studie zur schwedischen Philosophie der Gegenwart. ECW 21, Hamburg 2005, S. 3-116; Lang, Axel Hägerström, Wertung und Erkenntnis: Untersuchungen zu Axel Hägerströms Moraltheorie, Rodopi 1981; Bjarup, Skandinavischer Realismus, Hägerström - Lundstedt - Olivecrona - Ross, Freiburg 1978; Hart, Positivism and the Separation of Law and Morals (Fußn. 200).

367 Semiotik als Wissenschaft beginnt im 19. Jahrhundert, gerät mit Saussure, Grundfragen der allgemeinen Sprachwissenschaft, 3. Aufl. Berlin 1967 (Übersetzung der frz. Originalausgabe v. 1916) und den Arbeiten von Pierce (zu diesem s. das Sonderheft von International Journal for the Semiotics of Law Vol. 21, Nr. 3/Sept, 2008: The Semiotics of Charles Peirce) zunehmend in die Diskussion auch anderer Wissenschaften, s. Eco, Einführung in die Semiotik, München 1994.

368 Lang, Axel Hägerström (Fußn. 366), S. 57 ff.

369 Ogden/Richards, The Meaning of Meaning, London 1927, S. 125. 
Konsequenz, dass sich über moralische Vorstellungen weder wahr noch falsch urteilen lässt. Darauf beruht der „Wertnihilismus“ des skandinavischen Rechtsrealismus, ${ }^{370}$ der weitgehend von Axel Hägerström geprägt wurde. In seiner Antrittsvorlesung „Om moraliska föreställningars sanning“"371 arbeitet er erstmals eine „,non-cognitive theory of ethics“"372 aufgrund der Feststellung aus, dass die

„Moralphilosophie als Wissenschaft einzig und allein eine Wissenschaft von den moralischen Bewertungen in ihrem geschichtlichen Wachstum ist." 373

Hägerström, dessen Motto „,censeo metaphysicam esse delendam“374 war, prägte eine ganze Generation sozialdemokratischer Juristen, der Prominenteste darunter wohl Karl Schlyter. Sein Lebenslauf (1879-1959) ${ }^{375}$ kann exemplarisch genannt werden:

Der Großvater war angesehener Rechtsprofessor, der Vater Lektor (Latein) in Lund. Zu dessen Entsetzen trat Schlyter während des Jurastudiums in Lund 1906 der Sozialdemokratischen Partei bei. 1920 wurde er (für über 20 Jahre) Mitglied des Reichstags. 1932 36 war er Justizminister in der Regierung Per Albin Hansson.

- Schlyter setzte durch, dass erstmals eine Frau ins Richteramt berufen wurde,

- er war maßgeblich an der Strafrechtsreform 1934 beteiligt, nach der „blackmailing“ (dessen Opfer bis dahin meist Homosexuelle waren) strafbar wurde,

- 1935 legte er das Gesetz zur Reform des Jugendstrafvollzugs vor, das für Täter zwischen 18 und 21 galt und erzieherische Maßnahmen, insbes. berufliche Ausbildung in speziellen Anstalten ohne vorherige zeitliche Begrenzung für 1 bis 4 Jahre vorsah,

- unter der Parole „Avfolka fängelserna!“ (Entvölkert die Gefängnisse) schaffte er die (Ersatz-) Haftstrafen für solche Straftäter ab, die nicht in der Lage waren, Geldstrafen zu zahlen - von 1930 bis 1940 sank die Zahl der aus Geldmangel einsitzenden Häftlinge von 11.000 auf 650 .

- Er setzte in Zusammenarbeit mit Gerhard Simson ${ }^{376}$ die grundlegende Reform des schwedischen Strafvollzugs (1945) durch, deren Prinzip darin bestand: „An inmate should be treated with respect for his human value. He should receive such treatment that his correction is furthered." 377

370 Lang, Axel Hägerström (Fußn. 366), S. 63.

371 Am 11. März 1911 in Uppsala, dtsch: „Über die Wahrheit moralischer Vorstellungen“; zu dieser s. Bjarup, Ought and Reality, Hägerström's Inaugural Lecture Re-considered, SSiL Vol. 40 / 2000, S. 11-72, und Cassirer, Axel Hägerström (Fußn. 366), S. 55 ff.

372 Bjarup, ebda., S. 11.

373 Zitiert bei Cassirer, Axel Hägerström (Fußn. 366), S. 53.

374 Hart, Scandinavian Realism (Fußn. 366), S. 288.

375 S. zum Folgenden Sundell, Karl Schlyter - en biografi, Stockholm 1998; engl. ders., Karl Schlyter a Swedish Lawyer and Politician, SSiL Vol. 39/1999, S. 506 ff. Zum Einfluss Schlyters auf eine ganze Juristengeneration s. Modéer, "Den kulan visste var den tog!", Om svenska juristers omvärldssyn 1935 - 1955, in: Andersson/Lindell (Hrsg.), Festskrift till Per Henrik Lindblom, Uppsala 2004, S. 443-468; wegen seiner 36 Jahre als Redaktör der SvJT galt Schlyter als „Spinne im Netz“ des juristischen Beziehungsgeflechts, s. S. 445.

376 Simson war als deutscher Jude Emigrant in Schweden, s. Göppinger, Juristen jüdischer Abstammung im „Dritten Reich“, 2. Aufl. München 1990, S. 317 ff.

377 Das von Schlyter formulierte Prinzip ist fast wortgleich bis heute gültiger Gesetzestext, s. mit Nachweis Sundell (Fußn. 375), SSiL Vol. 39/1999, S. 512. 
- Er suchte und pflegte zahlreiche und intensive internationale Kontakte, darunter bis zu dessen Tod mit Adolf Schönke 378 und gründete die bedeutende (bis heute auch international offen ausgerichtete) Fachzeitschrift Svensk Juristtidning.

- In seiner Amtszeit als Justizminister erging aber auch das erste Sterilisierungsgesetz, an dessen „Reform“ 1941 er persönlich mitwirkte und im Reichstag damit begründete, dass nunmehr von einer asozialen Lebensweise ,as a rule could be said to be combined with psychic inferiority of one kind or another." 379

1930 schrieb er in einem Zeitungsartikel, dass der ,unmerkliche Eingriff Sterilisierung“, wenn sachliche Abwägungen es rechtfertigten, einer gesetzlichen Grundlage nicht bedürfe, weil das ,Interesse der Gesellschaft“ dann allein schon hinreichende Entscheidungsgrundlage sei. ${ }^{380}$ Es dauerte bis zum Jahr 1938, dass im Reichstag auf Antrag der rechten Opposition erstmals in seiner Geschichte überhaupt die Menschenrechte diskutiert wurden. 381 Man setzte daraufhin eine Kommission ein, die sog. „TingstenKommission“, 382 deren Ergebnisse zwar später als „Wendepunkt in der schwedischen Grundrechtsgeschichte" bezeichnet werden sollten, in ihrer Gegenwart aber in den Archiven verschwanden. Die mit dem Folkhem-Bau beschäftigten Sozialdemokraten sahen hinter dem Bestreben, dem Einzelnen gegen Vor- und Fürsorgemaßnahmen der Behörden den Rechtsweg zu eröffnen, ,,antidemokratische Kritik am Regierungsauftrag des Parlaments.“ Ekelöf skizzierte 1942 den Unterschied zwischen Rechtsstaat und Terrorregime auf eine insofern sehr ,,schwedische“ Weise:

„was den Rechtsstaat von einer Gesellschaft unterscheidet, in der die Ordnung durch Terror aufrecht erhalten wird, besteht darin, dass in ersterem die Bürger dem Gesetz aus Pflichtgefühl gehorchen, während im anderen Fall dies nur aus Angst geschieht.““383

Statt den Schutz durch vermeintliche Rechte zu suchen, sollte der Einzelne sich vielmehr ,ins Kollektiv einfügen, das seine Mitglieder am besten zu schützen weiß.“ Aber eben nur die Mitglieder. Lange Zeit galt, dass eine auf Recht und Gesetz verpflichtete Verwaltung ohne eigenständige Verwaltungsgerichtsbarkeit auskommen könnte:

„Der schwedischen Tradition entspricht es am besten, die Garantien, die innerhalb der Verwaltung wirksam sind, zu stärken. [...] Besser als die beste Kontrolle ist es, die Kontrolle überflüssig zu machen." 384

378 Dessen Bibliothek Schlyter bewunderte, ,the nucleus, from which developed the famous research institute, the Max-Planck-Institut für Strafrecht in Freiburg i. Br.", Sundell (Fußn. 375) SSiL Vol. 39/1999, S. 510.

379 Sundell (Fußn. 375), SSiL Vol. 39/1999, S. 508, mit Nachweis des Reichtstagsprotokolls.

380 S. mit Nachweisen Zaremba, De rena och de andra (Fußn. 274), S. 223-224.

381 S. hierzu und zum Folgenden Zaremba, De rena och de andra (Fußn. 274), S. 236 ff., und Petrén, Vägen till svensk rättighetskatalog, in: Institutet för offentlig och internationell rätt (Hrsg.), Skrifter till H. G. Sundbergs minne, Stockholm 1978, S. 234 ff.

$382 \mathrm{Zu}$ dieser s. ausf. Östling, Nazismens sensmoral (Fußn. 329), S. 88 ff.; Petrén, Domstols lagprövningsrätt, SvJT 1956, S. 500-509, und Call, Grundrechtsschutz in Schweden (Fußn. 359), S. $66 \mathrm{ff}$.

383 Ekelöf, Rättssamhälle och rättsäkerhet, SvJT 1942, S. 7 ff., zitiert bei Modéer, „Den kulan visste var den tog!” (Fußn. 375), S. 448, übersetzt vom Verf.

384 Herlitz, Rechtsschutzfragen in Schweden, in: Bachof u. a. (Hrsg.), Gedächtnisschrift für Walter Jellinek (Fußn. 352), S. 419- 432 (423). S. auch ders., Le droit administratif Suédois, Revue interna- 
Von einer von der Verwaltung institutionell getrennten Verwaltungsgerichtsbarkeit kann im Grunde erst seit den Reformen um 1970 gesprochen werden. ${ }^{385}$

Die Parallele zu Forsthoffs Idee von der Teilhabe an der Daseinsvorsorge statt individuellem, womöglich auf Grundrechte gestütztem Rechtsschutz liegt ebenso auf der Hand, wie zur NS-ideologischen Bestimmung des Verwaltungszwecks ,nicht vom Gesetz her, sondern von der Erfüllung der Gemeinschaftszwecke des Volksganzen.“386 Die Parallele zeigt sich auch bei der Umsetzung der Idee: Wenn Sachzwang und die technische Möglichkeiten, diesem abzuhelfen gleichzeitig vorliegen, dann kann daraus eine Eigendynamik entstehen, die Einzelinteressen ohne Rechtsmacht wenn nicht dezidiert beseitigt, so doch einfach übergeht.

\section{Vorsorge und das Problem, die Zukunft rechtlich zu regeln}

Nicht nur für den Rechtsvergleich gilt, dass man „hinterher“ meist klüger ist, als zuvor. Dies gilt selbst dann, wenn man zuvor schon weiß, dass es manchmal sehr schwierig sein kann, die für einen Rechtsvergleich ,richtige Frage“ zu stellen. Bei allem aus der Hoffnung auf Erfolg geborenen „Pragmatismus“ (also Konzentration auf, wie man hofft, präzis abzugrenzende Einzelfragen) lässt es sich nicht immer vermeiden, dass ganz unterschiedliche, zuvor nicht anvisierte Rechtsbeziehungen oder gar Rechtsgebiete in den Blick kommen können - was umso mehr gilt, wenn man nach mehrdeutigen Begriffen wie dem der „Vorsorge“ fragt. Manchmal kann überhaupt erst nach Durchführung des Rechtsvergleichs der Kernpunkt der Frage erkannt werden.

\section{Individuelle Rechtssicherheit vor (Daseins-)Vorsorge}

Der Gedankenschritt vom Wortsinn „Vorsorge“ über die unterschiedlichen Begriffe Risiko und Sicherheit zur „Daseinsvorsorge“ als neuer Aufgabenstellung der Leistungsverwaltung in den 1930er Jahren ließ es reizvoll erscheinen, mit Schweden und

tional des sciences administratives 1953, S. 533 ff., und ders., Swedish administrative law, The International and Comparative Law Quarterly 1953, S. 224 ff.; s. auch den Überblick von Lagerqvist Veloz Rocha, Utvecklingslinjer inom svensk offentlig rätt under de senaste hundra åren, Juridisk Tidskrifts jubileumshäfte: Juridiska Fakulteteten i Stockholm 1907-2007, S. 48-54.

385 Ds 1992:38, Domstolsväsendet, S. 19 ff., und Strömberg/Lundell, Allmän förvaltningsrätt, 24. Aufl. Malmö 2008, S. 175-177; Wennergren, Förvaltningsprocesslagen m. m., 5. Aufl. Stockholm 2006, Kap. Förvaltningsprocesslag (1971:291), S. 99 ff.; Moeller, Kontrollen im öffentlichen Recht und Demokratiegebot in Schweden - eine Besonderheit in Europa, Münster 2004, insbesondere S. 191 ff.; Vahlne Westerhäll, Den starka statens fall?, En rättsvetenskaplig studie av svensk social trygghet 1950 - 2000, Stockholm 2002, S. $190 \mathrm{ff}$.

386 Frank (Hrsg.), Deutsches Verwaltungsrecht, München 1937, Einführung; zitiert bei Stolleis, Gemeinwohlformeln im nationalsozialistischen Recht (Fußn. 152), S. 234. 
Deutschland zwei Länder zu vergleichen, in denen dieses Konzept gleichermaßen rigoros in praktische Politik umgesetzt worden ist. Das Ergebnis bestätigt die wichtigste Forderung des funktionalen Rechtsvergleichs: Es genügt nicht, Normen als solche zu vergleichen ${ }^{387}$ - die Vorsorge für die „Gesundheit des Volkskörpers“ durch Unfruchtbarmachen von Personen mit negativen Anlagen erfolgte in Schweden und Deutschland nach inhaltlich fast identischen Gesetzen und hatte für die Betroffenen auch die gleichen schweren Folgen. ${ }^{388}$ Dennoch: Die Sozialingenieure wollten vor allem das Leben im Volksheim verbessern und unterschieden sich dadurch konträr von der rassistischen, auf einem „Freund-Feind-Schema“ beruhenden Zielsetzung der „Ausmerzung des Heterogenen“.

Trotz dieses Unterschieds wurde aber in beiden Fällen offenbar, dass Recht allein auch im modernen Staat ,nicht garantiert, was es garantieren soll, Richtigkeit, Eindeutigkeit, Sicherheit. All das, auf das Laien bis heute gern vertrauen. "389 Dieses Vertrauen setzt nämlich voraus, dass Gesetzgeber, Richter und Rechtswissenschaft, besonders aber die in der Gesellschaft die Macht haben, diese Garantie ernsthaft geben wollen. Sogar an sich unverdächtige Begriffe wie „Vorsorge“ können andernfalls zum Anlass oder zur Begründung für Eingriffe werden, deren Rechtswidrigkeit selbst radikalen Rechtspositivisten $^{390}$ offenbar sein müsste. Wenn eine Gesellschaft zwar ein dichtes Gewebe von Vorschriften kennt, aber keinen wirksamen Schutz elementarer Menschenrechte, kann es sein, dass der Blick auf diesen „normativen Vordergrund“ erst das dahinter verborgene eigentliche ,vorrechtliche Problem“ sichtbar macht.

\section{Vorsorge gegen die Unsicherheit der Zukunft durch Recht?}

Die Suche nach dem Begriff „Vorsorge“ im inter- und supranationalen Recht führte zum (primär) umweltschutzrechtlichen „Vorsorgeprinzip“. Damit werden einerseits Vorsorge- und Vorbeugepflichten statuiert, andererseits ist aber z. B. Verwaltungshandeln nicht schon deshalb zu unterlassen, weil nicht alle wissenschaftlich möglichen Zweifel für dessen Folgen ausgeräumt sind. „Vorsorge“ soll ,anhand praktischer Ver-

387 Inzwischen wird „eine funktionale Rechtsvergleichung“ schon als Argument dafür genannt, dass in der Rechtswissenschaft allgemein „Rationalisierung der Auslegung [...] den expliziten Einbezug sozialwissenschaftlicher Erkenntnisse (fordert)“, s. van Aaken, Funktionale Rechtswissenschaftstheorie für die gesamte Rechtswissenschaft, in: Jestaedt/Lepsius (Hrsg.), Rechtswissenschaftstheorie, Bd. 2, Tübingen 2008, S. 79-104 (93).

388 Gemeint ist der erste Eingriff der Sterilisation - dass man im NS-Staat alsbald zur „Euthanasie“ und dann zum Beseitigen unwerten Lebens schlechthin schritt, stellt diesen Teil der Geschichte Deutschlands außerhalb jeden Vergleich.

389 Fögen, Römische Rechtsgeschichten, Über Ursprung und Evolution eines sozialen Systems, Göttingen 2002, S. 181.

390 Die Recht und Moral zwar getrennt denken, nicht aber keine Moral kennen! 
nunft“391 getroffen werden, aber nicht zum Stillstand führen, weil wegen des wissenschaftlich erreichten Erkenntnisstands niemand mehr vollständige, also auch zukünftig bestehende „Sicherheit" garantieren kann. Diese „,neue“ Unsicherheit betrifft die Idee von Recht dann unmittelbar, wenn man Recht als Instrument sieht, die Zukunft zu sichern:

„Recht [...] ermöglicht Wechsel auf die Zukunft, für deren Verität und Bonität eine erhöhte Garantie besteht, eine Garantie, die erst zusammenbricht, wenn sich die Verhältnisse ganz grundlegend und drastisch verändern. Recht greift in die Zeit der Zukunft vor." 392

Im Sozialrecht wäre das geradezu exemplarisch auf die Regelung zukünftiger Ansprüche zielende Recht der Alterssicherung. Nun hat die Prüfung des SGB VI ergeben, dass das Gesetz „Vorsorge“ nur als Befreiungstatbestand für Aufwendungen der privaten Altersvorsorge und deren Berücksichtigung bei der Rentenanpassung nennt. Das könnte im Gegenschluss bedeuten, dass das SGB VI als das „eigentliche“ Vorsorgesystem verstanden werden will, obwohl der Text dies wörtlich so nicht aussagt. Die Frage ist dann, ob die in der Rentenversicherung gesammelten Beiträge die einkommenslose Zeit im Alter für die Versicherten rechtlich so absichern, wie die Futtervorräte der Ameise deren Überleben im Winter. Wenn man (zwangsweise) Beiträge an die Rentenversicherung abführt, soll man darauf vertrauen dürfen, dass auf diesen Tatbestand im Alter auch das Recht auf Leistungen folgt.

Das Bundesverfassungsgericht hat deshalb für Deutschland schon früh mit dem allgemeinen rechtsstaatlichen Vertrauensschutz argumentiert, später dann die Rentenversicherung in den spezifischen Vertrauensschutz des Art. 14 GG einbezogen. ${ }^{393}$ In der Beitragszahlung wurde die der Eigentümerposition entsprechend schutzwürdige Eigenleistung gesehen.

Wieder bietet sich ein Rechtsvergleich mit Schweden an. Dort hat man im Jahr 2000 die Alterssicherung grundlegend reformiert und auf ein beitragsbezogenes System umgestellt. ${ }^{394}$ Die Alterssicherung beruht seither auf drei Teilen: Der wichtigste ist die auf einem „Verteilungssystem“ (fördelningssystemet) genannten Umlageverfahren beruhende einkommensbezogene Altersrente. Der zweite Teil ist die auf dem Kapitaldeckungsverfahren beruhende Prämienrente (premiepension) ${ }^{395}$. Beide Rentenleistungen

391 BVerfGE 49, oben unter II. 3.

392 Fögen, Römische Rechtsgeschichten (Fußn. 389), S. 130. Die Autorin fährt fort: „Wenn Gnaeus Flavius den Kalender raubt, so werden nicht nur die Gerichtstage bekannt. Vielmehr wird die Zeit der Zukunft, die man durch Recht strukturieren kann, verfügbar."

393 S. statt vieler Wallerath, Rentenversicherung und Verfassungsrecht, in: HDR, 11 Rdnr. 31-34 und 85-96.

394 S. Köhler, Die Reform der Alterssicherung in Schweden, in: Becker u. a. (Hrsg.), Alterssicherung in Deutschland, Festschrift für Franz Ruland zum 65. Geburtstag, Baden-Baden 2007, S. 691-712.

395 Die Prämienrente verbindet sozial- und privatrechtliche Elemente: Sie ist obligatorisch und beruht hinsichtlich der Berechnungsgrundlagen der Beitragsseite auf den auch für die Einkommensrente geltenden sozialrechtlichen Regeln. Dagegen werden die daraus entstehenden Ansprüche privat- 
werden ergänzt durch die Garantierente (garantipension), einer steuerfinanzierten (Not)Absicherung für diejenigen alten Menschen, die keine oder keine hinreichende einkommensbezogene Rente verdient haben. Mit Verteilungssystem ist gemeint, dass mit den Beiträgen eines Jahres die im selben Jahr auszuzahlenden Renten finanziert werden. Die jährlich als Beiträge eingezogenen 16 Prozent der rentenbegründenden Einkünfte müssen also für die Jahresausgaben reichen. Damit regiert nicht mehr das Leistungsversprechen die Höhe der für seine Einlösung erforderlichen Beiträge, sondern die jeweilige Wirtschaftskraft der Solidargemeinschaft der Versicherten. Deshalb wird sich erst in der Zukunft weisen, wie hoch die individuelle Rente sein wird. Die individuelle Beitragsleistungen über das gesamte Erwerbsleben bestimmt die Höhe der Leistungen somit nur in Relation zu den anderen Versicherten, also den Teilaspekt der Vorsorge des „wie geleistet" wird.

Im Effekt ist dies auch in der deutschen Rentenversicherung nicht anders: Die häufigen Änderungen der Anpassungsformel und die Änderung des Ziels der Sicherung eines angemessenen Lebensstandards hin zu der Vorgabe, dass der Beitragssatz bis 2030 die gesetzliche Maßgabe von $22 \%$ nicht übersteigt, ${ }^{396}$ lassen die zukünftig zu erwartenden Gegenleistungen zur Beitragszahlung ebenso relativ werden, wie dies in Schweden der Fall ist. Was in Deutschland vom Bundesverfassungsgericht mühsam mit den ,großen Weichmachern“397 als (meist gerade noch) verfassungsmäßig begründet werden muss, etwa dem der „Funktionsfähigkeit der Rentenversicherung“, oder dem der Rentenversicherung als „Solidargemeinschaft" innerhalb derer ein Risikoausgleich stattfinden kann 398 oder dem der Relativierung des an sich bestehenden rechtsstaatlichen Vertrauensschutzes durch die Zumutung, dass

„damit gerechnet werden konnte, dass der Gesetzgeber angesichts der angespannten Finanzlage der gesetzlichen Rentenversicherung noch weitergehende Änderungen an dem zunächst langfristig angelegten Übergangskonzept des Rentenreformgesetzes 1992 vornehmen werde, “399

hat der Gesetzgeber in Schweden als Reformziel offen gelegt: Die Alterssicherung ist Teil der Wirtschaftsleistung. Wenn diese sinkt, müssen auch die Altersrentner mit sinkenden Leistungen rechnen. ${ }^{400}$ Das wurde aktuell bei der Prämienrente schmerzlich

rechtlich definiert, sie genießen Eigentumsschutz und der Versicherte kann über ihre Anlage auf dem Kapitalmarkt, ihre Verwaltung und Verwendung frei bestimmen.

396 Ruland (Fußn. 10), SGb 10/2008, S. 573.

397 Voßkuhle, Die Renaissance der „Allgemeinen Staatslehre“ im Zeitalter der Europäisierung und Internationalisierung, JUS 2004, S. 3, zitiert bei van Aaken, in: Jestaedt/Lepsius (Hrsg.), Rechtswissenschaftstheorie (Fußn. 387), S. 92, die neben diesem Ausdruck noch Böckenfördes „Schleusenbegriffe" wie „Demokratie“ und „Sozialstaat" zitiert.

398 S. aktuell BVerfG, Beschluss vom 11. Nov. 2008, BvL 3/05 u. a., Pressemitteilung, S. 1.

399 BVerfG, Beschluss vom 11. Nov. 2008, BvL 3/05 u. a., Pressemitteilung, S. 2.

400 Ruland (Fußn. 10), SGb 10/2008, S. 570 sagt dasselbe für die DRV: „Die Alterssicherung, für die wir mehr als $13 \%$ des Bruttosozialprodukts ausgeben, hängt so stark von der wirtschaftlichen und sozialen Entwicklung unseres Gemeinwesens ab, dass sie im Guten wie im Schlechten immer nur als Teil des Ganzen verstanden werden muss.“ 
spürbar, mit der alle Versicherten an Chancen und Risiken des Kapitalmarkts mit 2,5\% ihrer Alterssicherungsbeiträge teilnehmen sollen. Im Januar 2005 hatten nur $29 \%$ aller Versichertenein Plus auf ihrem Konto. Im ersten Halbjahr 2008 verloren alle im Prämienrentensystem angesparten Fondsvermögen $16 \%$ an Wert. 401 Aber auch das Umlagesystem ist von der globalen Finanzkrise betroffen: Die zur Finanzierung der Übergangsleistungen eingerichteten Fonds verloren aktuell erheblich.

Doch noch mehr zeigt die deutsche Geschichte, dass die rechtliche Konstruktion

"geleistet wird, weil und wie vorgesorgt ist,"

das für Vorsorge notwendige Vertrauen nicht rechtfertigt: Im 1. Weltkrieg ging das Vermögen der Rentenversicherung durch die Reichsanleihen von 1916 weitgehend verloren, die Inflation und die Weltwirtschaftskrise vernichteten es und die Reichsanleihen im Dritten Reich führten es nach kurzer Erholung zum endgültigen Zusammenbruch.

Nicht das durch Beitragszahlung erworbene Recht sichert also in beiden Ländern als individuelle Vorsorgeleistung den Rentenanspruch im Alter - also nicht die causa ,weil gezahlt worden ist" Altersarmut als unerträglich empfindet. Dass diese Art „Generationenvertrag“ auch in ferner Zukunft immer eingehalten werden wird, kann aber kein in der Gegenwart gesetztes Recht erzwingen.

\section{Neue Unsicherheit für individualrechtliche Vorsorge?}

Weil das Bedürfnis nach Sicherheit angeblich unstillbar ist und in

„Anlehnung an Tocquevilles Paradox, dass die Ungleichheitsempfindlichkeit einer Ge"sellschaft mit wachsender Gleichheit zunimmt", 402

wird aktuell eine „Wiederkehr der Unsicherheit“ diskutiert, die angeblich darauf beruht, dass das von dem in den modernen Wohlfahrtsstaaten geweckten Sicherheitsbedürfnis in der Praxis nicht (mehr) mit Sicherheitsleistungen entsprochen werden kann. ${ }^{403}$ Die Kontroverse zeigt freilich wohl vor allem, dass die Unsicherheit des Daseins kein Phänomen der 1930er Jahre war, dem inzwischen durch den Ausbau der Wohlfahrts- und Sozialstaaten (nachhaltig) abgeholfen wäre.

Noch deutlicher wird dies durch ein ebenso bedrückendes wie höchst aktuelles Beispiel für das Weiterleben der alten Hoffnung, durch Rechtsakte die Zukunft regeln zu können: Gemeint ist die gegenwärtig im Gesetzgebungsverfahren diskutierte Regelung der sog. „Patientenverfügung“, also der individuell getroffenen Anordnung über den

401 S. Bjerre, Tungt fall för ppm-fonderna, Dagens Nyheter vom 8. Juli 2008, Ekonomi, S. 3.

402 Vogel, Die Staatsbedürftigkeit der Gesellschaft, Hamburg 2007, S. 120, der dabei einmal mehr die „Forsthoff'sche Formel“ von der Daseinsvorsorge wieder entdeckt.

403 Dazu schon oben unter I. 1. van Dyk/Lessenich (Fußn. 13), Mittelweg 36, 17. Jg. Heft 5 und die Beiträge in Social Policy Administration, vol. 42/2008 Nr. 6, Special Issue, und in Ulbert/Werthes (Hrsg.), Menschliche Sicherheit (beide unter Fußn. 14). 
Umfang einer Behandlung, die ein Patient für den Fall trifft, dass er sich (dermaleinst, wie jeder hofft) nicht mehr äußern kann. Es geht also darum, für das Sterben Vorsorge zu treffen. Dass dafür überhaupt ein Bedürfnis besteht, liegt nicht allein an den technischen Möglichkeiten der modernen Medizin, sondern auch am Verlassenheitsgefühl des modernen Menschen und seiner daraus rührenden

„Angst, er werde, sobald er einmal um seinen eigenen Verstand gebracht ist, zugleich von allen guten Geistern verlassen sein." “404

Wieder stellt sich die Frage, wieweit das Recht des Einzelnen reicht, in die Zeit regelnd vorzugreifen, hier also für sein individuelles Sterben Vorsorge zu treffen. Individualrechtliche „Vorsorge“ wird in diesem Fall deshalb um eine weitere Komponente kompliziert, weil die individuell getroffene Anordnung auch für die Menschen bindend sein soll, die (in ferner Zukunft) rechtlich eigentlich dazu verpflichtet sind, das Sterben solange zu verhindern, wie das medizinisch möglich und ethisch vertretbar ist.

Diese Art Vorsorge und die dazu denkbaren rechtlichen Gestaltungsmöglichkeiten wäre aber eine pragmatisch einzugrenzende Fragestellung für eine eigene rechtsvergleichende Studie.

404 Lauerer/Lüddecke, Gesetz der Angst, Patientenverfügungen können nur eine Notbehelf sein, Süddeutsche Zeitung Nr. 285 vom 8. Dezember 2008, S. 11; eine Übersicht über die juristische Literatur zum Thema findet sich bei Zimmermann, Vorsorgevollmacht, Betreuungsverfügung, Patientenverfügung, Berlin 2007. 


\section{Diskussionsbericht}

I. In der Diskussion wurde zunächst die Aussagekraft von Systematisierungen erörtert. Es wurde die Frage aufgeworfen, ob die rechtsdogmatische Zuordnung eines Systems als Vorsorge- oder Fürsorgesystem tatsächlich so bedeutsam sei. Wichtiger als die rechtsdogmatische Zuordnung sei die Notwendigkeit, dass ein System als gerecht empfunden werde. Insbesondere sollten nicht die Gelder der Allgemeinheit, also öffentliche Mittel, überwiegend den bessergestellten Einkommensschichten zugute kommen. Es wurde bedauert, dass immer noch viele der Systeme der sozialen Sicherheit den Ansatz verfolgten, diejenigen zu begünstigen, die ohnehin bereits gut gesichert seien.

In Anlehnung an den Beitrag von Köhler wurde ergänzend darauf hingewiesen, dass das Vertrauen in die Zukunft der Rentensysteme nicht nur durch die Solidarität begründen werden könne. Solidarität sei ohnehin nur ein Begriff, der sehr unterschiedlich interpretiert werde. Vielmehr gründe sich das Vertrauen in die Zukunft der Rentenversicherung auf ein individuelles Eigeninteresse des Versicherten. Denn jeder, der ein gutes Einkommen habe, möchte später eine gute Rente erhalten. Dies setze voraus, dass das System durch entsprechende Finanzierung aufrecht erhalten werde.

II. Im weiteren Verlauf der Diskussion wurde die Bedeutung des demographischen und ökonomischen Wandels erörtert. Obwohl die Fakten langfristig im Voraus bekannt seien, werde oftmals zu spät auf Veränderungen reagiert. Hier müsse gewährleistet werden, dass politischen Entscheidungen eine längerfristige Perspektive zugrunde gelegt wird. Einige Ökonomen setzten verstärkt oder allein auf Kapitaldeckung. Angesichts der Schwankungen der Wechselkurse und der möglichen staatlichen Eingriffe bleibe abzuwarten, wie viel bei einem Kapitaldeckungsverfahren nicht nur nominal, sondern auch real als Rentenleistung zurückerlangt werde. Schließlich erfülle soziale Sicherung nicht nur individuelle Interessen, sondern diene zudem auch der sozialen Kohäsion. Die demographische Entwicklung werde eine große Belastung für kommende Generationen sein. Hier müsse die Politik rechtzeitig handeln.

III. Sodann wurde das Verhältnis von öffentlicher und privater Sicherung in Großbritannien und in den Niederlanden beleuchtet. In den Referaten von Pitschas und Ebsen war bereits die Ergänzung und Substitution von öffentlicher sozialer Sicherung durch Elemente der Privatversicherung angesprochen worden. In diesen beiden Ländern wurde die eigenverantwortliche Absicherung über die Privatversicherung sehr forciert. Dies führte zu der Überlegung, ob dadurch die Privatversicherung zu einer Art „Sozialversicherung" werde und diese gleichsam überlagere. Allerdings müssten dann in der Privatversicherung auch vergleichbare Leistungen erbracht werden wie in den öffentlichen Sicherungssystemen. Als Beispiel könne die private Pflegeversicherung in Deutschland genannt werden, die zwar nicht optional gewählt werden kann, sich im Leistungskatalog aber an der sozialen Pflegeversicherung orientieren muss. Die stärkere Rolle privater 